\title{
Tuning the Geometric and Electronic Structure of Synthetic High-Valent Heme Iron(IV)-Oxo Models in the Presence of a Lewis Acid and Various Axial Ligands
}

\author{
Melanie A. Ehudin $\uparrow$, , Leland B. Gee ${ }^{\ddagger}$, , Sinan Sabuncu§, Augustin Braun ${ }^{\ddagger}$, Pierre Moenne- \\ Loccoz $^{\S}$, Britt Hedman ${ }^{\perp}$, Keith O. Hodgson ${ }^{\ddagger, \perp}$, Edward I. Solomon ${ }^{\star}, \neq, \perp$, and Kenneth D. \\ Karlin $^{*}, \dagger$ \\ †Department of Chemistry, Johns Hopkins University, Baltimore, Maryland 21218, United States \\ ‡Department of Chemistry, Stanford University, Stanford, California 94305, United States \\ $\S$ Department of Biochemistry \& Molecular Biology, Oregon Health \& Science University, Portland, \\ Oregon 97239-3098, United States \\ ${ }^{\perp}$ Stanford Synchrotron Radiation Lightsource, SLAC National Accelerator Laboratory, Stanford \\ University, Menlo Park, California 94025, United States
}

\section{Abstract}

High-valent ferryl species (e.g., (Por) $\left.\mathrm{Fe}^{\mathrm{IV}}=\mathrm{O}, \mathrm{Cmpd}-\mathrm{II}\right)$ are observed or proposed key oxidizing intermediates in the catalytic cycles of heme-containing enzymes (P-450s, peroxidases, catalases, and cytochrome $\mathrm{c}$ oxidase) involved in biological respiration and oxidative metabolism. Herein, various axially ligated iron(IV)-oxo complexes were prepared to examine the influence of the identity of the base. These were generated by addition of various axial ligands (1,5dicyclohexylimidazole (DCHIm), a tethered-imidazole system, and sodium derivatives of 3,5dimethoxyphenolate and imidazolate). Characterization was carried out via UV-vis, electron paramagnetic resonance (EPR), 57Fe Mössbauer, Fe X-ray absorption (XAS), and ${ }^{54 / 57} \mathrm{Fe}$ resonance Raman (rR) spectroscopies to confirm their formation and compare the axial ligand perturbation on the electronic and geometric structures of these heme iron(IV)-oxo species. Mössbauer studies confirmed that the axially ligated derivatives were iron(IV) and six-coordinate complexes. XAS and ${ }^{54 / 57} \mathrm{Fe}$ rR data correlated with slight elongation of the iron-oxo bond with increasing donation from the axial ligands. The first reported synthetic H-bonded iron(IV)-oxo heme systems were made in the presence of the protic Lewis acid, 2,6-lutidinium triflate $\left(\mathrm{LutH}^{+}\right)$, with (or without) DCHIm. Mössbauer, rR, and XAS spectroscopic data indicated the formation of molecular Lewis acid ferryl adducts (rather than full protonation). The reduction potentials of these novel Lewis acid adducts were bracketed through addition of outer-sphere reductants. The

\footnotetext{
*Corresponding Authors: edward.solomon@stanford.edu, karlin@jhu.edu. $\mathbb{4}$ M.A.E. and L.B.G. contributed equally to this work.

Supporting Information

The Supporting Information is available free of charge on the ACS Publications website at DOI: 10.1021/jacs.9b00795.

Synthetic and analytical details (methodologies and UV-vis, rR, Mössbauer, EXAFS, EPR, and NMR spectra), including Figures S1S40, Tables S1-S10, and Schemes S1-S15 (PDF)

Notes

The authors declare no competing financial interest
} 
oxidizing capabilities of the ferryl species with or without Lewis acid vary drastically; addition of LutH $^{+}$to $\mathrm{F}_{8} \mathrm{Cmpd}-\mathrm{II}\left(\mathrm{F}_{8}=\right.$ tetrakis (2,6-difluorophenyl) porphyrinate) increased its reduction potential by more than $890 \mathrm{mV}$, experimentally confirming that H-bonding interactions can increase the reactivity of ferryl species.

\section{Graphical Abstract}

\section{Building Synthetic Ferryl Models}

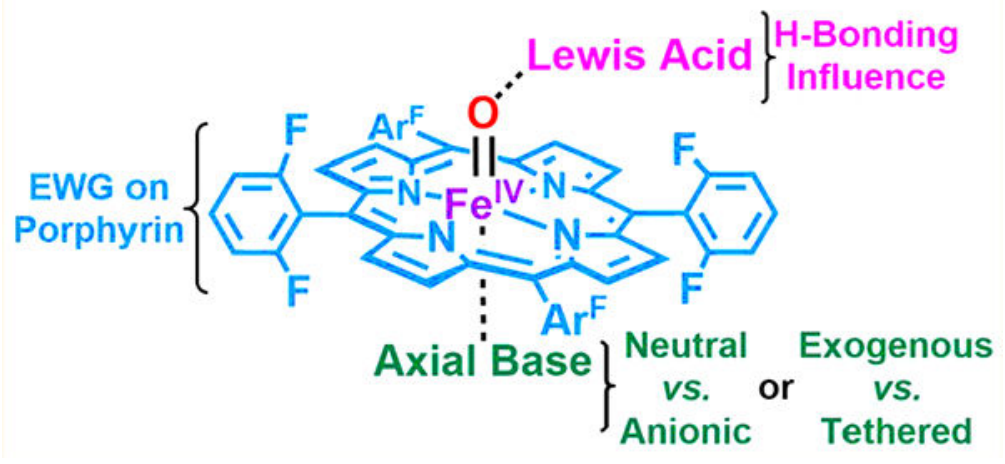

\section{INTRODUCTION}

Heme metalloenzymes activate dioxygen or hydrogen peroxide to generally form two intermediates: the highly oxidizing oxoiron(IV) porphyrin cation radical formally known as Compound-I (Cmpd-I) and the one-electron reduced ferryl porphyrin Compound-II (CmpdII). These high-valent intermediates can be found in peroxidases, catalases, oxidases, P450s, and globins. ${ }^{1-3}$ Many of these metalloenzymes have various proximal axial bases that allow the formation of a protonated ferryl derivative or a valence tautomer of Compound-I $\left(\left(\mathrm{Por}^{\bullet+}\right) \mathrm{Fe}^{\mathrm{IV}}=\mathrm{O}\right)$ or $-\mathrm{II}$ as a key reactive intermediate (Figure 1). High-valent oxoiron(IV) complexes are key oxidative reactive intermediates in heme and non-heme iron enzymes, catalyzing various essential biochemical processes (e.g., catabolism, angiogenesis, respiration, and apoptosis). ${ }^{1,3-11}$ The oxidative and oxygenation reactions catalyzed by heme metalloenzymes and the nature of intermediate ferryl species have been the focus of many studies, but due to the transient nature of these intermediates, synthetic iron porphyrin models have played an essential role in understanding the biological intermediates in dioxygen activation and oxygen-atom-transfer reactions in nature. ${ }^{3,12}$

Synthetic systems of these ferryl intermediates allow for greater insight into the effects of various factors (e.g., nearby amino acid residues, proximal axial bases, or $\mathrm{p} K_{\mathrm{a}}$ values) that mitigate their formation, stability, efficiency, and reactivity. Synthetic high-valent iron(IV)oxo heme systems have been reported to be able to mimic the oxidative behavior of analogous enzymatic reactive intermediates performing reactions such as alkene epoxidation, aliphatic and aromatic hydroxylation, $\mathrm{N}$ - or O-dealkylation, S-oxidation, and halogenation of alkanes. ${ }^{2-4,12,14-24}$ Synthetic model studies have been found to give important mechanistic insight into the behavior of cytochrome P450 oxygenases (e.g., their roles in drug metabolism); however, the specifics of key steps involving highly reactive 
intermediates remain to be fully elucidated. ${ }^{3,25,26}$ More efficient and biomimetic model systems of these enzymes are needed, especially of cytochrome P450, which exhibits promising catalytic oxidative properties for various biosynthetic pathways. This would allow for the application of these enzymes beyond their normal functions in selective catalytic oxidation of strong aliphatic $\mathrm{C}-\mathrm{H}$ bonds (e.g., hydroxylation of alkanes) for renewable energy/fuel research; ${ }^{25,27}$ for example, heme metalloenzymes have been employed as electrocatalysts to develop an alternative energy source to replace the scarce fossil fuels. ${ }^{28}$

Balch and co-workers were the first to report on a synthetic oxoiron(IV) porphyrin species, 23,29,30 and Groves and coworkers were the first to prepare synthetic oxoiron(IV) heme cation radical complexes. ${ }^{24,31-33}$ A number of synthetic model studies focus on investigation of the nature/reactivity of iron(IV)-oxo porphyrin $\pi$-cation radicals; ${ }^{34-39}$ however, reports on iron(IV)-oxo heme complexes are more limited. Efforts have been predominantly directed toward studying the protonation state of Cmpd-II as its basicity has been shown to drive the reactivity of Cmpd-I (having implications for two-electron oxidations). ${ }^{1}$ Studies by Green and co-workers have shown, employing rapid-mixing $\mathrm{pH}$-jump experiments coupled with spectroscopy, that the identity of the axial ligand in heme enzymes plays a critical role in the ferryl protonation of Cmpd-II. ${ }^{40-43}$ Notably, heme-thiolate proteins such as chloroperoxidase (CPO) and P450s have been shown to have a very basic Cmpd-II ferryl oxygen due to the strong electron donation by the axial cysteine ligand. ${ }^{40}$ This "push" effect from the proximal ligand has been reported to be key to ferryl protonation, leading to $\mathrm{Fe}-\mathrm{O}$ elongation and shortening of the Fe-S bond. ${ }^{42-44}$ Work on catalase and ascorbate peroxidase (APX) has demonstrated that tyrosinate and histidine with anionic character, respectively, are electron-donating enough to maintain a highly basic ferryl capable of generating an $\mathrm{Fe}^{\mathrm{IV}}-\mathrm{OH}$ species. ${ }^{41,45}$ Most peroxidases contain a well-conserved aspartate near the $\mathrm{N}_{\delta}$ atom of the proximal histidine (Figure 1), resulting in either $\mathrm{Fe}^{\mathrm{IV}}=\mathrm{O}$ formation for horseradish peroxidase (HRP) Cmpd-II or an $\mathrm{Fe}^{\mathrm{IV}}-\mathrm{OH}$ species for APX Cmpd-II. $33,46-48$ In globins, where the proximal histidine is only engaged in a weak hydrogen bond interaction and has no anionic character, Cmpd-II is an $\mathrm{Fe}^{\mathrm{IV}}=\mathrm{O}$ species, even at $\mathrm{pH}$ 's as low as $3 .{ }^{49}$ Collectively, this indicates not only the identity of the axial ligand but also that its secondary coordination sphere tunes the $\mathrm{Fe}^{\mathrm{IV}}=\mathrm{O} / \mathrm{OH}$ unit.

In spite of these important enzymatic studies, there still remains a need for further enzymatic and synthetic model studies to examine the influence of axial ligation on facilitating protonation, verify the protonation state of Cmpd-II in various enzymes, and determine the basicity of metal-oxo moieties. ${ }^{3}$ Many enzymatic and synthetic investigations remain controversial, $, 1,3$ and significant efforts are still necessary to interrogate the properties of heme ferryl intermediates. Synthetic high-valent model systems are useful in understanding how ferryl intermediates dictate enzyme reactivity and direct catalysis toward hydroxylation of unactivated $\mathrm{C}-\mathrm{H}$ bonds in $\mathrm{P} 450$ s or electron transfer in peroxidases. ${ }^{7,12}$ Efforts have also explored the use of Lewis acids, particularly in nonheme or porphyrinoid systems, to examine the role of Lewis acidic ions in modulating chemistry, for instance, the $\mathrm{H}^{+}$in cytochrome $\mathrm{P} 450$ or the $\mathrm{Ca}^{2+}$ ion of the oxygen-evolving $\mathrm{Mn}_{4} \mathrm{O}_{5}$ cluster of photosystem II. Reports have experimentally demonstrated the importance of Lewis acidic ions (or secondary coordination sphere interactions) in enhancing reactivity. ${ }^{50-58}$ There is no conclusive report on synthetic heme $\mathrm{Fe}^{\mathrm{IV}}-\mathrm{OH}$ species, which would be paramount in 
understanding P450 chemistries, and knowing the conditions which would allow for the generation of such species (and their characterization) would be significant toward our understanding of such a key reactive intermediate.

Herein, the full spectroscopic characterization of seven synthetic high-valent heme iron(IV)oxo (Compound II) species is reported, wherein the physical properties of the iron(IV)-oxo species were examined by addition of axial ligands, a Lewis acid, or both. A catalase CmpdII synthetic model has been prepared, possessing a phenolate ligand, although, as will be discussed below, its physical properties turn out to be somewhat unexpected (vide infra). Ferryl derivatives were prepared with the strong electron-donating exogenous bases 1,5dicyclohexylimidazole (DCHIm), sodium 3,5-dimethoxyphenolate (hereafter referred to as $\left.\mathrm{ArO}^{-}\right)$, and sodium imidazolate $\left(\mathrm{Im}^{-}\right)$to act as the axial ligand with tetrakis $(2,6-$ difluorophenyl)porphyrinate $\left(\mathrm{F}_{8}\right)$ heme (Figure 2). A comparison was also made between a tethered $\left(\mathrm{P}^{\mathrm{Im}}\right)$ and untethered (DCHIm) imidazole axial base, (DCHIm)-F $\mathrm{Cmpd}-\mathrm{II}$ vs $\mathrm{P}^{\mathrm{Im}} \mathrm{Cmpd}-\mathrm{II}$, to explore how the tether addition affects the imidazole coordination to iron and its effect on the bond length of the iron(IV)-oxo moiety (Figure 2). Interestingly, we report the first (that we know of) Mössbauer and extended X-ray absorption fine structure (EXAFS) spectroscopic data of a synthetic imidazole tethered heme Cmpd-II system. Further, the effects of the relative basicity of the ligands and their character (anionic or neutral) on the structural and electronic properties are assessed and compared to known synthetic models and enzymatic systems. Results discussed in this work provide a significant expansion on the heretofore limited axially ligated heme Cmpd-II synthetic model system literature and EXAFS data to date comprised of a single report by PennerHahn et al. ${ }^{33}$

This study also includes two synthetic heme iron(IV)-oxo derivatives formed from addition of the protic Lewis acid (LA) 2,6-lutidinium triflate $\left(\mathrm{LutH}^{+}\right)$), yielding two models to study the interaction of a proton/acid molecule with an iron(IV)-oxo species (Figure 3). This can give important insights into the established protonated Compound II intermediate complex found in key enzymes such as cytochrome P450. The structure and electronic properties of these seven various ferryl derivatives were characterized by UV-vis, 2H NMR, continuouswave (CW) X-band EPR, ${ }^{54 / 57} \mathrm{Fe}$-labeled resonance Raman (rR), 57Fe Mössbauer, Fe Kedge X-ray absorption spectroscopy (XAS), and complementary computational analysis experiments to obtain a spectroscopic handle on various axially ligated ferryl models and Lewis acid Cmpd-II adducts; such data are lacking in the literature. XAS and ${ }^{57} \mathrm{Fe}$ Mössbauer provide atom-specific information about the geometric and electronic structures around Fe. The pre-edge region of the Fe K-edge XAS spectrum has intensity directly correlated to the dipole character of the $1 \mathrm{~s} \rightarrow 3 \mathrm{~d}$ transition caused by $4 \mathrm{p}-3 \mathrm{~d}$ mixing in noncentrosymmetric systems. ${ }^{59}$ In our application, besides distinguishing five-versus sixcoordination, the pre-edge intensity increases as the $\mathrm{Fe}=\mathrm{O}$ bond length decreases due to increased $4 \mathrm{p}$ mixing. 57Fe Mössbauer isomer shifts are connected to the oxidation of the ${ }^{57} \mathrm{Fe}$ atom with lower values correlating to higher oxidation. Low-spin Fe(IV) complexes are distinguishable from other oxidation and spin states, providing a good handle on sample purity. Quadrupole splitting parameters in Mössbauer spec troscopy have less straightforward correlations, and these depend on the electric field gradient tensor. An approximate trend related to our application here is that strong bonding along the molecular 
$z$-axis adds a negative contribution to the quadrupole splitting, which in this case would lower the magnitude of the splitting. ${ }^{60}$

Application of these spectroscopic methods leads to the following, as described in this report: The purity of the Lewis acid and axially ligated ferryl derivatives is confirmed (via Mössbauer spectroscopy), which also supports that they are iron(IV) species (from the isomer shift) and five- or sixcoordinate complexes based on the quadrupole splitting. XAS and ${ }^{54 / 57} \mathrm{Fe}$ rR data correlate with slight elongation of the iron-oxo bond with increasing electron donation from the axial ligands. Mössbauer, rR, and XAS spectroscopic data support the formation of molecular Lewis acid ferryl adducts (rather than full proton transfer occurring), wherein $\mathrm{rR}$ and XAS data indicate that the Lewis acid adducts possess a slightly elongated iron(IV)-oxo bond for F Cmpd-II $\left(\mathrm{LutH}^{+}\right)$.

Through the use of outer-sphere chemical reductants, bracketed reduction potentials of (DCHIm) $\mathrm{F}_{8} \mathrm{Cmpd}-\mathrm{II}$ and $\mathrm{F}_{8} \mathrm{Cmpd}$-II, with and without $\mathrm{LutH}^{+}$, have been obtained. It was found that addition of the Lewis acid greatly increases the oxidizing capabilities of these synthetic iron(IV)-oxo complexes; for example, the reduction potential of $\mathrm{F}_{8} \mathrm{Cmpd}$-II-(LutH ${ }^{+}$) is $>890 \mathrm{mV}$ more positive than that of $\mathrm{F}_{8} \mathrm{Cmpd}$-II. The results obtained provide leads toward a systematic approach to the development of additional biomimetic synthetic models to answer many of the controversial questions concerning high-valent species in heme enzymes.

\section{RESULTS AND DISCUSSION}

Tethered/Exogenous Imidazole Axial Base: $\mathrm{F}_{8} \mathrm{Cmpd}-\mathrm{II},(\mathrm{DCHIm}) \mathrm{F}_{8} \mathrm{Cmpd}-\mathrm{II}$, and $\mathrm{P}^{\mathrm{Im}} \mathrm{Cmpd}-\mathrm{II}$.

The UV-vis spectra of $\mathrm{F}_{8} \mathrm{Cmpd}-\mathrm{II}$, (DCHIm) $\mathrm{F}_{8} \mathrm{Cmpd}-\mathrm{II}$, and $\mathrm{P}^{\mathrm{Im}} \mathrm{Cmpd}-\mathrm{II}$ were previously reported; ${ }^{61-66}$ however, no further spectroscopic evidence was provided, and the conditions described there were different than those used in the present work. The reduced iron complex $\mathrm{F}_{8} \mathrm{Fe}^{\mathrm{II}}$ or $\mathrm{P}^{\mathrm{Im}} \mathrm{Fe}^{\mathrm{II}}$ was cooled to $-90{ }^{\circ} \mathrm{C}$ in a 1:9 MeTHF:toluene $(\mathrm{MeTHF}=2-$ methyltetrahydrofuran) solvent mixture and 1 equiv of meta-chloroperbenzoic acid ( $m$ CPBA) oxidant was added to form $\mathrm{F}_{8} \mathrm{Cmpd}$-II or $\mathrm{P}^{\mathrm{Im}} \mathrm{Cmpd}$-II, respectively. Subsequently, 2 equiv of the strongly electron-donating exogenous axial base DCHIm was added to $\mathrm{F}_{8} \mathrm{Cmpd}-\mathrm{II}$, yielding (DCHIm) $\mathrm{F}_{8} \mathrm{Cmpd}-\mathrm{II}$ (Scheme 1).

\section{Initial Observations: Cmpd-II Complex Generation.}

Preliminary synthetic experimentation revealed that preparing $\mathrm{F}_{8} \mathrm{Cmpd}-\mathrm{II}$ in coordinating solvents such as tetrahydrofuran, MeTHF, or $n$-butyronitrile (vs non-coordinating solvents as dichloromethane or toluene) resulted in a stable and pure complex. This was supported by the lack of decomposition and by the lack of ferric impurities observed by UV-vis and EPR spectroscopies. However, $\mathrm{F}_{8} \mathrm{Cmpd}$-II was less reactive toward exogenous bases (e.g., phenolate, imidazolate, various imidazoles), substrates (i.e., phenols, $\mathrm{C}-\mathrm{H}$ substrates), or Lewis acids in coordinating solvents; thus, exploration of the use of different solvent systems was carried out to optimize reactivity and stability to form stable synthetic ferryl model complexes with interesting oxidative capabilities (Figures 2 and 3). Interestingly, it was found that the mixture 1:9 MeTHF:toluene resulted in a solvent system that allowed for 
the generation of $\mathrm{F}_{8} \mathrm{Cmpd}-\mathrm{II}$, in which it was stable, pure, and reactive toward exogenous bases/Lewis acids as observed by UV-vis, EPR, rR, EXAFS, and Mössbauer spectroscopies (vide infra). It was originally postulated that $\mathrm{F}_{8} \mathrm{Cmpd}-\mathrm{II}$ 's high stability and purity in coordinating solvents was due to the solvent acting as a weakly bound axial ligand to help stabilize the $\mathrm{Fe}^{\mathrm{IV}}=\mathrm{O}$ moiety. However, EXAFS spectroscopy indicates that $\mathrm{F}_{8} \mathrm{Cmpd}-\mathrm{II}$ is five-coordinate, which was further corroborated by the pre-edge intensity and Mössbauer spectroscopy (Table 1, vide infra). Thus, the increased thermal stability imparted by the addition of a small percentage of MeTHF in the solvent may be a result of more favorable solvation of the iron(IV)-oxo moiety.

Addition of 1 equiv of $m C P B A$ to $\mathrm{F}_{8} \mathrm{Fe}^{\mathrm{II}}$ resulted in a UV- vis spectral shift from 422 to $415 \mathrm{~nm}$ in its Soret band and from 542 to $544 \mathrm{~nm}$ in the Q-band, forming the parent $\mathrm{F}_{8} \mathrm{Fe}^{\mathrm{IV}}(=\mathrm{O})$ species (Scheme 1, Figures 2 and 4). The subsequent addition of DCHIm was characterized by a red shift in the $\lambda_{\max }$ of the Soret (415 to $421 \mathrm{~nm}$ ) and of the Q-band (544 to $552 \mathrm{~nm}$ ) generating (DCHIm) $\mathrm{F}_{8}$ Cmpd-II. A similar red shift was observed upon addition of 1 equiv of $m$ CPBA to $\mathrm{P}^{\mathrm{Im}} \mathrm{Fe}^{\mathrm{II}}\left(419,525\right.$ to $422,554 \mathrm{~nm}$ ), forming $\mathrm{P}^{\mathrm{Im}} \mathrm{Cmpd}-\mathrm{II}$ (Table 1 and Figures 2, 4, and S4) The complexes (DCHIm) $\mathrm{F}_{8} \mathrm{Cmpd}-\mathrm{II}$ and $\mathrm{P}^{\mathrm{Im}} \mathrm{Cmpd}-\mathrm{II}$ were stable in solution at $-90{ }^{\circ} \mathrm{C}(>2 \mathrm{~h})$; note that 2 equiv of DCHIm was needed to ensure full incorporation of the axial ligand (no $\mathrm{F}_{8} \mathrm{Cmpd}-\mathrm{II}$ remained). These spectral values are consistent with previous reports (Table $\mathrm{S} 1$ ), wherein six-coordinate or imidazole-ligated synthetic heme iron(IV)-oxo species exhibit red-shifted UV- vis absorption $\lambda_{\max }$ values (vs analogous five-coordinate species).

\section{Mössbauer Spectroscopic Characterization.}

To confirm the species' purity, determine the oxidation state (or electronic density at the metal center) via the isomer shift $[\delta(\mathrm{mm} / \mathrm{s})]$, and the electric field gradient at the iron via the quadrupole splitting $\left[\Delta E_{\mathrm{Q}}(\mathrm{mm} / \mathrm{s})\right],{ }^{57} \mathrm{Fe}$ Mössbauer spectroscopy was employed, in which all spectra were recorded at $80 \mathrm{~K}$ in the absence of a magnetic field. ${ }^{67}$ The Mössbauer spectrum of the ferrous precursor $\mathrm{F}^{57} \mathrm{Fe}^{\mathrm{II}}$ in 1:9 MeTHF:toluene was a mixture of two quadrupole doublets with parameters [major species $(60 \%) \Delta E_{\mathrm{Q}}=2.09 \mathrm{~mm} / \mathrm{s}$ and $\delta=0.64$ $\mathrm{mm} / \mathrm{s}$ and minor species $(40 \%) \Delta E_{\mathrm{Q}}=2.53 \mathrm{~mm} / \mathrm{s}$ and $\left.\delta=0.94 \mathrm{~mm} / \mathrm{s}\right]$ that are typical for high-spin ferrous heme complexes (Table S2 and Figure S11). ${ }^{68-70}$ These parameters of the minor species were similar to the $\mathrm{F}_{8}{ }^{57} \mathrm{Fe}^{\mathrm{II}}$ spectrum previously reported by Karlin and coworkers ${ }^{71}$ in acetone at $-80^{\circ} \mathrm{C}$ where they observed one species with parameters $\Delta E_{\mathrm{Q}}=$ $2.66 \mathrm{~mm} / \mathrm{s}$ and $\delta=0.93 \mathrm{~mm} / \mathrm{s}$ and suggested that one solvent molecule is bound. Thus, $\mathrm{F}_{8}{ }^{57} \mathrm{Fe}^{\mathrm{II}}$ in 1:9 MeTHF:toluene was determined to be a mixture of the five-coordinate (MeTHF) $\mathrm{F}_{8}{ }^{57} \mathrm{Fe}^{\mathrm{II}}$ (due to the similarity of its parameters to (acetone) $\mathrm{F}_{8}{ }^{57} \mathrm{Fe}^{\mathrm{II}}$ ) and the sixcoordinate (MeTHF) ${ }_{2} \mathrm{~F}_{8}{ }^{57} \mathrm{Fe}^{\mathrm{II}}$ species (due to its decreased quadrupole splitting and its similarity to other high-spin ferrous species ${ }^{68-70}$ ) (Chart 1 ).

$\mathrm{P}^{\mathrm{Im} 57} \mathrm{Fe}^{\mathrm{II}}$ was prepared for the first time in this work. (Note: See synthetic details in the Experimental Section.) The Mössbauer spectrum of $\mathrm{P}^{\mathrm{Im} 57} \mathrm{Fe}^{\mathrm{II}}$ indicated three different species (Chart 1), where there are two different six-coordinate low-spin ferrous species $\left(\Delta E_{\mathrm{Q}}\right.$ $=1.68 \mathrm{~mm} / \mathrm{s}$ and $\delta=0.49 \mathrm{~mm} / \mathrm{s}$ and $\Delta E_{\mathrm{Q}}=0.92 \mathrm{~mm} / \mathrm{s}$ and $\left.\delta=0.44 \mathrm{~mm} / \mathrm{s}\right)$ and one fivecoordinate high-spin ferrous species $\left(\Delta E_{\mathrm{Q}}=2.48 \mathrm{~mm} / \mathrm{s}\right.$ and $\left.\delta=0.96 \mathrm{~mm} / \mathrm{s}\right)($ Table $\mathrm{S} 2$ and 
Figure S13). The high-spin parameters of $\mathrm{P}^{\mathrm{Im} 57} \mathrm{Fe}^{\mathrm{II}}$ are in accordance with the values of a typical high-spin five-coordinate ferrous compound, ${ }^{68-70}$ with either the tethered imidazole or solvent binding, and with the parameters for the high-spin five-coordinate complex (MeTHF) $\mathrm{F}_{8}{ }^{57} \mathrm{Fe}^{\mathrm{II}}$. It was previously established that the tethered imidazole of the $\mathrm{P}^{\mathrm{Im}}$ system can easily coordinate to iron or persist free in solution. This was demonstrated by the EPR of $\mathrm{P}^{\mathrm{Im}} \mathrm{Fe}^{\mathrm{III}} \mathrm{SbF}_{6}$ or $\mathrm{P}^{\mathrm{Im}} \mathrm{Fe}^{\mathrm{III}} \mathrm{OH}$ wherein two sets of signals were observed, that of a high-spin iron(III) species and that of a low-spin iron(III) complex. ${ }^{63}$ Previous ${ }^{1} \mathrm{H}$ NMR data on $\mathrm{P}^{\mathrm{Im}} \mathrm{Fe}^{\mathrm{II}}$ in various solvents showed that it can exist in either a high-spin five-coordinate (in noncoordinating solvents, with the imidazole tether bound axially) or low-spin sixcoordinate (in coordinating solvent, with the tether and one solvent molecule bound axially) geometry. ${ }^{72}$ While the exact nature of the second low-spin species observed in our Mössbauer (36\%) cannot be determined, we suggest that it could be (MeTHF) ${ }_{2} \mathrm{P}^{\mathrm{Im}} \mathrm{Fe}^{\mathrm{II}}$, with the tether unbound or a species with one solvent molecule and the tether bound in a different orientation (Chart 1).

Samples for Mössbauer spectroscopy of $\mathrm{F}^{57}{ }_{8} \mathrm{Fe}^{\mathrm{IV}} \mathrm{O}$, (DCHIm) $\mathrm{F}_{8}{ }^{57} \mathrm{Fe}^{\mathrm{IV}}=\mathrm{O}$, and $\mathrm{P}^{\mathrm{Im} 57} \mathrm{Fe}^{\mathrm{IV}}=\mathrm{O}$ were all prepared in a manner similar to those utilized for UV-vis experiments in 1:9 MeTHF:toluene at $-90^{\circ} \mathrm{C}$. The results confirm that all three complexes possess the heme-iron in the $\mathrm{Fe}^{\mathrm{IV}}$ oxidation, based on the fitted isomer shifts found to be around 0.1 $\mathrm{mm} / \mathrm{s}$ (Tables 1 and S2), a hallmark of other known synthetic and enzymatic ferryl systems understood as lowered $3 \mathrm{~d}$ electron shielding causing increased electron density at the nucleus, which results in a decreased isomer shift relative to lower oxidations (Tables $1, \mathrm{~S} 1$, and $\mathrm{S} 2$ and Figures 5 and S13). ${ }^{11,42,44} \mathrm{~F}_{8}{ }^{57} \mathrm{Fe}^{\mathrm{IV}}=\mathrm{O}\left(\Delta E_{\mathrm{Q}}=2.06 \mathrm{~mm} / \mathrm{s}\right.$ and $\left.\delta=0.11 \mathrm{~mm} / \mathrm{s}\right)$ and $(\mathrm{DCHIm}) \mathrm{F}_{8}{ }^{57} \mathrm{Fe}^{\mathrm{IV}}=\mathrm{O}\left(\Delta E_{\mathrm{Q}}=1.073 \mathrm{~mm} / \mathrm{s}\right.$ and $\left.\delta=0.11 \mathrm{~mm} / \mathrm{s}\right)$ were both fit with one quadrupole doublet and, under the aforementioned conditions, were of high purity (Figure 5 and Tables 1 and S2). Addition of DCHIm to $\mathrm{F}_{8} \mathrm{Cmpd}$-II resulted in a decrease in the quadrupole splitting from 2.06 to $1.07 \mathrm{~mm} / \mathrm{s}$, which is consistent with the formation of a sixcoordinate species as the covalency of the axial base affects the $\mathrm{d}_{\mathrm{z}}{ }^{2}$ orbital due to an increased electron density upon binding (Tables 1 and S2 and Figure 5).

In previous reports, synthetic iron(IV)-oxo species with various porphyrins and with/without 1-methylimidazole (1-MeIm) serving as an axial base ligand have been characterized. Their Mössbauer spectroscopic parameters are summarized in Table S1. Every synthetic ferryl system with 1-MeIm has an isomer shift around $0.1 \mathrm{~mm} / \mathrm{s}$ and a quadrupole splitting around $1 \mathrm{~mm} / \mathrm{s}$ in accordance with the values reported here for (DCHIm) $\mathrm{F}_{8} \mathrm{Cmpd}$-II (Tables $1, \mathrm{~S} 1$, and S2 and Figure 5). Consistent with the three $\mathrm{P}^{\mathrm{Im}} \mathrm{Fe}^{\mathrm{II}}$ species observed in the Mössbauer spectrum, there were three ferryl PIm Cmpd-II species $\left(\Delta E_{\mathrm{Q}}=1.06 \mathrm{~mm} / \mathrm{s}\right.$ and $\delta=0.11 \mathrm{~mm} / \mathrm{s}$; $\Delta E_{\mathrm{Q}}=1.22 \mathrm{~mm} / \mathrm{s}$ and $\delta=0.11 \mathrm{~mm} / \mathrm{s}$; and $\Delta E_{\mathrm{Q}}=2.06 \mathrm{~mm} / \mathrm{s}$ and $\delta=0.16 \mathrm{~mm} / \mathrm{s}$ ) ascribed to the fluxional nature of the tether (Chart 2, Figure S13, and Tables 1 and S2). Comparison of

$\mathrm{F}_{8} \mathrm{Cmpd}-\mathrm{II}$ and other five-coordinate synthetic heme ferryl systems (Tables 1 and S1) helped us to assign the five-coordinate $\mathrm{P}^{\mathrm{Im}} \mathrm{Cmpd}$-II species with the tether free in solution to the complex with the higher quadrupole splitting around $2 \mathrm{~mm} / \mathrm{s}$. One might consider the possibility that the tethered imidazole interacts with the oxo atom ligand (since it is not coordinated to iron in the five-coordinate ferryl species), but this is most likely not occurring; the isomer shift and quadrupole splitting parameters for $\mathrm{F}_{8} \mathrm{Cmpd}$-II and the fivecoordinate $\mathrm{P}^{\mathrm{Im}} \mathrm{Cmpd}-\mathrm{II}$ are very similar, and greater changes might be expected if this 
interaction occurred. The sixcoordinate imidazole-tethered $\mathrm{P}^{\mathrm{Im}} \mathrm{Cmpd}-\mathrm{II}$ species had values in agreement with (DCHIm) $\mathrm{F}_{8} \mathrm{Cmpd}$-II (Chart 2 and Table 1), so the imidazole being tethered or not does not seem to have a major effect on the electron density or electric field gradient at the iron center as observed by Mössbauer spectroscopy. The second sixcoordinate species may arise from a different conformation of the tethered axial base when bound to the iron ion (e.g., the tether may be coming out of the plane) or from solvent binding (see Chart 2). DFT calculations support the conclusion that for $\mathrm{P}^{\mathrm{Im}} \mathrm{Cmpd}-\mathrm{II}$ the major species in solution favors the tethered imidazole coordinated to the iron metal center (vide infra).

\section{Resonance Raman Spectroscopic Characterization of $\mathrm{F}_{8} \mathrm{Cmpd}$-II and (DCHIm) $\mathrm{F}_{8} \mathrm{Cmpd-II}$.}

Similar to the work by Bajdor and Nakamoto, who compared rR spectra of unlabeled $\left({ }^{56} \mathrm{Fe}\right)$ and ${ }^{54} \mathrm{Fe}$ tetraphenylporphyrin iron(IV)-oxo complexes to identify $\mathrm{Fe}=\mathrm{O}$ stretches, ${ }^{74}$ this study utilized ${ }^{57 / 54} \mathrm{Fe}$ derivatives in synthetic heme iron(IV)-oxo systems. There are examples in the literature of labeling the oxidant or adding labeled water to exchange iron(IV)-oxo groups (Table S1), but these approaches proved unsuccessful here. Further, ${ }^{57 / 54} \mathrm{Fe}$ rR spectroscopy was employed to aid the Mössbauer results and to examine the effects of the axial ligands on the iron(IV)-oxo stretching vibration (Table 1 and Figure 6). The heme complex, $\mathrm{F}_{8} \mathrm{Fe}^{\mathrm{III}}(\mathrm{Cl})$, was prepared by metalating the $\mathrm{F}_{8}$ ligand with either ${ }^{57} \mathrm{FeCl}$ or ${ }^{54} \mathrm{FeCl}_{2}$, followed by reduction to form the previously published $\mathrm{F}_{8}{ }^{57} \mathrm{Fe}^{\mathrm{II}}$ and the newly synthesized (for this report) heme complex $\mathrm{F}_{8}{ }^{54} \mathrm{Fe}^{\mathrm{II}} .{ }^{71}$

The rR data of $\mathrm{F}_{8} \mathrm{Cmpd}-\mathrm{II}$ and (DCHIm) $\mathrm{F}_{8} \mathrm{Cmpd}$-II confirmed their iron(IV) oxidation state by the oxidation state marker band $v_{4}$ around $1370 \mathrm{~cm}^{-1}$ (Table 1 and Figure S10). The midfrequency region also provides clear evidence for the isotope sensitive $v(\mathrm{Fe}=\mathrm{O})$ mode in the $800^{-} 850 \mathrm{~cm}^{-1}$ region (Figure 6 and Table 1). The iron(IV)-oxo stretching frequency of $\mathrm{F}_{8} \mathrm{Cmpd}$-II shifted from 833 to $811 \mathrm{~cm}^{-1}\left(\Delta=-22 \mathrm{~cm}^{-1}\right)$ upon addition of DCHIm, consistent with electron donation from the exogenous axial base causing slight elongation of the $\mathrm{Fe}=\mathrm{O}$ bond (Figures 6, S7, and $\mathrm{S} 8$ and Table 5). This is in good agreement with previous reports (Table S1), wherein the addition of an axial base, either 1-methylimidazole or a strongly donating ligand, lowered the observed $v(\mathrm{Fe}=\mathrm{O})$. For instance the addition of 1MeIm to (TPP) $\mathrm{Fe}^{\mathrm{IV}}(=\mathrm{O})$ or to $(\mathrm{OEP}) \mathrm{Fe}^{\mathrm{IV}}(=\mathrm{O})[\mathrm{TPP}=$ tetraphenylporphyrinate; $\mathrm{OEP}=$ octaethylporhyrinate], showed that the $v(\mathrm{Fe}=\mathrm{O})$ frequency decreased from 852 to $820 \mathrm{~cm}^{-1}$ $\left(\Delta=-32 \mathrm{~cm}^{-1}\right)$ (Table S1). ${ }^{74-77}$ Application of Badger's rule with the parameters determined by Green, ${ }^{78} r_{\mathrm{e}}=55.702 / \mathrm{v}_{\mathrm{e}}{ }^{2 / 3}+1.003$, indicates that based on the $\mathrm{rR}$ data the $\mathrm{Fe}=\mathrm{O}$ bond is slightly elongated, from 1.632 to $1.644 \AA$, upon addition of DCHIm to $\mathrm{F}_{8} \mathrm{Cmpd}$-II. As the dielectric constants for MeTHF and toluene are 7.0 and 2.4, respectively, and protein interiors are modeled with a dielectric of $4-10$, we do not expect our application of Badger's rule to deviate significantly from Green's application to biological systems. $\mathrm{Fe}=\mathrm{O}$ bond distance determinations coming from XAS are discussed below.

\section{Anionic Axial Ligands: $\left(\mathrm{ArO}^{-}\right) \mathrm{F}_{8} \mathrm{Cmpd}^{-I I}$ and $\left(\mathrm{Im}^{-}\right)-\mathrm{F}_{8} \mathrm{Cmpd}-\mathrm{II}$.}

Since various axial ligands, many of them having an anionic nature, are present in hemecontaining enzymes, attempts to synthesize $\mathrm{F}_{8} \mathrm{Cmpd}$-II derivatives with axially ligated substituted phenolate $\left(\mathrm{ArO}^{-}\right)$and unsubstituted imidazolate $\left(\mathrm{Im}^{-}\right)$donors were carried out. It 
is noteworthy that phenolates without electron-donating moieties are unreactive toward $\mathrm{F}_{8} \mathrm{Cmpd}-\mathrm{II}$ in 1:9 MeTHF:toluene at $-90{ }^{\circ} \mathrm{C}$, failing to form a new species as determined by UV-vis spectroscopy (no spectral change). However, when 2 equiv of sodium 3,5dimethoxyphenolate, in a mixture of 15 -crown-5 ether and butyronitrile, was added to $\mathrm{F}_{8} \mathrm{Cmpd}-\mathrm{II}$ in 1:9 MeTHF:toluene at $-90{ }^{\circ} \mathrm{C}$, there was a red shift in the Soret and Q-band from $(415,544 \mathrm{~nm}$ to $420,548 \mathrm{~nm})$, the latter values being similar to $\mathrm{t} h$ o s e o b s e $\mathrm{r}$ v e d f or (DCHIm) $\mathrm{F}_{8} \mathrm{Cmpd}-\mathrm{II}$ (Figures 5 and S2 and Table 1). When 3,5-dimethoxyphenol was added to $\mathrm{F}_{8} \mathrm{Cmpd}-\mathrm{II}$, there was an immediate spectral change to a known ferric species (the resulting UV-vis was similar to the authentic UV-vis signature of $\mathrm{F} \mathrm{Fe} \mathrm{e}^{\mathrm{III}} \mathrm{OH}$, see Figure S35), further confirmed by observance of a high-spin ferric $g=6$ signal via EPR spectroscopy. This control experiment provided evidence that 3,5-dimethoxyphenolate (not phenol) binds the iron center. The existence of the Cmpd-II system, $\left(\mathrm{ArO}^{-}\right) \mathrm{F}_{8} \mathrm{Cmpd}-\mathrm{II}$ (Figure 2), and its characterization (here), may well facilitate future efforts toward designing a protonated catalase Cmpd-II model, to further elucidate compound structure, electronic structure/bonding, and reactivity, as pertains to the findings uncovered by Green and coworkers, as mentioned in the Introduction.

Addition of 2 equiv of sodium imidazolate, in a mixture of 15-crown-5 ether and butyronitrile, to $\mathrm{F}_{8} \mathrm{Cmpd}-\mathrm{II}$ in 1:9 MeTHF:toluene at $-90{ }^{\circ} \mathrm{C}$ formed the $\left(\mathrm{Im}^{-}\right) \mathrm{F}_{8} \mathrm{Cmpd}-\mathrm{II}$ derivative (Figure 2), which showed the characteristic red shift in th e S o r e t a n d Q - b a $\mathrm{n} \mathrm{d}$ (a s o b s e r v e d f o r (DCHIm) $\mathrm{F}_{8} \mathrm{Cmpd}-\mathrm{II}$ and $\left(\mathrm{ArO}^{-}\right) \mathrm{F}_{8} \mathrm{Cmpd}^{-I I}$, Figures 4 and S2) from 415, $544 \mathrm{~nm}$ to 420, $556 \mathrm{~nm}$ (Figure $\mathrm{S} 3$ and Table 1). Although addition of imidazole (as a neutral unsubstituted compound) to $\mathrm{F}_{8} \mathrm{Cmpd}-\mathrm{II}$ resulted in a similar UV-vis signature as compared to the $\left(\mathrm{Im}^{-}\right) \mathrm{F}_{8} \mathrm{Cmpd}$-II derivative, different Mössbauer parameters were observed, supporting the supposition that anionic imidazolate was bound in what we formulate as $\left(\mathrm{Im}^{-}\right) \mathrm{F}_{8} \mathrm{Cmpd}-\mathrm{II}$ (Figure S12 and Table S2).

The Mössbauer spectrum of $\left(\mathrm{ArO}^{-}\right) \mathrm{F}_{8} \mathrm{Cmpd}-\mathrm{II}$ showed one quadrupole doublet, supporting the compound's purity $\left(\Delta E_{\mathrm{Q}}=1.57 \mathrm{~mm} / \mathrm{s}\right.$ and $\left.\delta=0.12 \mathrm{~mm} / \mathrm{s}\right)$; however, $\left(\mathrm{Im}^{-}\right) \mathrm{F}_{8} \mathrm{Cmpd}$-II $\left(\Delta E_{\mathrm{Q}}=1.55 \mathrm{~mm} / \mathrm{s}\right.$ and $\left.\delta=0.12 \mathrm{~mm} / \mathrm{s}\right)$ had a minor (13\%) ferryl impurity of unreacted $\mathrm{F}_{8} \mathrm{Cmpd}$-II (Figure 7 and Tables 1 and S2). Both derivatives were confirmed to be of the iron(IV) oxidation state by the isomer shift around $0.1 \mathrm{~mm} / \mathrm{s}$ and six-coordinate from the decreased quadrupole splitting ( 2.0 to $1.5 \mathrm{~mm} / \mathrm{s})$ upon addition of imidazolate or phenolate to $\mathrm{F}_{8} \mathrm{Cmpd}$-II (Table 1). The isomer shift and quadrupole splitting increased with imidazolate (vs the neutral imidazole, DCHIm), which is not consistent with the expected increase in $\mathrm{Fe}-\mathrm{O}$ elongation and shortening of $\mathrm{Fe}-\mathrm{N}_{\mathrm{Im}}$ bond imparted by a better electrondonating axial ligand. The values for the phenolate Cmpd-II derivative (vs (DCHIm)F8Cmpd-II) were also not consistent with the expected parameters imparted by a better electron-donating axial ligand. These observations may be accounted for by considering the steric effects of the phenolate methoxy groups affecting the angle at which the axial ligand interacts with the iron center, which thus may hinder electron donation from the phenolate. It may also be due to the solvent mixture $\left(\mathrm{ArO}^{-}\right) \mathrm{F}_{8} \mathrm{Cmpd}-\mathrm{II}$ was prepared in, in that it is predominantly toluene (a nonpolar solvent), which could well favor ion pairing in solution. Thus, the phenolate may be interacting with both the iron and the crowned sodium ion, which may also be affecting the angle at which the phenolate coordinates to the iron (this could also affect the donation observed from $\left.\left(\mathrm{Im}^{-}\right) \mathrm{F}_{8} \mathrm{Cmpd}-\mathrm{II}\right)$. See also, below, the 
discussion of DFT calculations, since computations for both $\left(\mathrm{ArO}^{-}\right) \mathrm{F}_{8} \mathrm{Cmpd}-\mathrm{II}$ and (Im $\left.{ }^{-}\right) \mathrm{F}_{8} \mathrm{Cmpd}-\mathrm{II}$ resulted in values closer to the experimental spectroscopic data when a sodium ion was included.

The iron(IV) oxidation state and lack of strong electron donation from the phenolate or imidazolate axial ligands was also confirmed by $\mathrm{rR}$ spectroscopy employing ${ }^{57 / 54} \mathrm{Fe}$ labeling, wherein DCHIm effected a greater change on the $\mathrm{Fe}=\mathrm{O}$ bond, which does not follow the expected trend (Figure 6 and Table 1). Phenolate coordination to $\mathrm{F}_{8} \mathrm{Cmpd}-\mathrm{II}$ slightly weakened the $v(\mathrm{Fe}=\mathrm{O})$ from 833 to $829 \mathrm{~cm}^{-1}$, and $\left(\mathrm{Im}^{-}\right) \mathrm{F}_{8} \mathrm{Cmpd}-\mathrm{II}$ showed a similar $5 \mathrm{~cm}^{-1}$ downshift from 833 to $828 \mathrm{~cm}^{-1}$. Based on Badger's rule ${ }^{78}$ and the rR spectroscopic data, $\left(\mathrm{ArO}^{-}\right) \mathrm{F}_{8} \mathrm{Cmpd}-\mathrm{II}$ has an $\mathrm{Fe}=\mathrm{O}$ bond length of $1.634 \AA$, and (Im $\left.{ }^{-}\right) \mathrm{F}_{8} \mathrm{Cmpd}-\mathrm{II}$ has an $\mathrm{Fe}=\mathrm{O}$ bond length of $1.635 \AA$, both of which are typical for iron(IV)oxo systems, as seen in Table S1. As the results reported herein demonstrate, we have established conditions to generate synthetic Compound-II heme models with anionic axial ligands, and future studies with a more basic phenolate or different porphyrin system may be able to better mimic catalase.

\section{EXAFS/XANES Spectroscopy of the Axially Ligated Ferryl Derivatives.}

EXAFS spectroscopic literature is extremely limited for synthetic heme iron(IV)-oxo CmpdII systems relative to Mössbauer or $\mathrm{rR}$ literature; there is only one report to date, by PennerHahn and co-workers in 1986, for $(1-\mathrm{MeIm})(\mathrm{TTP}) \mathrm{Fe}^{\mathrm{IV}}(=\mathrm{O})[\mathrm{TTP}=$ mesotetratolylporphyrin], where the $\mathrm{Fe}=\mathrm{O}$ bond distance was determined to be $1.64^{-} 1.66 \AA^{3}{ }^{33}$ Due to early difficulties modeling the significant multiple scattering in hemes, there are few examples of synthetic heme $\mathrm{Fe}=\mathrm{O}$ EXAFS spectra; however, numerous EXAFS spectroscopy reports on heme enzyme intermediates have been reported by Green and coworkers. $1,3,40$ The present report will significantly add to the limited EXAFS reports for synthetic heme iron(IV)-oxo compounds.

The Fe EXAFS spectroscopy $\left(k=2^{-} 15.9 \AA^{-1}\right)$ fits for the synthetic $\mathrm{F}_{8} \mathrm{Cmpd}$-II models confirms the formation of $\mathrm{Fe}=\mathrm{O}$ units with an $\mathrm{Fe}=\mathrm{O}$ distance of $1.66 \AA$ for (DCHIm)$\mathrm{F}_{8} \mathrm{Cmpd}-\mathrm{II}$ and all other models at $1.65 \AA$, with the diffierences not being significant (Figure $\mathrm{S} 16$ and Table S3). With the exception of the $\left(\mathrm{ArO}^{-}\right) \mathrm{F}_{8} \mathrm{Cmpd}-\mathrm{II}$, fits were unable to resolve the axial ligand bond length from the pyrrole nitrogens in the first coordination sphere. For the $\mathrm{ArO}^{-}$axial ligand system, a marginally improved fit can be achieved by separating the axial ligand scattering path from the pyrrole nitrogen path slightly above the experimental resolution $\left(\mathrm{R}_{\text {axial }}-\mathrm{R}_{\text {pyrrole }}=0.12 \AA\right.$; resolution $=0.11 \AA$ ). Only the $\mathrm{F}_{8} \mathrm{Cmpd}-\mathrm{II}$ complex had a best fit with an $\mathrm{Fe}-\mathrm{N}_{\mathrm{p}} / \mathrm{N}$ coordination number of 4 (Table S3), substantiated by the large pre-edge intensity (Table 1 and see discussions below). The tethered $\mathrm{P}^{\mathrm{Im}}$ porphyrinate reveals a similar fit as the $(\mathrm{DCHIm}) \mathrm{F}_{8} \mathrm{Cmpd}$-II, but with a lower $\sigma^{2}$ factor for the pyrrole/ axial nitrogen paths.

While the EXAFS data are similar when comparing $\mathrm{F}_{8} \mathrm{Cmpd}-\mathrm{II}$ and its derivatives (due to the predominance of the signals from the pyrrole structure), there are key diffierences in the intensities of the pre-edge region (X-ray absorption near-edge spectroscopy, XANES) for each model (Figures 8 and S15A). The pre-edge quadrupole intensity is governed by the $3 \mathrm{~d}-$ hole metal character of the $1 \mathrm{~s} \rightarrow 3 \mathrm{~d}$ transition, and dipole intensity arises from $4 \mathrm{p}$ orbital 
mixing with the $3 \mathrm{~d}$ manifold for non-centrosymmetric molecules: ${ }^{59}$ in this case due to the strong axial distortion caused by the short $\mathrm{Fe}(\mathrm{IV})=\mathrm{O}$ bond.

Peak fitting of the pre-edge intensities reveals that the five-coordinate $\mathrm{F}_{8} \mathrm{Cmpd}-\mathrm{II}$ has the largest pre-edge area (Table 1), due to a large dipole contribution caused by $4 \mathrm{p}$ mixing into the $3 \mathrm{~d}$ orbitals. Of the six-coordinate models, the $\mathrm{ArO}^{-}$derivative has the largest pre-edge area, followed by that for the imidazolate, then the neutral imidazole (i.e., DCHIm) axially ligated species. The integrated pre-edge intensity area positively correlates with the $57 \mathrm{Fe}=\mathrm{O}$ stretching mode frequency observed by $\mathrm{rR}$, which maps naturally onto a shortening of the $\mathrm{Fe}=\mathrm{O}$ bond length, increased $4 \mathrm{p}-3 \mathrm{~d}$ orbital mixing, and concomitant increase in the dipole intensity of the pre-edge (Table 1). It is noteworthy that the difference in pre-edge area between $\mathrm{ArO}^{-}$and $\mathrm{Im}^{-}$axial ligand systems is not mirrored in the negligible difference in the $\mathrm{Fe}=\mathrm{O}$ frequency determined by $\mathrm{rR}$ spectroscopy. This may coincide with the increased $\mathrm{Fe}-$ Oaxial bond length determined by EXAFS spectroscopy (Table S3) relative to the unresolvable $\mathrm{Fe}-\mathrm{N}_{\text {axial }}$ distance in the $\mathrm{Im}^{-}$system. Attempts to fit the $\mathrm{P}^{\mathrm{Im}}$ pre-edge resulted in a significantly different background relative to the $\mathrm{F}_{8}$ complexes, likely related to the sample being a mixture of species (Table S2); thus we considered the pre-edge unreliable for comparative purposes. Although most obvious for the DCHIm complex (near 7117.8 eV), the spectra featured an inflection of the rising edge region, but could not be acceptably resolved by standard Fe K-edge XAS. However, these features will be explored by highenergy resolution fluorescence detected (HERFD) K-edge spectroscopy.

\section{Synthetic Heme Lewis Acid Adduct Ferryl Derivatives.}

UV-vis spectroscopic monitoring of the addition of 1 equiv of the Brønsted (and Lewis) acid 2,6-lutidinium triflate $\left(\mathrm{LutH}^{+}\right)$, dissolved in butyronitrile, to $\mathrm{F}_{8} \mathrm{Cmpd}$-II or (DCHIm) $\mathrm{F}_{8}$ Cmpd-II resulted in the formation of the Cmpd-II Lewis acid adducts, $\mathrm{F}_{8} \mathrm{Cmpd}$ $\mathrm{II}\left(\mathrm{LutH}^{+}\right)$and (DCHIm)- $\mathrm{F}_{8} \mathrm{Cmpd}-\mathrm{II}\left(\mathrm{LutH}^{+}\right)$, respectively (Figures 3, S5, and S6 and Table 2). The former adduct exhibited slightly shifted Soret and Q-band absorptions (i.e., changes from $415,544 \mathrm{~nm}$ to $413,546 \mathrm{~nm}$ ), while addition of $\mathrm{LutH}^{+}$to (DCHIm)- $\mathrm{F}_{8}$ Cmpd-II caused a blue shift in the Soret and Q-band peaks (i.e., from 421, 552 to 418, $539 \mathrm{~nm}$ ) (Figures S5 and $\mathrm{S} 6$ and Table 2). Interestingly, the interaction between $\mathrm{LutH}^{+}$and $\mathrm{F}_{8} \mathrm{Cmpd}-\mathrm{II}$ or (DCHIm) $\mathrm{F}_{8} \mathrm{Cmpd}$-II resulted in a decreased molar absorptivity in the Soret and Q-band (vs the increased molar absorptivity seen when an axial base was added, vide supra).

${ }^{57} \mathrm{Fe}$ Mössbauer spectroscopy of (DCHIm) $\mathrm{F}_{8} \mathrm{Cmpd}-\mathrm{II}-\left(\mathrm{LutH}^{+}\right)$indicated the complex consisted of one species of high purity as seen by the observation of one quadrupole doublet $\left(\Delta E_{\mathrm{Q}}=1.30 \mathrm{~mm} / \mathrm{s}\right.$ and $\left.\delta=0.07 \mathrm{~mm} / \mathrm{s}\right)$ (Figure 9). However, $\mathrm{F}_{8}$ Cmpd-II $\left(\mathrm{LutH}^{+}\right)\left(\Delta E_{\mathrm{Q}}=2.23\right.$ $\mathrm{mm} / \mathrm{s}$ and $\delta=0.08 \mathrm{~mm} / \mathrm{s}$ ) had an impurity of unreacted $\mathrm{F}_{8} \mathrm{Cmpd}-\mathrm{II}$ starting material (Figure 9). The identity of this impurity was later confirmed by ${ }^{57 / 54} \mathrm{Fe}$-labeled $\mathrm{rR}$ spectroscopy (vide infra, Figures S7 and S9, and Table 2). Both of the Lewis acid ferryl derivatives were confirmed to be of the iron(IV) oxidation state as reflected by the isomer shift around $\sim 0.1$ $\mathrm{mm} / \mathrm{s}$, and for $\mathrm{F}_{8} \mathrm{Cmpd}-\mathrm{II}\left(\mathrm{LutH}^{+}\right)$this was further confirmed by $\mathrm{rR}$ spectroscopy from the oxidation state marker band being $\sim 1370 \mathrm{~cm}^{-1}$ (Figure $\mathrm{S} 10$ and Table 2). Thus, addition of $\mathrm{LutH}^{+}$to both parent species resulted in a slight decrease in the isomer shift and a slight increase in the quadrupole splitting observed by Mössbauer spectroscopy. The increase in 
quadrupole splitting in both cases is consistent with a weakened $\mathrm{Fe}=\mathrm{O}$ bond. Further, the decreased isomer shift values are as expected due to the Lewis acid withdrawing electron density away from the iron nucleus through its interaction with the oxo ligand.

Resonance Raman spectroscopic data were only successfully collected for $\mathrm{F}_{8} \mathrm{Cmpd}-\mathrm{II}(\mathrm{LutH}$ ${ }^{+}$) (Figure $\mathrm{S} 9$ and Table 2). Upon addition of $\mathrm{LutH}^{+}$to $\mathrm{F}_{8} \mathrm{Cmpd}-\mathrm{II}$, the $v(\mathrm{Fe}=\mathrm{O})$ decreased from 833 to $819\left(\Delta=-14 \mathrm{~cm}^{-1}\right)$ and required addition of 5 equiv of $\mathrm{LutH}^{+}$to fully convert $\mathrm{F}_{8} \mathrm{Cmpd}$-II to the $\mathrm{F}_{8} \mathrm{Cmpd}-\mathrm{II}\left(\mathrm{LutH}^{+}\right)$complex (Figure S9). This $v^{57} \mathrm{Fe}=\mathrm{O}$ ) downshift to 819 $\mathrm{cm}^{-1}$ indicates that the Lewis acid caused a slight elongation of the $\mathrm{Fe}=\mathrm{O}$ bond of $0.007 \AA$ (from 1.632 to $1.639 \AA$ ) according to Badger's rule.

EXAFS spectroscopy is only accurate to $\sim 0.02 \AA$ and could not detect this slight difference between $\mathrm{F}_{8} \mathrm{Cmpd}-\mathrm{II}$ and $\mathrm{F}_{8} \mathrm{Cmpd}-\mathrm{II}\left(\mathrm{LutH}^{+}\right)$; however, the pre-edge intensity decreases for the $\mathrm{LutH}^{+}$adduct, indicating small elongation of the $\mathrm{Fe}-\mathrm{O}$ bond (Figure 10). EXAFS spectroscopy of $\mathrm{F}_{8} \mathrm{Cmpd}-\mathrm{II}\left(\mathrm{LutH}^{+}\right)$and $(\mathrm{DCHIm}) \mathrm{F}_{8} \mathrm{Cmpd}-\mathrm{II}\left(\mathrm{LutH}^{+}\right)$indicated that both species were Lewis acid adducts and not fully protonated $\mathrm{Fe}^{\mathrm{IV}}-\mathrm{OH}$ species, which is also inferred by the only slight spectroscopic changes observed (Figure S17 and Table S4). This is due to the presence of the very short $\mathrm{Fe}=\mathrm{O}$ bond $(1.64 \AA$ ), while protonated Cmpd-II species have $\mathrm{Fe}-\mathrm{O}$ bond lengths greater than or equal to $1.8 \AA .^{1}$ The interaction of the Lewis acid with the oxo ligand causes the pre-edge intensity to decrease from 54.3 to 48.8 units from $\mathrm{F}_{8} \mathrm{Cmpd}-\mathrm{II}$ to $\mathrm{F}_{8} \mathrm{Cmpd}-\mathrm{II}\left(\mathrm{LutH}^{+}\right)$and from 27.6 to 25.0 units from (DCHIm) $\mathrm{F}_{8} \mathrm{Cmpd}$ II to $(\mathrm{DCHIm}) \mathrm{F}_{8} \mathrm{Cmpd}-\mathrm{II}\left(\mathrm{LutH}^{+}\right)$, indicative of a small reduction in dipole character, caused by a reduction in ligand field axial distortion (elongating $\mathrm{Fe}-\mathrm{O}$ ). Although there is not full protonation, these may be promising systems for better understanding the interaction of hydrogen bonding with ferryl complexes in enzymes, which is known to contribute to the increased stability and reactivity of analogous high-valent intermediates.

\section{Electronic Structure Calculations.}

To obtain further insights into the geometric perturbations caused by the presence of the various axial ligands, geometry optimizations with DFT were performed for each of the $\mathrm{F}_{8}$ derived complexes (Table 3 and Figure S40). For each complex, we calculated the Mössbauer parameters of the geometry-optimized structures and determined the p-orbital contributions to the metal-based frontier molecular orbitals (FMOs) through Mulliken population analysis. In all cases, the quadrupole splitting was calculated to be positive agreeing with our assumption that strong axial bonding will lower the observed magnitude of $\Delta E_{\mathrm{Q}}$. Further, utilizing the Badger's rule parameters of Green, ${ }^{78}$ we estimate the $\mathrm{Fe}=\mathrm{O}$ bond stretching vibrational frequency from the geometry optimized bond length.

The calculations reveal the five-coordinate compound to have the shortest $\mathrm{Fe}-\mathrm{O}$ bond, which corresponds to the experimentally observed highest $\mathrm{rR}$ stretching frequency and pre-edge intensity relative to the other $\mathrm{F}_{8}$ models. Likewise, predicted isomer shift and quadrupole splitting values ( 0.09 and $2.23 \mathrm{~mm} / \mathrm{s}$, respectively) correspond well to the observed experimental values for the major Mössbauer species (Tables 1 and 3). The short Fe-O bond also coincides with the greatest p-orbital metal-based hole character, which is reflected in the high experimental pre-edge intensity. Addition of the DCHIm axial ligand results in an increase of the calculated $\mathrm{Fe}-\mathrm{O}$ bond length and decrease in quadrupole splitting, 
reproducing the observed experimental trends and coinciding with the addition of the ligand along the $z$-axis. The calculations show that addition of the axial ligand also decreases the porbital character of the metal-based FMOs by $42 \%$ relative to the five-coordinate parent complex, which maps well to the analogous $49 \%$ decrease in experimental pre-edge intensity.

Calculations including either of the ligands, $\mathrm{ArO}^{-}$or $\mathrm{Im}^{-}$, result in longer $\mathrm{Fe}-\mathrm{O}$ bonds (Table 3), coinciding with decreased $\mathrm{Fe}-\mathrm{O}$ Badger's rule stretching frequencies relative to the DCHIm complex. This contrasts with the experimental observations of higher stretching frequencies for the anionic ligands than the six-coordinate DCHIm model. Likewise, the anionic computational models demonstrate poor agreement with the experimental Mössbauer parameters. Inclusion of a $\mathrm{Na}^{+}$counterion near the anionic axial ligands improves the correlation to the experimental $\mathrm{Fe}-\mathrm{O}$ frequency, with a concomitant shift in predicted Mössbauer parameters toward the experimental values. These calculations suggest that the experimentally investigated anionic ligand models are potentially forming ion-pair complexes with the cation.

The geometry optimized structure of the tethered imidazole complex, $\mathrm{P}^{\mathrm{Im}}$, reveals a slight shortening of the $\mathrm{Fe}-\mathrm{O}$ bond, coupled with an increase in the predicted quadrupole splitting relative to the DCHIm-bound complex, mirroring the experimental data for the major component of the $\mathrm{P} I m$ Mössbauer sample. The $\mathrm{Fe}-\mathrm{N}_{\mathrm{ax}}$ bond is longer for $\mathrm{P} \mathrm{Im}$ and the average $\mathrm{Fe}-\mathrm{N}_{\mathrm{eq}}$ bonds are shorter, with the net effect being a higher $\Delta E_{\mathrm{Q}}$ despite having a slightly shorter $\mathrm{Fe}=\mathrm{O}$ bond than the DCHIm-bound model.

Inclusion of the $\mathrm{LutH}^{+} \mathrm{H}$-bonding to the oxo of the ferryl, for the five-coordinate and DCHIm-ligated models, elongates the Fe-O bond by $\sim 0.02 \AA$ (Chart 3). Addition of $\mathrm{LutH}^{+}$ also increases the predicted quadrupole splitting of both adducts relative to their respective non- $\mathrm{LutH}^{+}$counterparts and are in good agreement with the experimental Mössbauer parameters, consistent with an elongation of the $\mathrm{Fe}=\mathrm{O}$ bond. The Lewis acid adducts, relative to their non-Lewis acid counterparts, have lower p-orbital character of the metalbased FMOs by 35 and $49 \%$, respectively (Table 3 ). This calculated reduction in p-orbital character is not reflected by the change in pre-edge intensity for the six-coordinate Lewis acid adduct. The five-coordinate Lewis acid adduct XAS sample was a 50\% mixture of the non-LA species, therefore the DFT-derived p-orbital character cannot be compared.

\section{Outer-Sphere Electron-Transfer Reduction of the Lewis Acid Ferryl Derivatives.}

Various outer-sphere reductants (ferrocene derivatives, see SI for depicted structures) were added to $\mathrm{F}_{8} \mathrm{Cmpd}-\mathrm{II}$, (DCHIm) $\mathrm{F}_{8} \mathrm{Cmpd}-\mathrm{II}, \mathrm{F}_{8} \mathrm{Cmpd}-\mathrm{II}\left(\mathrm{LutH}^{+}\right)$, and (DCHIm) $\mathrm{F}_{8} \mathrm{Cmpd}$ $\mathrm{II}\left(\mathrm{LutH}^{+}\right)$to approximate the reduction potential of the iron(IV)-oxo functionality (Schemes 2 and S1-S12 and Figures 11 and S18-S29), and to compare and contrast the effects of the presence of a strongly donating axial ligand (i.e., DCHIm) and/or the Lewis acid interacting with the oxo ligand. Reactivity studies, monitored by UV-vis spectroscopy, showed that the Lewis acid derivative $(\mathrm{DCHIm}) \mathrm{F}_{8} \mathrm{Cmpd}-\mathrm{II}\left(\mathrm{LutH}^{+}\right)$could react with 10 equiv of decamethylferrocene $\left(\mathrm{Me}_{10} \mathrm{Fc}, E_{1 / 2}=-0.53 \mathrm{~V} \mathrm{vs} \mathrm{Fc}^{+/ 0} \text { in MeTHF }\right)^{79}$ or 10 equiv of octamethylferrocene $\left(\mathrm{Me}_{8} \mathrm{Fc}, E_{1 / 2}=-0.43 \mathrm{~V}\right.$ vs Fc$^{+/ 0}$ in MeTHF) ${ }^{79}$ but not 10 equiv of dimethylferrocene $\left(\mathrm{Me}_{2} \mathrm{Fc}, E_{1 / 2}=-0.115 \mathrm{vs} \mathrm{Fc}^{+/ 0}\right.$ in MeTHF) ${ }^{79}$ (Schemes 2, S2, and S3 and 
Figures 11, S19, and S20). The reactions with $\mathrm{Me}_{10} \mathrm{Fc}$ and $\mathrm{Me}_{8} \mathrm{Fc}$ showed the immediate spectral change from $418,539 \mathrm{~nm}$ to $420,530 \mathrm{~nm}$, with two unique low-energy bands in the 600-800 $\mathrm{nm}$ region assignable to their respective ferrocenium products (Schemes S2 and S3 and Figures 11, S19, and S20).

However, (DCHIm)F $\mathrm{F}_{8}$ Cmpd-II did not react with any of these reductants (Scheme S1 and Figure S18). The authentic $\mathrm{B}\left(\mathrm{C}_{6} \mathrm{~F}_{5}\right)_{4}{ }^{-}(\mathrm{BAr})$ salts of the oxidized forms of the reductants, decamethylferrocenium $\mathrm{BAr}^{\mathrm{F}}\left(\mathrm{Me}_{10} \mathrm{Fc}^{+}\right)$and octamethylferro cenium $\mathrm{BAr}^{\mathrm{F}}\left(\mathrm{Me} \mathrm{Fc}^{+}\right)$, were prepared in order to quantify the number of electrons transferred to (DCHIm) $\mathrm{F}_{8} \mathrm{Cmpd}-\mathrm{II}-$ $\left(\mathrm{LutH}^{+}\right)$in these reactions. Quantification of the low-energy ferrocenium peaks observed after completion of the reduction reactions indicated that 2 equiv of $\mathrm{Me}_{10} \mathrm{Fc}$ or $\mathrm{Me}_{8} \mathrm{Fc}$ was consumed in the reaction with $(\mathrm{DCHIm}) \mathrm{F}_{8} \mathrm{Cmpd}-\mathrm{II}\left(\mathrm{LutH}^{+}\right)$(Figures S19 and S20), based on standard curves produced from the authentic ferrocenium salts (Figures S30 and S31 and Tables S5 and S7). To further confirm this result, sequential addition of 0.5 equiv of $\mathrm{Me}_{10} \mathrm{Fc}$ to $(\mathrm{DCHIm}) \mathrm{F}_{8} \mathrm{Cmpd}-\mathrm{II}-\left(\mathrm{LutH}^{+}\right)$showed that no further reaction occurred after 2 equiv was added. Various ferrous derivatives were prepared independently to identify the resulting heme reaction product. It was thought that, due to the 2 equiv of DCHIm employed to form (DCHIm) $\mathrm{F}_{8}$ Cmpd-II, the final ferrous product might be coordinated by DCHIm. (DCHIm $)_{2} \mathrm{~F}_{8} \mathrm{Fe}^{\mathrm{II}}$ was prepared independently by addition of 2 equiv of DCHIm to $\mathrm{F}_{8} \mathrm{Fe}^{\mathrm{II}}$ in 1:9 MeTHF:toluene at $-90{ }^{\circ} \mathrm{C}$. The UV-vis absorption features of $(\mathrm{DCHIm})_{2} \mathrm{~F}_{8} \mathrm{Fe}$ II (Figures 11 (bottom) and S32) correlate directly with the spectrum observed for the final reaction mixture of $(\mathrm{DCHIm}) \mathrm{F}_{8} \mathrm{Cmpd}-\mathrm{II}\left(\mathrm{LutH}^{+}\right)$with $\mathrm{Me}_{10} \mathrm{Fc}$ or $\mathrm{Me}_{8} \mathrm{Fc}$ (Figures 11 (top), S19 and S20), all exhibiting a Soret and a Q-band at 420 and $530 \mathrm{~nm}$, respectively. Further, EPR spectroscopy (X-band, run at $10 \mathrm{~K}$ ) of the reaction mixtures after 5 equiv of $\mathrm{Me}_{10} \mathrm{Fc}$ or $\mathrm{Me}_{8} \mathrm{Fc}$ was added to (DCHIm) $\mathrm{F}_{8} \mathrm{Cmpd}-\mathrm{II}\left(\mathrm{LutH}^{+}\right)$was silent, analogous to the EPR silent spectra of $(\mathrm{DCHIm})_{2} \mathrm{~F}_{8} \mathrm{Fe}$ II in 1:9 MeTHF:toluene at $-90{ }^{\circ} \mathrm{C}$.

The Mössbauer spectrum of the reaction mixture of $(\mathrm{DCHIm}) \mathrm{F}_{8} \mathrm{Cmpd}-\mathrm{II}\left(\mathrm{LutH}^{+}\right)$with 10 equiv of $\mathrm{Me}_{10} \mathrm{Fc}$ showed two quadrupole doublets with a major species of $90 \%\left[\left(\Delta E_{\mathrm{Q}}=\right.\right.$ $1.01 \mathrm{~mm} / \mathrm{s}$ and $\delta=0.45 \mathrm{~mm} / \mathrm{s})]$ and minor species contributing $10 \%\left[\left(\Delta E_{\mathrm{Q}}=2.45 \mathrm{~mm} / \mathrm{s}\right.\right.$ and $\delta=0.50 \mathrm{~mm} / \mathrm{s}$ )] (Figure 12, Table S2). Similar products were identified in the Mössbauer spectrum of the reaction mixture of $(\mathrm{DCHIm}) \mathrm{F}_{8} \mathrm{Cmpd}-\mathrm{II}\left(\mathrm{LutH}^{+}\right)$with 10 equiv of $\mathrm{Me}_{8} \mathrm{Fc}$ (Figure S14 and Table S2). In combination with the similar UV-vis spectral features, the comparable Mössbauer parameters of the authentic standard of (DCHIm) ${ }_{2} \mathrm{~F}_{8} \mathrm{Fe}^{\mathrm{II}}$ (Table S2) determined the product mixture is predominantly composed (90\%) of the (DCHIm) ${ }_{2} \mathrm{~F}_{8} \mathrm{Fe}^{\mathrm{II}}$ species (Figure 12). It is postulated that the presence of 2 equiv of reductant and two protons, one from $\mathrm{LutH}^{+}$and one from 3-chlorobenzoic acid (the byproduct of $m \mathrm{CPBA}$ used to originally generate the ferryl complexes), allows for the reduction of the iron(IV) species to iron(II) (rather than iron(III) due to the thermodynamically favorable concomitant formation of the low-spin $\mathrm{d}^{6}\left(\mathrm{DCHIm}_{2} \mathrm{~F}_{8} \mathrm{Fe}^{\mathrm{II}}\right.$ product, and, of course, the release of water (Scheme 2).

With all the data taken together, the reduction potential of $(\mathrm{DCHIm}) \mathrm{F}_{8} \mathrm{Cmpd}-\mathrm{II}\left(\mathrm{LutH}^{+}\right)$can be approximated. Unfortunately, cyclic voltammetry was not able to be obtained for the ferrocene derivatives in the 1:9 MeTHF:toluene reaction mixture due to the insolubility of common electrolytes in this solvent mixture. Thus, the reduction potential values of the 
ferrocene derivatives in $\mathrm{MeTHF}^{79}$ were used to approximate the reduction potential of the iron(IV)-oxo species (Table S9). The reduction potential of the iron(IV)-oxo moiety of (DCHIm)F $\mathrm{F}_{8} \mathrm{Cmpd}-\mathrm{II}\left(\mathrm{LutH}^{+}\right)$can then be bracketed, $-0.43<E_{1 / 2}<-0.115 \mathrm{~V} \mathrm{vs} \mathrm{Fc}^{+/ 0}$, based on the reactivity studies described above (Table S9). Since (DCHIm)-F $\mathrm{F}_{8} \mathrm{Cmpd}-\mathrm{II}$ did not react with any of the reductants utilized (Scheme S1 and Figure S18), its reduction potential must be less than $-0.53 \mathrm{~V} \mathrm{vs} \mathrm{Fc}^{+/ 0}$, at least $100 \mathrm{mV}$ more negative than that of (DCHIm) $\mathrm{F}_{8}$ Cmpd-II $\left(\mathrm{LutH}^{+}\right)$. This substantiates that (DCHIm) $\mathrm{F}_{8}$ Cmpd-II is a worse oxidant than (DCHIm)- $\mathrm{F}_{8} \mathrm{Cmpd}-\mathrm{II}\left(\mathrm{LutH}^{+}\right)$, as expected, and provides indirect evidence for interaction of the Lewis acid with the oxo ligand. It also shows that even though small structural changes were observed (vide supra), large reactivity differences may be seen. Thus, (DCHIm) $\mathrm{F}_{8} \mathrm{Cmpd}-\mathrm{II}\left(\mathrm{LutH}^{+}\right)$can be used to examine the interaction of a proton with the oxo ligand of a ferryl species to give insights into the protonated Cmpd-II intermediate in cytochrome P450 monooxygenase and/or Lewis acid adducts of other enzyme or synthetic high-valent heme iron(IV)-oxo species. Also, due to hydrogen bonding being a prevalent factor in metalloenzymes to stabilize the formation of high-valent species, and/or modulate their reactivity, these or related compounds can be used as good models to support how hydrogen-bonded interactions help dictate an enzyme's reactivity.

Analogous reactivity studies were carried out for $\mathrm{F}_{8} \mathrm{Cmpd}-\mathrm{II}$ and $\mathrm{F}_{8} \mathrm{Cmpd}-\mathrm{II}\left(\mathrm{LutH}^{+}\right)$. In contrast to (DCHIm) $\mathrm{F}_{8} \mathrm{Cmpd}-\mathrm{II}$, these studies showed that $\mathrm{F}_{8} \mathrm{Cmpd}-\mathrm{II}$ can be reduced by $\mathrm{Me}_{10} \mathrm{Fc}$, but not $\mathrm{Me}_{8} \mathrm{Fc}$ (Schemes S4 and S5 and Figures S21 and S22). Addition of 10 equiv of $\mathrm{Me}_{10} \mathrm{Fc}$ to $\mathrm{F}_{8} \mathrm{Cmpd}-\mathrm{II}$, monitored by UV-vis spectroscopy (Scheme $\mathrm{S} 4$ and Figure $\mathrm{S} 21)$, resulted in the formation of $(\mathrm{MeTHF}) \mathrm{F} \mathrm{Fe}{ }^{\mathrm{III}}(\mathrm{X})$, with $\mathrm{X}=$ solvent or 3-chlorobenzoate. Quantification of the $\mathrm{Me}_{10} \mathrm{Fc}^{+}$peaks was not possible due to the overlapping intense lowenergy ferric band; however, the ferric state was confirmed by low-temperature $2 \mathrm{H}$ NMR spectroscopy employing the deuterated pyrrole $d_{8}-\mathrm{F}_{8}$ analogue (Figure S37). Though the reaction stopped at iron(III) and exhibited a similar ${ }^{2} \mathrm{H}$ NMR shift as (MeTHF) ${ }_{2} \mathrm{~F}_{8} \mathrm{Fe}^{\mathrm{II}}$ $(\mathrm{OH})$, the final product was found to not be the iron(III)-hydroxide complex due to differences in UV-vis absorption features (Scheme S4 and Figures S21, S33, and S34).

Interestingly, especially based on the small structural changes observed for $\mathrm{F}_{8} \mathrm{Cmpd}-\mathrm{II}(\mathrm{LutH}$ ${ }^{+}$) compared to $\mathrm{F}_{8} \mathrm{Cmpd}-\mathrm{II}$, the addition of $\mathrm{LutH}^{+}$greatly increased this species's reduction potential. Previous reports, ${ }^{80-84}$ on nonheme iron(IV)- or manganese(IV)-oxo complexes have shown that addition of Lewis acids such as $\mathrm{Sc}^{3+}$ or $\mathrm{HClO}_{4}$ increased the reduction potential of these species by $0.5-0.9 \mathrm{mV}$ (however, the greater differences in magnitude, as observed herein, were usually only detected when excess amounts of the Lewis acid were added). Thus, the unusually large increase in reduction potential observed here, with the addition of 1 equiv of $\mathrm{LutH}^{+}$(as a molecular adduct and not just a proton transferred, vide supra), is notable. In fact, $\mathrm{F}_{8} \mathrm{Cmpd}-\mathrm{II}\left(\mathrm{LutH}^{+}\right)$was found to react with $\mathrm{Me}_{10} \mathrm{Fc}, \mathrm{Me}_{8} \mathrm{Fc}$, $\mathrm{Me}_{2} \mathrm{Fc}$, ferrocene $(\mathrm{Fc})$, acetylferrocene (AcetylFc, $E_{1 / 2}=+0.235 \mathrm{~V} \mathrm{vs} \mathrm{Fc}^{+/ 0}$ in $\mathrm{MeTHF}^{79}$ ), and diacetylferrocene (DiacetylFc, $E_{1 / 2}=+0.460 \mathrm{~V}_{\mathrm{vs} \mathrm{Fc}}{ }^{+/ 0}$ in MeTHF (Table S9, Schemes 3, S6-S9, and S11, and Figures S23-S26 and S28). However, $\mathrm{F}_{8} \mathrm{Cmpd}-\mathrm{II}\left(\mathrm{LutH}^{+}\right)$did not react with tris(4-bromophenyl)amine $\left(\mathrm{E}_{1 / 2}=+0.695 \mathrm{~V} \mathrm{vs} \mathrm{Fc}^{+/ 0}\right.$ in MeTHF (Table S9, Scheme S11, and Figure S28). These reactions with $\mathrm{F}_{8} \mathrm{Cmpd}-\mathrm{II}\left(\mathrm{LutH}^{+}\right)$resulted in the formation of more complicated reaction mixtures. The stronger reductants $\mathrm{Me}_{10} \mathrm{Fc}$ and $\mathrm{Me}_{8} \mathrm{Fc}$ were able to predominately reduce the iron(IV)-oxo Lewis acid adduct by two 
electrons, forming (X)2F8Fe ${ }^{\mathrm{II}}$, with $\mathrm{X}=\mathrm{MeTHF}$ or 3-chlorobenzoic acid (Scheme 3,

Pathway 3, Schemes S6 and S7, and Figures S23 and S24), whose assignment is based on similar absorption features ( $\lambda_{\max }$ of 428 and $529 \mathrm{~nm}$ ) as (DCHIm) $2 \mathrm{~F}^{2} \mathrm{Fe}^{\mathrm{II}}\left(\lambda_{\max }\right.$ of 420 and $530 \mathrm{~nm})$. The low-energy ferrocenium peaks were quantified and supported the conclusion that $\sim 2$ equiv of reductant was consumed (Tables S6 and S8); a minor ferric impurity could be observed in the Soret peak region at $411 \mathrm{~nm}$ and slightly in the Q-band (Figures S23 and S24). Also, EPR spectroscopy (X-band, run at $10 \mathrm{~K}$ ) of the reaction mixtures after 5 equiv of $\mathrm{Me}_{10} \mathrm{Fc}$ or $\mathrm{Me}_{8} \mathrm{Fc}$ was added to $\mathrm{F}_{8} \mathrm{Cmpd}-\mathrm{II}\left(\mathrm{LutH}^{+}\right)$was silent, analogous to the EPR-silent spectrum of $(\mathrm{DCHIm}) 2 \mathrm{~F} 8 \mathrm{FeII}$ in 1:9 MeTHF:toluene at $-90{ }^{\circ} \mathrm{C}$. Thus, a six-coordinate ferrous complex was the product when employing these stronger reductants.

However, addition of weaker reductants such as $\mathrm{Me}_{2} \mathrm{Fc}, \mathrm{Fc}$, AcetylFc, and DiacetylFc did not result in two-electron reduction of the iron(IV)-oxo to iron(II); predominately a ferric species was observed via UV-vis spectroscopy (Scheme 3 Pathway 2A, Figures S25, S26, and S28 and Schemes S8, S9, and S11). To determine the final product from the reactions with the weaker reductants, 3-chlorobenzoic acid was added to $\mathrm{F}_{8} \mathrm{Fe}^{\mathrm{III}} \mathrm{OH}$, supporting that (MeTHF) $\mathrm{F}_{8} \mathrm{Fe}^{\mathrm{III}}\left(\mathrm{OH}_{2}\right)$ is the resulting species based on the similar Soret of $411 \mathrm{~nm}$ and the highly characteristic multiple peak Q-band signature between the authentically generated species and the reaction mixtures (Schemes S8, S9, S11, S13, and S14 and Figures S25, S26, S28, S33, and S34). However, due to the relatively intense, broad low-energy band of the ferric species spanning $\sim 650-1100 \mathrm{~nm}$, the ferrocenium products for the weaker reductants were not able to be quantified due to the overlap of the peaks. The ferric nature of the reaction product was supported by $2 \mathrm{H}$ NMR spectroscopy, which showed a paramagnetic shift around 124 ppm (Figure S38). Also, addition of 5 equiv of AcetylFc and 10 equiv DiacetylFc to the EPR-silent $\mathrm{F} \mathrm{Cmpd-II(}\left(\mathrm{LutH}^{+}\right)$complex resulted in a high-spin ferric signal ( $g=6$ and 2) (Figure S28). To further confirm the iron(III) oxidation state, 10 equiv of $\mathrm{Me}_{10} \mathrm{Fc}$ was added to the $\mathrm{Fc}$ and AcetylFc reaction mixtures (Schemes S10 and S12 and Figures S27, S29 and S38), resulting in an immediate spectral change to $529 \mathrm{~nm}$, similar to the UV-vis signature and ${ }^{2} \mathrm{H}$ NMR shift of the reaction mixtures when $\mathrm{Me}_{10} \mathrm{Fc}$ or $\mathrm{Me}_{8} \mathrm{Fc}$ was used (Scheme 3 Pathway 2B, Figures S23, S24 and S39). Further evidence for the reduction of the ferric species to ferrous was the quantification of the decamethylferrocenium peaks, which showed a one-electron reduction (as observed by the low-energy bands, Schemes S10 and S12 and Figures S27 and S29). The independently generated (MeTHF)- $\mathrm{F}_{8} \mathrm{Fe}^{\mathrm{III}}\left(\mathrm{OH}_{2}\right.$ ) was also able to be reduced by $\mathrm{Me}_{10} \mathrm{Fc}$ (Scheme 3, Pathway 1B), forming a similar $529 \mathrm{~nm} \mathrm{UV-vis} \mathrm{signature,} \mathrm{and} \mathrm{the} \mathrm{low-energy} \mathrm{Me}_{10} \mathrm{Fc}^{+}$ peaks were quantified to indicate a 1-electron reduction occurred (Scheme S14 and Figure S34). The comparable UV-vis (Figures S25, S26, S28, S33, and S34) and ${ }^{2} \mathrm{H}$ NMR signatures (Figure $\mathrm{S} 38$ and S39) of the independently generated (MeTHF) $\mathrm{F}_{8} \mathrm{Fe}^{\mathrm{III}}\left(\mathrm{OH}_{2}\right.$ ) and the $\mathrm{Me}_{2} \mathrm{Fc}, \mathrm{Fc}$, AcetylFc reaction mixtures supports that the ferric aqua complex was formed; additional support is that both can be further reduced by one electron (Figures S27, S29, S34, S38, and S39).

These reactivity studies allow us to bracket the reduction potential of $\mathrm{F}_{8} \mathrm{Cmpd}-\mathrm{II},-0.53<$ $E_{1 / 2}<-0.43 \mathrm{~V}$ vs $\mathrm{Fc}^{+/ 0}$, demonstrating that $\mathrm{F}_{8} \mathrm{Cmpd}$-II is a stronger oxidant than (DCHIm) $\mathrm{F}_{8} \mathrm{Cmpd}-\mathrm{II}$ (Tables 4 and S9). However, the reduction potential of $\mathrm{F}_{8} \mathrm{Cmpd}-$ $\mathrm{II}\left(\mathrm{LutH}^{+}\right)$is bracketed to be between +0.460 and $+0.695 \mathrm{~V} \mathrm{vs} \mathrm{Fc}^{+/ 0}$, since DiacetylFc was 
capable of reducing this species, but no reaction occurred with tris(4-bromophenyl)amine (Scheme S11 and Figure S28C). Thus, addition of $\mathrm{LutH}^{+}$to $\mathrm{F}_{8} \mathrm{Cmpd}-\mathrm{II}$ increases the reduction potential of the complex by greater than $0.890 \mathrm{~V}$, indicating that $\mathrm{F}_{8} \mathrm{Cmpd}-\mathrm{II}(\mathrm{LutH}$ ${ }^{+}$) is a strong oxidant (Tables 4 and S9). These reduction reactions are not expected to be reversible, e.g., $\mathrm{Fe}^{\mathrm{III}}\left(\mathrm{OH}_{2}\right) \rightarrow \mathrm{Fe}^{\mathrm{IV}}\left(\mathrm{OH}_{2}\right)$ is thermodynamically unfavorable due to the likely instability of a protonated iron(IV)-oxo complex, while (DCHIm) ${ }_{2} \mathrm{~F}_{8} \mathrm{Fe}^{\mathrm{II}} \rightarrow$ (DCHIm) $\mathrm{F}_{8}$ Cmpd-II- $\left(\mathrm{LutH}^{+}\right)$would be unfavorable because the former is a highly stable low-spin $\mathrm{d}^{6}$ complex. These synthetic heme iron(IV)-oxo Lewis acid derivatives may pave the way for the preparation of a fully protonated $\mathrm{Fe}^{\mathrm{IV}}-\mathrm{OH}$ model

\section{CONCLUSIONS}

High-valent ferryl intermediates with various axial ligands catalyze numerous oxidative processes in metalloenzymes. Investigations utilizing synthetic systems may allow for a greater understanding of structures and bonding (i.e., electronic structure), plus mechanistic insights into enzymatic pathways. This aids in the understanding of the nature of these highly oxidizing intermediates, which can be harnessed for numerous practical applications (drug development, catalysis, synthesis, fuel cells, etc.). However, there have been limited reports on synthetic heme Cmpd-II models with varying axial ligation, with no synthetic model systems studied for catalase. Herein, the full characterization of synthetic Cmpd-II models with and without various axial bases was achieved, and the electronic properties were examined using a wide array of spectroscopic techniques, including UV-vis, EPR, ${ }^{2} \mathrm{H}$ NMR, Mössbauer, ${ }^{57 / 54} \mathrm{Fe}$-labeled rR, and EXAFS.

Addition of axial bases such as imidazole, imidazolate, or phenolate causes a slight elongation of the $\mathrm{Fe}=\mathrm{O}$ bond. This is the first report of a synthetic heme Cmpd-II model containing phenolate axial ligation as a model for the enzyme catalase. This synthetic model complex could also potentially be used in future electrocatalytic studies to understand how catalase (and analogous enzymes) disproportionates reactive oxygen species (e.g., $\mathrm{H}_{2} \mathrm{O}_{2}$ ), minimizing harmful ROS reactions. ${ }^{28}$ The first Mössbauer and EXAFS data of a synthetic heme axially ligated phenolate or tethered imidazole iron(IV)-oxo species are also reported. The work reported herein offers significantly expanded EXAFS characterization of synthetic heme iron(IV)-oxo complexes beyond that currently reported in the literature. Further, the iron(IV)-oxo vibrational frequency was identified by $\mathrm{rR}$ employing $54 \mathrm{Fe}$ and $57 \mathrm{Fe}$ derivatives (vs needing to synthesize 18-O-labeled oxidant (e.g., mCPBA) or using 18-Olabeled water for an exchange reaction, which leads to adverse reactions).

This work reports on the first hydrogen-bonded synthetic heme Lewis acid iron(IV)-oxo adducts with and without an axial base. Addition of the protic Lewis acid, 2,6-lutidinium triflate, to $\mathrm{F}_{8} \mathrm{Cmpd}-\mathrm{II}$ or (DCHIm) $\mathrm{F}_{8} \mathrm{Cmpd}-\mathrm{II}$ resulted in a slight elongation of the $\mathrm{Fe}=\mathrm{O}$ bond, which was supported by rR and/or XAS analysis. These novel ferryl Lewis acid adducts, $\mathrm{F}_{8} \mathrm{Cmpd}-\mathrm{II}\left(\mathrm{LutH}^{+}\right)$and $(\mathrm{DCHIm}) \mathrm{F}_{8} \mathrm{Cmpd}-\mathrm{II}\left(\mathrm{LutH}^{+}\right)$, showed increased (more positive) reduction potentials compared to their counterparts without $\mathrm{LutH}^{+}$; in fact, the reduction potential of $\mathrm{F}_{8} \mathrm{Cmpd}-\mathrm{II}$ increased by almost a volt upon addition of $\mathrm{LutH}^{+}$. Thus, addition of $\mathrm{LutH}^{+}$causes a direct interaction with the oxo ligand and makes these synthetic 
Cmpd-II compounds much more oxidizing, further supporting the importance of the protonation or hydrogen-bonding state of Cmpd-II in enzymatic systems.

\section{EXPERIMENTAL SECTION}

\section{General.}

All reagents and solvents purchased and used were of commercially available quality except as noted. Inhibitor-free 2-methyltetrahydrofuran (MeTHF) and tetrahydrofuran (THF) were distilled over $\mathrm{Na} /$ benzophenone under Ar and deoxygenated with Ar before use. Toluene was distilled over calcium hydride and deoxygenated with Ar before use. Butyronitrile was distilled over sodium carbonate and potassium permanganate and deoxygenated with $\mathrm{Ar}$ before use. Solvent deoxygenation was achieved by bubbling Ar through the desired solvent for $\geq 45 \mathrm{~min}$ via an addition funnel connected to a receiving Schlenk flask. All solvents were stored in amber bottles under $4 \AA$ sieves. The oxidant, 3-chloroperbenzoic acid (mCPBA) was purified according to published procedures. ${ }^{85}$ Air-free manipulations were performed in a Vac atmosphere OMNI-LAB drybox or under argon atmosphere using standard Schlenk techniques. Low-temperature UV-vis spectroscopy experiments were carried out by using a Cary-50 Bio spectrophotometer equipped with an Unisoku USP-203A cryostat with a modified Schlenk cuvette with a $1 \mathrm{~cm}$ path quartz cell. The spectrometer was equipped with Cary WinUV Scanning Kinetics software. All NMR spectra were recorded in 9 in., $5 \mathrm{~mm}$ o.d. NMR tubes on a Bruker $300 \mathrm{MHz}$ NMR instrument equipped with a tunable deuterium probe to enhance deuterium detection. The ${ }^{2} \mathrm{H}$ chemical shifts were calibrated to natural abundance deuterium solvent peaks. EPR spectra were collected with an ER 073 magnet equipped with a Bruker ER041 X-band microwave bridge and a Bruker EMX 081 power supply: microwave frequency $=9.42 \mathrm{GHz}$, microwave power $=0.201 \mathrm{~mW}$, attenuation $=30$ $\mathrm{db}$, modulation amplitude $=10 \mathrm{G}$, modulation frequency $=100 \mathrm{kHz}$, temperature $=10 \mathrm{~K}$. Mössbauer spectra were recorded on a spectrometer from SEE Co. (Edina, MN) operating in the constant acceleration mode in a transmission geometry. The sample was kept in an SVT-400 cryostat from Janis (Wilmington, MA), using liquid $\mathrm{N}_{2}$ as a cryogen for $80 \mathrm{~K}$ measurements. Isomer shifts were determined relative to the centroid of the spectrum of a metallic foil of $a$-Fe collected at room temperature. Data analysis was performed using version F of the program WMOSS (www.wmoss.org), and quadrupole doublets were fit to Lorentzian line shape. XAS data were collected at beamlines 7-3 and 9-3 at the Stanford Synchrotron Radiation Lightsource (SSRL) at the SLAC National Accelerator Laboratory under ring operating conditions of $500 \mathrm{~mA}$ over an energy range of $6785-8100 \mathrm{eV}$, with the samples maintained at $10 \mathrm{~K}$. To mitigate $\mathrm{X}$-ray induced sample damage, we parsed each sample into 6-8 spots and collected 1-2 scans per spot. However, consistent in our experience with many synthetic model complexes frozen in dry organic solvents, we observed no significant scan-to-scan changes in the pre-edge nor edge positions at the $\mathrm{Fe} \mathrm{K}$ edge energies, and we were able to utilize the first and second scans for nearly all the models. The exception was the six-coordinate lutidinium complex, which had a $\sim 4 \%$ scanto-scan reduction in maximum pre-edge intensity and a slight $(<0.1 \mathrm{eV})$ change in the edgethe EXAFS analysis presented here utilized both scans per spot, but no significant differences were observed by fitting the first scans only. The pre-edge area analysis for the six-coordinate lutidinium complex utilized only the first measured scans. Data were 
background subtracted, splined, and normalized by the PYSPLINE software. ${ }^{86}$ Theoretical EXAFS scattering amplitudes were calculated by FEFF (version 7.0). ${ }^{87}$ These amplitudes were then used in the fitting performed through the EXAFSPAK suite for the parameters: $\mathrm{Fe}$ -X path distance R, path mean square deviation $\sigma^{2}$, and threshold energy $E_{0}$. Two multiple scattering paths $(\mathrm{Fe}-\mathrm{N}-\mathrm{C} a / \beta)$ were included with $\sigma^{2}$ fixed to that of the pertinent $\mathrm{Fe}-\mathrm{C}_{a / \beta}$ paths consistent with previous heme EXAFS studies. ${ }^{88}$ For the first coordination sphere, alternative fits were attempted to isolate the axial ligand path from the equatorial pyrrole nitrogens path—but resulted in unreasonable $\sigma^{2}$ values and/or distances not resolvable by the experimental parameters, except for the $\mathrm{ArO}^{-}$axial ligand as discussed in the text. Preedge areas were determined by fitting one or two pre-edge peaks, two background peaks to model the rising-edge, and one peak for the edge jump utilizing least-squares fitting in the Igor Pro version 6.37 with Pearson VII functions, and integrals were taken using the Igor program "areaxy" trapezoidal integration function. The averages and standard deviations were taken from 11 best fits for each spectrum (in the range 7105-7122 eV), where the width of the edge jump peak was fixed from the first fit and adjusted by alternating steps of $\pm 0.1 \mathrm{eV}$, and then all other parameters were refit again to a maximum of 5 fits in each direction.

Density Functional Theory geometry optimizations were performed in vacuum with the program ORCA version 4.0, ${ }^{89}$ using the $\mathrm{BP} 86^{90}$ functional and Ahlrich's triple- $\zeta$ basis set Def2-TZVPP ${ }^{91}$ for all atoms at the grid6 integration grid level and the CP(PPP) basis set for $\mathrm{Fe}$ at the grid7 integration grid level. ${ }^{57} \mathrm{Fe}$ isomer shift calibration coefficients used were those calculated previously. ${ }^{92}$ Inclusion of dispersion effects (D3) ${ }^{93}$ for the calculations caused no significant deviation from observables of the non-corrected calculations (Table S10) presented in the main text, except in the case of the Lewis-acid adducts where addition of dispersion correction caused a larger tilt in the Lewis-acid relative to the $\mathrm{Fe}-\mathrm{O}$ axis. The difference does not significantly change the $\mathrm{Fe}-\mathrm{O}$ bond length, but it changes the calculated quadrupole splitting for the six-coordinate complex by $-0.32 \mathrm{~mm} / \mathrm{s}$. For $\left(\mathrm{ArO}^{-}\right) \mathrm{F}_{8} \mathrm{Cmpd}-\mathrm{II}$ and $\left(\mathrm{Im}^{-}\right) \mathrm{F}_{8} \mathrm{Cmpd}-\mathrm{II}$, calculations were performed with and without the presence of a sodium ion. Calculations with a sodium ion present yielded results closer to the experimentally observed parameters. See Supporting Information for further details.

\section{Synthesis.}

The complexes $\mathrm{F}_{8} \mathrm{Fe}^{\mathrm{II}}, \mathrm{F}_{8}{ }^{57} \mathrm{Fe}^{\mathrm{II}}$, $\mathrm{P}^{\mathrm{Im}} \mathrm{Fe}^{\mathrm{II}}$ and $\mathrm{d}_{8}-\mathrm{F}_{8} \mathrm{Fe}^{\mathrm{II}}$ were synthesized as previously described. ${ }^{63,71,72,94}{ }^{54} \mathrm{Fe}^{\mathrm{II}} \mathrm{Cl}_{2}$ and the compounds $\left(\mathrm{F}_{8} \mathrm{TPP}\right)^{54} \mathrm{Fe} \mathrm{e}^{\mathrm{III}}-\mathrm{Cl}$ and $\left(\mathrm{F}_{8} \mathrm{TPP}\right)^{54} \mathrm{Fe}^{\mathrm{II}}$ were synthesized according to the literature methods described by Karlin and coworkers to make the ${ }^{57} \mathrm{Fe}$ derivative, ${ }^{71}$ with the only difference being that ${ }^{54} \mathrm{Fe}^{\mathrm{II}} \mathrm{Cl}_{2}$ was utilized in the metalation of $\mathrm{F}_{8}$.

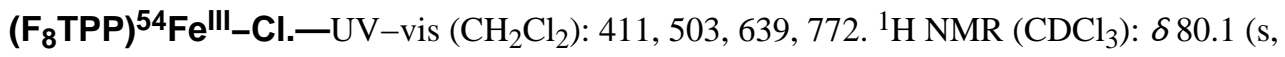
br, $8 \mathrm{H}), 13.8(\mathrm{~s}, 4 \mathrm{H}), 12.5$ (s, $4 \mathrm{H}), 7.6(\mathrm{~s}, 4 \mathrm{H})$. Calculated for $\mathrm{C}_{44} \mathrm{H}_{20} \mathrm{ClF}_{8} \mathrm{FeN}_{4}$ : C, 62.32; H, 2.38; N, 6.61. Found: C, 62.44; H, 2.51; N 6.58. 


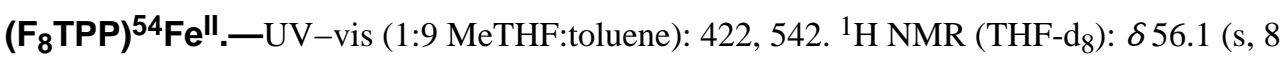
$\mathrm{H}), 8.4$ (s, 4H), 7.2 (s, 8H). Calculated for $\mathrm{C}_{44} \mathrm{H}_{20} \mathrm{~F}_{8} \mathrm{FeN}_{4}$ : C, 65.04; H, 2.48; N, 6.90.

Found: C, 64.56; H, 2.83; N 6.87 .

The compound $\mathrm{P}^{\mathrm{Im}} \mathrm{Fe}^{\mathrm{III}}-\mathrm{Cl}$ was synthesized by using the same procedure Karlin and coworkers used to prepare the previously reported $\mathrm{P}^{\mathrm{Im}} \mathrm{Fe}^{\mathrm{III}} \mathrm{OH} .{ }^{72}$ However, the only difference was that the solution was stirred in $\mathrm{HCl}$ and then neutralized to $\mathrm{pH} 7$ with sodium bicarbonate, instead of $\mathrm{NaOH}$ at the end of metalation procedure. Likewise, $\mathrm{P}^{\mathrm{Im} 57} \mathrm{Fe}^{\mathrm{III}}-\mathrm{Cl}$ was made using the same procedure, except starting with ${ }^{57} \mathrm{Fe}^{\mathrm{II}} \mathrm{Cl}_{2}$ instead of ${ }^{56} \mathrm{Fe}^{\mathrm{II}} \mathrm{Cl}_{2}$. The newly synthesized $\mathrm{P}^{\mathrm{Im} 57} \mathrm{Fe}^{\mathrm{II}}$ was formed using the same procedure ${ }^{72}$ Karlin and coworkers used to prepare the previously reported $\mathrm{P}^{\mathrm{Im} 56} \mathrm{Fe}^{\mathrm{II}}$.

(Plm) ${ }^{57} \mathrm{Fe}^{\text {III }} \mathbf{C l} \cdot \mathbf{C H}_{\mathbf{2}} \mathrm{Cl}_{2}$. - Calculated for $\mathrm{C}_{56} \mathrm{H}_{33} \mathrm{~N}_{7} \mathrm{Cl}_{3} \mathrm{~F}_{6} \mathrm{FeO}$ : C, 61.36; H, 3.30; N, 8.95. Found: C, 61.45; H, 3.28; N 9.18.

(Plm) ${ }^{57} \mathrm{Fe}^{\mathrm{Il}} \cdot \mathbf{2} \mathrm{H}_{\mathbf{2}} \mathrm{O}$.—Calculated for $\mathrm{C}_{55} \mathrm{H}_{35} \mathrm{~N}_{7} \mathrm{~F}_{6} \mathrm{FeO}_{3}: \mathrm{C}, 65.29 ; \mathrm{H}, 3.49 ; \mathrm{N}, 9.69$. Found: C, 64.65; H, 3.54; N 9.45.

Sodium 3,5-Dimethoxyphenolate.-In the glovebox, a vial of 3,5-dimethoxyphenol $(0.510 \mathrm{~g}, 3.31 \mathrm{mmol})$ was dissolved in $2 \mathrm{~mL}$ of THF. Next, 1 equiv of sodium hydride ( 0.079 $\mathrm{g}, 3.31 \mathrm{mmol}$ ) was added, and the reaction mixture was stirred for $20 \mathrm{~min}$. Over the course of the reaction, bubbles were observed, indicating release of hydrogen, and the vial became slightly warm. Subsequently, the reaction mixture was concentrated to give a white solid. ${ }^{1} \mathrm{H}$ NMR (DMSO): $\delta 5.3(\mathrm{~d}, 2.12 \mathrm{~Hz}, 2 \mathrm{H}), 5.1(\mathrm{t}, 2.16 \mathrm{~Hz}, 1 \mathrm{H}), 3.5(\mathrm{~s}, 6 \mathrm{H})$.

Decamethylferrocenium BArF._-To a suspension of $350 \mathrm{mg}(1.07 \mathrm{mmol})$ of decamethylferrocene in $125 \mathrm{~mL}$ of acetonitrile were added $173.1 \mathrm{mg}(1.02 \mathrm{mmol})$ of solid $\mathrm{AgNO}_{3}$ and $731.8 \mathrm{mg}(1.02 \mathrm{mmol})$ of $\mathrm{KBC}_{24} \mathrm{~F}_{20}$, causing an immediate color change. The solution was allowed to react for $30 \mathrm{~min}$, after which time the acetonitrile solution was extracted with $(2 \times 75 \mathrm{~mL})$ of hexane. The acetonitrile solution was saved and solvent removed. The solid was suspended in $\sim 120 \mathrm{~mL}$ of tetrahydrofuran and filtered through a pad of Celite. The tetrahydrofuran was removed, yielding a green solid which was crystallized by chilling a hot methanol:ethanol:acetonitrile:water solution. After filtration and drying, the yield was $825 \mathrm{mg}$ (76\% yield) of $\mathrm{Me}_{10} \mathrm{FcBAr}^{\mathrm{F}}$. Calculated for $\mathrm{C}_{44} \mathrm{H}_{30} \mathrm{BF}_{20} \mathrm{Fe}$ : C, 52.57; H, 3.01. Found: 52.37 ; H, 3.49 .

Octamethylferrocenium BArF.-Synthesized by the same procedure as $\mathrm{Me}_{10} \mathrm{FcBAr}^{\mathrm{F}}$ above, using octamethylferrocene in place of decamethylferrocene. Calculated for $\mathrm{C}_{42} \mathrm{H}_{26} \mathrm{BF}_{20} \mathrm{Fe}: \mathrm{C}, 51.62 ; \mathrm{H}, 2.68$. Found: 51.67; H, 2.67.

\section{Spectroscopic Sample Preparations.}

UV-Vis.- $\mathrm{F}_{8} \mathrm{Cmpd}-\mathrm{II}$, (DCHIm) $\mathrm{F}_{8} \mathrm{Cmpd}-\mathrm{II}$, and $\mathrm{P}^{\mathrm{Im}} \mathrm{Cmpd}-\mathrm{II}$ were synthesized as previously described. ${ }^{62-65,72}$ High-valent iron(IV)-oxo complexes were generated by preparing a $3.0 \mathrm{~mL}$ 1:9 MeTHF:toluene solution $(0.01 \mathrm{mM}$ or $0.1 \mathrm{mM})$ of $\mathrm{F} 8 \mathrm{Fe}^{\mathrm{II}}$ or $\mathrm{P}^{\mathrm{Im}} \mathrm{Fe}^{\mathrm{II}}$ in a $10 \mathrm{~mm}$ path length quartz Schlenk cuvette, which was then sealed with a rubber septum in the glovebox. The cuvette was then cooled in the cryostat chamber to $-90{ }^{\circ} \mathrm{C}$, and the 
solution was then allowed to thermally equilibrate ( $\sim 10 \mathrm{~min})$ before various reagents were added. The reduced iron(II) precursors were subjected to 1 equiv of $m C P B A$ dissolved in toluene at $-90{ }^{\circ} \mathrm{C}$, forming the $\mathrm{F}_{8} \mathrm{Cmpd}-\mathrm{II}$ or $\mathrm{P}^{\mathrm{Im}} \mathrm{Cmpd}-\mathrm{II}$ species after 5 min (denoted by a characteristic increase in the extinction coe-cient of the Q-band). Subsequently, 2 equiv of 1,5-dicyclohexylimidazole (DCHIm) dissolved in toluene, 2 equiv of sodium 3,5dimethoxyphenolate $\left(\mathrm{ArO}^{-}\right)$, or 2 equiv of sodium imidazolate $\left(\mathrm{Im}^{-}\right)$was added to $\mathrm{F}_{8} \mathrm{Cmpd}$ II, resulting in a red shift in the Soret and Q-band, yielding (DCHIm) $\mathrm{F}_{8} \mathrm{Cmpd}-\mathrm{II}$, (ArO $\left.{ }^{-}\right) \mathrm{F}_{8} \mathrm{Cmpd}-\mathrm{II}$, or $\left(\mathrm{Im}^{-}\right)-\mathrm{F}_{8} \mathrm{Cmpd}-\mathrm{II}$, respectively. Due to solubility issues, sodium 3,5dimethoxyphenolate and sodium imidazolate were added in a 4:1 15-crown-5 ether:butyronitrile solution instead of in toluene.

One equivalent of 2,6-lutidinium triflate, prepared as previously described by Tilley and coworkers, ${ }^{95}$ was added in butyronitrile to $\mathrm{F}_{8} \mathrm{Cmpd}$-II or (DCHIm) $\mathrm{F}_{8} \mathrm{Cmpd}-\mathrm{II}$, generating $\mathrm{F}_{8} \mathrm{Cmpd}-\mathrm{II}\left(\mathrm{LutH}^{+}\right)$or $(\mathrm{DCHIm}) \mathrm{F}_{8} \mathrm{Cmpd}-\mathrm{II}\left(\mathrm{LutH}^{+}\right)$, respectively. Various ferrocene derivatives $\left(\mathrm{Me}_{10} \mathrm{Fc}, \mathrm{Me}_{8} \mathrm{Fc}, \mathrm{Me}_{2} \mathrm{Fc}, \mathrm{Fc}\right.$, AcetylFc, DiacetylFc) or tris(4bromophenyl)amine were added to $\mathrm{F}_{8} \mathrm{Cmpd}-\mathrm{II}$, (DCHIm)- $\mathrm{F}_{8} \mathrm{Cmpd}-\mathrm{II}, \mathrm{F}_{8} \mathrm{Cmpd}-\mathrm{II}\left(\mathrm{LutH}^{+}\right)$, and $(\mathrm{DCHIm}) \mathrm{F}_{8} \mathrm{Cmpd}-\mathrm{II}\left(\mathrm{LutH}^{+}\right)$, wherein the reactions were monitored by UV-vis, ${ }^{2} \mathrm{H}$ NMR, or Mössbauer spectroscopies. The absorbance at $784 \mathrm{~nm}$ was monitored for various concentrations of decamethylferrocenium $\mathrm{BAr}^{\mathrm{F}}(0.025-0.29 \mathrm{mM})$ and at $779 \mathrm{~nm}$ for octamethylferrocenium $\mathrm{BAr}^{\mathrm{F}}(0.025-0.20 \mathrm{mM}$ ), forming standard curves (Figures $\mathrm{S} 30$ and S31) to quantify the number of electrons transferred at the end of the reaction. See Supporting Information for further details.

X-Band EPR.—Compound-II derivatives were generated by adding 1 equiv of $m \mathrm{CPBA}$ and, depending on the derivative, 1 equiv of axial ligand to a 1:9 MeTHF:toluene solution containing $1 \mathrm{mM}$ of $\mathrm{F}_{8} \mathrm{Fe}^{\mathrm{II}}$ or $\mathrm{P}^{\mathrm{Im}} \mathrm{Fe}^{\mathrm{II}}$ (total volume $=0.6 \mathrm{~mL}$ ) at $-90^{\circ} \mathrm{C}$ (acetone/liquid nitrogen cold bath). Upon addition of reagent(s), the solution was bubbled with Ar for $20 \mathrm{~s}$ to ensure thorough mixing. In each case, upon addition of $m C P B A$, the solution was allowed to react for $5 \mathrm{~min}\left(\mathrm{~F}_{8} \mathrm{Cmpd}-\mathrm{II}\right.$ and $\mathrm{P}^{\mathrm{Im}} \mathrm{Cmpd}-\mathrm{II}$ were frozen after $\left.5 \mathrm{~min}\right)$, following the addition of 2 equiv of axial ligand to form (DCHIm) $\mathrm{F}_{8} \mathrm{Cmpd}-\mathrm{II},\left(\mathrm{ArO}^{-}\right) \mathrm{F}_{8} \mathrm{Cmpd}-\mathrm{II}$, and (Im $\left.{ }^{-}\right) \mathrm{F}_{8} \mathrm{Cmpd}-\mathrm{II}$. Next, 1 equiv of 2,6-lutidinium triflate was added in butyronitrile to $\mathrm{F}_{8} \mathrm{Cmpd}$ II or (DCHIm) $\mathrm{F}_{8} \mathrm{Cmpd}-\mathrm{II}$, generating $\mathrm{F}_{8} \mathrm{Cmpd}-\mathrm{II}\left(\mathrm{LutH}^{+}\right)$and (DCHIm)- $\mathrm{F}_{8} \mathrm{Cmpd}-\mathrm{II}\left(\mathrm{LutH}^{+}\right)$. After the complexes were generated, tubes were frozen in $\mathrm{N}_{2 \text { (liq), }}$, and all spectra were recorded at $10 \mathrm{~K}$. All complexes were EPR silent (X-band), consistent with an integer spin electronic spin value and the typical EPR signature of an $\mathrm{S}=1$ Compound-II species.

${ }^{54 / 57} \mathbf{F e}$-Labeled $\boldsymbol{r} \boldsymbol{R}$. - The oxoiron(IV) complexes were generated in the same fashion as the EPR spectroscopy samples; however, samples were made at $2 \mathrm{mM}$ and employed the ${ }^{57} \mathrm{Fe}$ and ${ }^{54} \mathrm{Fe}$ derivatives with a total volume of $0.3 \mathrm{~mL}$ at $-90{ }^{\circ} \mathrm{C}$ (acetone/liquid nitrogen bath) in a 7-in., $5 \mathrm{~mm}$, rubber septum-capped, NMR tube. Resonance Raman spectra were obtained with a $407 \mathrm{~nm}$ laser excitation $(4 \mathrm{~mW})$ on samples maintained at $110 \mathrm{~K}$ and with constant spinning as described previously. ${ }^{94}$

${ }^{2} \boldsymbol{H}$ NMR.-The oxoiron(IV) complexes were generated in the same fashion as the EPR spectroscopy samples; however, they were prepared using the pyrrole-deuterated analogue, $d_{8}-\mathrm{F}_{8} \mathrm{Fe}^{\mathrm{II}}$, at $5.0 \mathrm{mM}$ concentrations with a total volume of $0.6 \mathrm{~mL}$ at $-90{ }^{\circ} \mathrm{C}$ (acetone/liquid 
$\mathrm{N}_{2}$ ) in a 9-in., $5 \mathrm{~mm}$, rubber septum-capped, NMR tube. Upon addition of reagent(s), the solution was bubbled with Ar for $20 \mathrm{~s}$ to ensure thorough mixing. ${ }^{2} \mathrm{H}$ NMR spectra were acquired on a Bruker AVANCE $300 \mathrm{MHz}$ NMR spectrometer at 46.072 MHz. Experiments were carried out at $-90{ }^{\circ} \mathrm{C}$ using a recycle delay of $0.01 \mathrm{~s}$, and a total of 5120 scans were collected. The peaks were referenced to the one of toluene solvent peaks at $7.1 \mathrm{ppm}$ (the $-\mathrm{CH}$ group of toluene, which is the most upfield).

${ }^{57} \mathbf{F e}$ Mössbauer.-Samples were prepared similarly to how they were generated for UV -vis spectroscopy. However, the reduced $\mathrm{F}^{57}{ }_{8} \mathrm{Fe}^{\mathrm{II}}$ or $\mathrm{P}^{\mathrm{Im}}{ }^{57} \mathrm{Fe}^{\mathrm{II}}$ complexes were employed. The iron starting material was prepared as a $2.0 \mathrm{~mL} \mathrm{1:9} \mathrm{MeTHF:toluene} \mathrm{solution} \mathrm{at} 2 \mathrm{mM}$ under $\mathrm{Ar}$ in a $10 \mathrm{~mL}$ Schlenk flask in the glovebox, which was then subsequently cooled to $-90{ }^{\circ} \mathrm{C}$ for $10 \mathrm{~min}$. Reagents were then added accordingly to form desired complexes as described in the UV-vis section. See Supporting Information for further details. Samples were prepared by cooling a pipet in liquid nitrogen and then quickly filling a pre-chilled Delrin Mössbauer cup. All Mössbauer spectra were taken at $80 \mathrm{~K}$ in the absence of a magnetic field using liquid nitrogen as a cryogen.

XAS.-Samples were prepared in a similar fashion to the Mössbauer samples as above. All samples except the DCHIm ligated sample were prepared in 10\% MeTHF and 90\% toluene with a concentration at $2.0 \mathrm{mM}$ employing the $\mathrm{F}^{57}{ }_{8} \mathrm{Fe}^{\mathrm{II}}$ analogue. Mössbauer spectroscopy was run on all the XAS samples to confirm the purity of that particular batch, and the reported Mössbauer purities reflect the purity of the corresponding XAS spectra. The DCHIm samples were the only exception; the samples were prepared in $100 \%$ toluene and were $90 \%$ pure by Mössbauer with the impurity being the ferrous precursor. Samples were prepared by cooling a pipet in liquid nitrogen and then quickly filling pre-chilled Delrin cell, and immediately frozen in liquid nitrogen. Every compound was generated twice and measured for XAS.

\section{Supplementary Material}

Refer to Web version on PubMed Central for supplementary material.

\section{ACKNOWLEDGMENTS}

The research support of the U.S. National Institutes of Health (GM60353 to K.D.K.) is gratefully acknowledged. This research was supported by the National Institute of General Medical Sciences under award numbers R01GM040392 (E.I.S.), R01GM074785 (P.M.-L.), and F32GM122194 (L.B.G.). The SSRL Structural Molecular Biology Program is supported by the U.S. Department of Energy Office of Biological and Environmental Research and by the National Institutes of Health, National Institute of General Medical Sciences, Grant P41GM103393 (to K.O.H. and B.H.). Some computational work was performed under the XSIM project on the CORI computing system at NERSC, a U.S. Department of Energy Office of Science User Facility operated under Contract No. DEAC02-05CH11231. We also gratefully acknowledge Dr. David P. Goldberg for the use of his Mössbauer instrument and Jesse B. Gordon for assistance in running the samples. M.A.E. would also like to especially thank Dr. David A. Quist for helpful discussions and for aiding in sample preparation. We acknowledge the help of Drs. Matthew Latimer and Erik Nelson for assistance at SSRL beamlines 9-3 and 7-3. L.B.G. also acknowledges Dr. Thomas Kroll for assistance in pre-edge fitting.

\section{REFERENCES}

(1). Behan RK; Green MT On the Status of Ferryl Protonation. J. Inorg. Biochem 2006, 100, 448-459. [PubMed: 16500711] 
(2). Adam SM; Wijeratne GB; Rogler PJ; Diaz DE; Quist DA; Liu JJ; Karlin KD Synthetic Fe/Cu Complexes: Toward Understanding Heme-Copper Oxidase Structure and Function. Chem. Rev 2018, 118, 10840-11022. [PubMed: 30372042]

(3). Huang X; Groves JT Oxygen Activation and Radical Transformations in Heme Proteins and Metalloporphyrins. Chem. Rev 2018, 118, 2491-2553. [PubMed: 29286645]

(4). Huang X; Groves JT Beyond Ferryl-Mediated Hydroxylation: 40 Years of the Rebound Mechanism and C-H Activation. JBIC, J. Biol. Inorg. Chem 2017, 22, 185-207 [PubMed: 27909920]

(5). Rittle J; Younker JM; Green MT Cytochrome P450: The Active Oxidant and Its Spectrum. Inorg. Chem 2010, 49, 3610-3617. [PubMed: 20380463]

(6). Krest CM; Onderko EL; Yosca TH; Calixto JC; Karp RF; Livada J; Rittle J; Green MT Reactive Intermediates in Cytochrome P450 Catalysis. J. Biol. Chem 2013, 288, 17074-17081. [PubMed: 23632017]

(7). Gumiero A; Metcalfe CL; Pearson AR; Raven EL; Moody PCE Nature of the Ferryl Heme in Compounds I and II. J. Biol. Chem 2011, 286, 1260-1268. [PubMed: 21062738]

(8). Denisov IG; Makris TM; Sligar SG; Schlichting I Structure and Chemistry of Cytochrome P450. Chem. Rev 2005, 105, 2253-2278. [PubMed: 15941214]

(9). Sono M; Roach MP; Coulter ED; Dawson JH Heme-Containing Oxygenases. Chem. Rev 1996, 96, 2841-2888. [PubMed: 11848843]

(10). Ortiz de Montellano PR Hydrocarbon Hydroxylation by Cytochrome P 450 Enzymes. Chem. Rev 2010, 110, 932-948. [PubMed: 19769330]

(11). Hohenberger J; Ray K; Meyer K The Biology and Chemistry of High-Valent Iron-Oxo and IronNitrido Complexes. Nat. Commun 2012, 3, 720. [PubMed: 22395611]

(12). Groves JT High-Valent Iron in Chemical and Biological Oxidations. J. Inorg. Biochem 2006, 100, 434-447. [PubMed: 16516297]

(13). Groves JT Enzymatic C-H Bond Activation: Using Push to Get Pull. Nat. Chem 2014, 6, 89-91. [PubMed: 24451580]

(14). Nam W; Ryu YO; Song WJ Oxidizing Intermediates in Cytochrome P450 Model Reactions. JBIC, J. Biol. Inorg. Chem 2004, 9, 654-660. [PubMed: 15365902]

(15). Nam W High-Valent Iron(IV)-Oxo Complexes of Heme and Non-Heme Ligands in Oxygenation Reactions. Acc. Chem. Res 2007, 40, 522-531. [PubMed: 17469792]

(16). Dawson JH; Sono M Cytochrome P-450 and Chloroperoxidase: Thiolate-Ligated Heme Enzymes. Spectroscopic Determination of Their Active Site Structures and Mechanistic Implications of Thiolate Ligation. Chem. Rev 1987, 87, 1255-1276.

(17). Groves JT; Viski P Asymmetric Hydroxylation, Epoxidation, and Sulfoxidation Catalyzed by Vaulted Binaphthyl Metalloporphyrins. J. Org. Chem 1990, 55, 3628-3634.

(18). Groves JT; Nemo TE; Myers RS Hydroxylation and Epoxidation Catalyzed by Iron-Porphine Complexes. Oxygen Transfer from Iodosylbenzene. J. Am. Chem. Soc 1979, 101, 1032-1033.

(19). Groves JT; McClusky GA; White RE; Coon MJ Aliphatic Hydroxylation by Highly Purified Liver Microsomal Cytochrome P-450. Evidence for a Carbon Radical Intermediate. Biochem. Biophys. Res. Commun 1978, 81, 154-160. [PubMed: 656092]

(20). Traylor TG; Kim C; Richards JL; Xu F; Perrin CL Reactions of Iron(III) Porphyrins with Oxidants. Structure-Reactivity Studies. J. Am. Chem. Soc 1995, 117, 3468-3474.

(21). Dicken CM; Woon TC; Bruice TC Kinetics and Mechanisms of Oxygen Transfer in the Reaction of P-Cyano-N,NDimethylaniline N-Oxide with Metalloporphyrin Salts. 3. Catalysis by [MesoTetrakis(2,6-Dichlorophenyl)Porphinato]Iron(III) Chloride. J. Am. Chem. Soc 1986, 108, 16361643.

(22). Nam W; Park S; Lim IK; Lim MH; Hong J; Kim J First Direct Evidence for Stereospecific Olefin Epoxidation and Alkane Hydroxylation by an Oxoiron(IV) Porphyrin Complex. J. Am. Chem. Soc 2003, 125, 14674-14675. [PubMed: 14640620]

(23). Chin DH; Balch AL; La Mar GN Formation of Porphyrin Ferryl $\left(\mathrm{FeO}^{2+}\right)$ Complexes through the Addition of Nitrogen Bases to Peroxo-Bridged Iron(III) Porphyrins. J. Am. Chem. Soc 1980, 102, 1446-1448. 
(24). Groves JT; Gross Z; Stern MK Preparation and Reactivity of Oxoiron(IV) Porphyrins. Inorg. Chem 1994, 33, 5065-5072.

(25). Guo M; Dong H; Li J; Cheng B; Huang YQ; Feng YQ; Lei A Spectroscopic Observation of Iodosylarene Metalloporphyrin Adducts and Manganese(V)-Oxo Porphyrin Species in a Cytochrome P450 Analogue. Nat. Commun 2012, 3, 1190-1199. [PubMed: 23149735]

(26). Moody PCE; Raven EL The Nature and Reactivity of Ferryl Heme in Compounds I and II. Acc. Chem. Res 2018, 51, 427-435. [PubMed: 29327921]

(27). Ray K; Heims F; Schwalbe M; Nam W High-Valent Metal-Oxo Intermediates in Energy Demanding Processes: From Dioxygen Reduction to Water Splitting. Curr. Opin. Chem. Biol 2015, 25, 159-171. [PubMed: 25703840]

(28). Sengupta K; Chatterjee S; Dey A In Situ Mechanistic Investigation of $\mathrm{O}_{2}$ Reduction by Iron Porphyrin Electrocatalysts Using Surface-Enhanced Resonance Raman Spectroscopy Coupled to Rotating Disk Electrode (SERRS-RDE) Setup. ACS Catal. 2016, 6, 6838-6852.

(29). Balch AL; Chan YW; Cheng RJ; La Mar GN; Latos-Grazynski L; Renner MW Oxygenation Patterns for Iron(II) Porphyrins. Peroxo and Ferryl $\left(\mathrm{Fe}^{\mathrm{IV}} \mathrm{O}\right)$ Intermediates Detected by Proton Nuclear Magnetic Resonance Spectroscopy during the Oxygenation of (Tetramesitylporphyrin)Iron(II). J. Am. Chem. Soc 1984, 106, 7779-7785.

(30). Balch AL; Latos-Grazynski L; Renner MW Oxidation of Red Ferryl $\left[\left(\mathrm{Fe}^{\mathrm{IV}} \mathrm{O}\right)^{2+}\right]$ Porphyrin Complexes to Green Ferryl $\left[\left(\mathrm{Fe}^{\mathrm{IV}} \mathrm{O}\right)^{2+}\right]$ Porphyrin Radical Complexes. J. Am. Chem. Soc 1985, 107, 2983-2985

(31). Groves JT; Haushalter RC; Nakamura M; Nemo TE; Evans BJ High-Valent Iron-Porphyrin Complexes Related to Peroxidase and Cytochrome P-450. J. Am. Chem. Soc 1981, 103, 2884 2886.

(32). Groves JT; Watanabe Y Reactive Iron Porphyrin Derivatives Related to the Catalytic Cycles of Cytochrome P-450 and Peroxidase. Studies of the Mechanism of Oxygen Activation. J. Am. Chem. Soc 1988, 110, 8443-8452.

(33). Penner-Hahn JE; Dawson JH; Renner M; Groves JT; Eble KS; Hodgson KO; McMurry TJ; Balch AL Structural Characterization of Horseradish Peroxidase Using EXAFS Spectroscopy. Evidence for $\mathrm{Fe}=\mathrm{O}$ Ligation in Compounds I and II. J. Am. Chem. Soc 1986, 108, 7819-7825. [PubMed: 22283292]

(34). Fujii H Model Complexes of Heme Peroxidases In Heme Peroxidases; Raven E, Dunford B, Eds.; The Royal Society of Chemistry: Cambridge, 2016; pp 181-217.

(35). Fujii H Electronic Structure and Reactivity of High-Valent Oxo Iron Porphyrins. Coord. Chem. Rev 2002, 226, 51-60.

(36). Takahashi A; Kurahashi T; Fujii H Redox Potentials of Oxoiron(IV) Porphyrin $\pi$-Cation Radical Complexes: Participation of Electron Transfer Process in Oxygenation Reactions. Inorg. Chem 2011, 50, 6922-6928 [PubMed: 21714484]

(37). Takahashi A; Kurahashi T; Fujii H Effect of Imidazole and Phenolate Axial Ligands on the Electronic Structure and Reactivity of Oxoiron(IV) Porphyrin $\pi$-Cation Radical Complexes: Drastic Increase in Oxo-Transfer and Hydrogen Abstraction Reactivities. Inorg. Chem 2009, 48, 2614-2625. [PubMed: 19216512]

(38). Bell SR; Groves JT A Highly Reactive P450 Model Compound I. J. Am. Chem. Soc 2009, 131, 9640-9641. [PubMed: 19552441]

(39). Boaz NC; Bell SR; Groves JT Ferryl Protonation in Oxoiron(IV) Porphyrins and Its Role in Oxygen Transfer. J. Am. Chem. Soc 2015, 137, 2875-2885. [PubMed: 25651467]

(40). Green MT; Dawson JH; Gray HB Oxoiron(IV) in Chloroperoxidase Compound II Is Basic: Implications for P450 Chemistry. Science 2004, 304, 1653-1656. [PubMed: 15192224]

(41). Yosca TH; Langston MC; Krest CM; Onderko EL; Grove TL; Livada J; Green MT Spectroscopic Investigations of Catalase Compound II: Characterization of an Iron(IV) Hydroxide Intermediate in a Non-Thiolate-Ligated Heme Enzyme. J. Am. Chem. Soc 2016, 138, 16016-16023. [PubMed: 27960340]

(42). Behan RK; Hoffart LM; Stone KL; Krebs C; Green MT Evidence for Basic Ferryls in Cytochromes P450. J. Am. Chem. Soc 2006, 128, 11471-11474. [PubMed: 16939270] 
(43). Stone KL; Behan RK; Green MT Resonance Raman Spectroscopy of Chloroperoxidase Compound II Provides Direct Evidence for the Existence of an Iron(IV)-Hydroxide. Proc. Natl. Acad. Sci. U. S. A 2006, 103, 12307-12310. [PubMed: 16895990]

(44). Stone KL; Hoffart LM; Behan RK; Krebs C; Green MT Evidence for Two Ferryl Species in Chloroperoxidase Compound II. J. Am. Chem. Soc 2006, 128, 6147-6153. [PubMed: 16669684]

(45). Kwon H; Basran J; Casadei CM; Fielding AJ; Schrader TE; Ostermann A; Devos JM; Aller P; Blakeley MP; Moody PCE; Raven EL Direct Visualization of a Fe(IV)-OH Intermediate in a Heme Enzyme. Nat. Commun 2016, 7, 13445. [PubMed: 27897163]

(46). Schulz CE; Sage JT; Debrunner PG; Hager LP; Rutter R Mössbauer and Electron Paramagnetic Resonance Studies of Horseradish Peroxidase and Its Catalytic Intermediates. Biochemistry 1984, 23, 4743-4754. [PubMed: 6093863]

(47). Hasinoff BB; Dunford HB Kinetics of the Oxidation of Ferrocyanide by Horseradish Peroxidase Compounds I and II. Biochemistry 1970, 9, 4930-4939. [PubMed: 5480158]

(48). Sitter AJ; Reczek CM; Terner J Observation of the FeIVO Stretching Vibration of Ferryl Myoglobin by Resonance Raman Spectroscopy. Biochim. Biophys. Acta, Protein Struct. Mol. Enzymol 1985, 828, 229-235.

(49). Zeng W; Barabanschikov A; Zhang Y; Zhao J; Sturhahn W; Alp EE; Sage JT SynchrotronDerived Vibrational Data Confirm Unprotonated Oxo Ligand in Myoglobin Compound II. J. Am. Chem. Soc 2008, 130, 1816-1817. [PubMed: 18201090]

(50). Baglia RA; Krest CM; Yang T; Leeladee P; Goldberg DP High-Valent Manganese-Oxo Valence Tautomers and the Influence of Lewis/Brönsted Acids on C-H Bond Cleavage. Inorg. Chem 2016, 55, 10800-10809. [PubMed: 27689821]

(51). Yano J; Yachandra V Mn 4 Ca Cluster in Photosynthesis: Where and How Water Is Oxidized to Dioxygen. Chem. Rev 2014, 114, 4175-4205. [PubMed: 24684576]

(52). Umena Y; Kawakami K; Shen J-R; Kamiya N Crystal Structure of Oxygen-Evolving Photosystem II at a Resolution of 1.9 Å. Nature 2011, 473, 55-60. [PubMed: 21499260]

(53). Rivalta I; Brudvig GW; Batista VS Oxomanganese Complexes for Natural and Artificial Photosynthesis. Curr. Opin. Chem. Biol 2012, 16, 11-18. [PubMed: 22481113]

(54). Kanady JS; Tsui EY; Day MW; Agapie T A Synthetic Model of the Mn3Ca Subsite of the Oxygen-Evolving Complex in Photosystem II. Science 2011, 333, 733-736 [PubMed: 21817047]

(55). Tsui EY; Tran R; Yano J; Agapie T Redox-Inactive Metals Modulate the Reduction Potential in Heterometallic Manganese-Oxido Clusters. Nat. Chem 2013, 5, 293-299. [PubMed: 23511417]

(56). Tsui EY; Agapie T Reduction Potentials of Heterometallic Manganese-Oxido Cubane Complexes Modulated by Redox-Inactive Metals. Proc. Natl. Acad. Sci. U. S. A 2013, 110, 10084-10088. [PubMed: 23744039]

(57). Fukuzumi S Electron-Transfer Properties of High-Valent Metal-Oxo Complexes. Coord. Chem. Rev 2013, 257, 1564-1575

(58). Park J; Morimoto Y; Lee YM; Nam W; Fukuzumi S Unified View of Oxidative C-H Bond Cleavage and Sulfoxidation by a Nonheme Iron(IV)-Oxo Complex via Lewis Acid-Promoted Electron Transfer. Inorg. Chem 2014, 53, 3618-3628. [PubMed: 24605985]

(59). Westre TE; Kennepohl P; DeWitt JG; Hedman B; Hodgson KO; Solomon EI A Multiplet Analysis of Fe K-Edge 1s $\rightarrow$ 3d Pre-Edge Features of Iron Complexes. J. Am. Chem. Soc 1997, 119, 6297-6314.

(60). Gütlich P; Bill E; Trautwein AX Hyperfine Interactions. Mössbauer Spectroscopy and Transition Metal Chemistry; Springer: Berlin/Heidelberg, 2011; pp 73-135.

(61). Pan Z; Newcomb M Kinetics and Mechanism of Oxidation Reactions of Porphyrin-Iron(IV)-Oxo Intermediates. Inorg. Chem 2007, 46, 6767-6774. [PubMed: 17630728]

(62). Adam SM; Garcia-Bosch I; Schaefer AW; Sharma SK; Siegler MA; Solomon EI; Karlin KD Critical Aspects of Heme-Peroxo-Cu Complex Structure and Nature of Proton Source Dictate Metal-O Peroxo Breakage versus Reductive O-O Cleavage Chemistry. J. Am. Chem. Soc 2017, 139, 472-481. [PubMed: 28029788]

(63). Garcia-Bosch I; Sharma SK; Karlin KD A Selective Stepwise Heme Oxygenase Model System: An Iron(IV)-Oxo Porphyrin $\pi$-Cation Radical Leads to a Verdoheme-Type Compound via an Isoporphyrin Intermediate. J. Am. Chem. Soc 2013, 135, 16248-16251. [PubMed: 24147457] 
(64). Halime Z; Kieber-Emmons MT; Qayyum MF; Mondal B; Gandhi T; Puiu SC; Chufán EE; Sarjeant AAN;Hodgson KO; Hedman B; Solomon EI; Karlin KD Heme- Copper-Dioxygen Complexes: Toward Understanding Ligand-Environmental Effects on the Coordination Geometry, Electronic Structure, and Reactivity. Inorg. Chem 2010, 49, 3629-3645. [PubMed: 20380465]

(65). Sharma SK; Schaefer AW; Lim H; Matsumura H; Moenne-Loccoz P; Hedman B; Hodgson KO; Solomon EI; Karlin KD A Six-Coordinate Peroxynitrite Low-Spin Iron(III) Porphyrinate Complex - The Product of the Reaction of Nitrogen Monoxide $(\cdot \mathrm{NO}(\mathrm{g}))$ with a Ferric-Superoxide Species. J. Am. Chem. Soc 2017, 139, 17421-17430. [PubMed: 29091732]

(66). Jeong YJ; Kang Y; Han AR; Lee YM; Kotani H; Fukuzumi S; Nam W Hydrogen Atom Abstraction and Hydride Transfer Reactions by Iron(IV)-Oxo Porphyrins. Angew. Chem., Int. Ed 2008, 47, 7321-7324.

(67). Sharma VK; Zboril R Ferryl and Ferrate Species: Mössbauer Spectroscopy Investigation. Croat. Chem. Acta 2015, 88, 363-368

(68). Hu C; Schulz CE; Scheidt WR All High-Spin ( $\mathrm{S}=2$ ) Iron(II) Hemes Are NOT Alike. Dalton Trans. 2015, 44, 18301-18310. [PubMed: 26387976]

(69). Münck E; Champion PM Heme Proteins and Model Compounds: Mossbauer Absorption and Emission Spectroscopy. Ann. N. Y. Acad. Sci 1975, 244, 142-162. [PubMed: 166590]

(70). Champion PM; Chiang R; Muenck E; Debrunner P; Hager LP Moessbauer Investigations of High-Spin Ferrous Heme Proteins. II. Chloroperoxidase, Horseradish Peroxidase, and Hemoglobin. Biochemistry 1975, 14, 4159-4166. [PubMed: 1182095]

(71). Ghiladi RA; Chufán EE; del Río D; Solomon EI; Krebs C; Huynh BH; Huang H; MoënneLoccoz P; Kaderli S;Honecker M; Zuberbühler AD; Marzilli L; Cotter RJ; Karlin KD Further Insights into the Spectroscopic Properties, Electronic Structure, and Kinetics of Formation of the Heme-Peroxo-Copper Complex $\left[\left(\mathrm{F}_{8} \text { TPP }\right) \mathrm{Fe}^{\mathrm{III}}-\left(\mathrm{O}_{2-}{ }^{2-}\right)-\mathrm{Cu}{ }^{\mathrm{II}}(\mathrm{TMPA})\right]^{+}$. Inorg. Chem 2007, 46, 3889-3902. [PubMed: 17444630]

(72). Li Y; Sharma SK; Karlin KD New Heme-dioxygen and Carbon Monoxide Adducts Using Pyridyl or Imidazolyl Tailed Porphyrins. Polyhedron 2013, 58, 190-196

(73). Sharma SK; Kim H; Rogler PJ; Siegler MA; Karlin KD Isocyanide or Nitrosyl Complexation to Hemes with Varying Tethered Axial Base Ligand Donors: Synthesis and Characterization. JBIC, J. Biol. Inorg. Chem 2016, 21, 729-743. [PubMed: 27350154]

(74). Bajdor K; Nakamoto K Formation of Ferryltetraphenylporphyrin by Laser Irradiation. J. Am. Chem. Soc 1984, 106, 3045-3046.

(75). Nakamoto K Resonance Raman Spectra and Biological Significance of High-Valent Iron(IV,V) Porphyrins. Coord. Chem. Rev 2002, 226, 153-165.

(76). Proniewicz LM; Bajdor K; Nakamoto K Resonance Raman Spectra of Ferrylporphyrins and Related Compounds in Dioxygen Matrixes. J. Phys. Chem 1986, 90, 1760-1766.

(77). Kean RT; Oertling WA; Babcock GT Characterization of Six-Coordinate Ferryl Protoheme by Resonance Raman and Optical Absorption Spectroscopy. J. Am. Chem. Soc 1987, 109, 21852187.

(78). Green MT Application of Badger's Rule to Heme and Non-Heme Iron-Oxygen Bonds: An Examination of Ferryl Protonation States. J. Am. Chem. Soc 2006, 128, 1902-1906. [PubMed: 16464091]

(79). Peterson RL; Ginsbach JW; Cowley RE; Qayyum MF; Himes RA; Siegler MA; Moore CD; Hedman B; Hodgson KO; Fukuzumi S; Solomon EI; Karlin KD Stepwise Protonation and Electron-Transfer Reduction of a Primary Copper-Dioxygen Adduct. J. Am. Chem. Soc 2013, 135, 16454-16467. [PubMed: 24164682]

(80). Yoon H; Lee Y-M; Wu X; Cho K-B; Sarangi R; Nam W; Fukuzumi S Enhanced ElectronTransfer Reactivity of Nonheme Manganese(IV)-Oxo Complexes by Binding Scandium Ions. J. Am. Chem. Soc 2013, 135, 9186-9194. [PubMed: 23742163]

(81). Park J; Morimoto Y; Lee Y-M; Nam W; Fukuzumi S Proton-Promoted Oxygen Atom Transfer vs Proton-Coupled Electron Transfer of a Non-Heme Iron(IV)-Oxo Complex. J. Am. Chem. Soc 2012, 134, 3903-3911. [PubMed: 22339209] 
(82). Wang D; Zhang M; Bühlmann P; Que L Redox Potential and C-H Bond Cleaving Properties of a Nonheme $\mathrm{Fe}^{\mathrm{IV}}=\mathrm{O}$ Complex in Aqueous Solution. J. Am. Chem. Soc 2010, 132, 7638-7644. [PubMed: 20476758]

(83). Chen J; Yoon H; Lee Y-M; Seo MS; Sarangi R; Fukuzumi S; Nam W Tuning the Reactivity of Mononuclear Nonheme Manganese ${ }^{\mathrm{IV}}$-Oxo Complexes by Triflic Acid. Chem. Sci 2015, 6, 3624-3632. [PubMed: 26146538]

(84). Fukuzumi S; Ohkubo K; Lee Y-M; Nam W Lewis Acid Coupled Electron Transfer of MetalOxygen Intermediates. Chem. -Eur. J 2015, 21, 17548-17559. [PubMed: 26404482]

(85). Chai C; Armarego WLF Purification of Laboratory Chemicals, 6th ed.; Elsevier Inc.: Amsterdam, 2009.

(86). Tenderholt A; Hedman B; Hodgson KO PySpline: A Modern, Cross-Platform Program for the Processing of Raw Averaged XAS Edge and EXAFS Data. AIP Conf. Proc. 2006, 882, 105-107.

(87). Ankudinov AL; Rehr JJ Relativistic Calculations of Spin-Dependent X-Ray-Absorption Spectra. Phys. Rev. B: Condens. Matter Mater. Phys 1997, 56, R1712-R1716.

(88). Wilson SA; Green E; Mathews II; Benfatto M; Hodgson KO; Hedman B; Sarangi R X-Ray Absorption Spectroscopic Investigation of the Electronic Structure Differences in Solution and Crystalline Oxyhemoglobin. Proc. Natl. Acad. Sci. U. S. A 2013, 110, 16333-16338. [PubMed: 24062465]

(89). Neese F Software Update: The ORCA Program System, Version 4.0. Wiley Interdiscip. Rev. Comput. Mol. Sci 2018, 8, No. e1327.

(90). Becke AD Density-Functional Exchange-Energy Approximation with Correct Asymptotic Behavior. Phys. Rev. A: At., Mol., Opt. Phys 1988, 38, 3098-3100.

(91). Weigend F; Ahlrichs R Balanced Basis Sets of Split Valence, Triple Zeta Valence and Quadruple Zeta Valence Quality for H to Rn: Design and Assessment of Accuracy. Phys. Chem. Chem. Phys 2005, 7, 3297-3305. [PubMed: 16240044]

(92). Römelt M; Ye S; Neese F Calibration of Modern Density Functional Theory Methods for the Prediction of 57Fe Mössbauer Isomer Shifts: Meta-GGA and Double-Hybrid Functionals. Inorg. Chem 2009, 48, 784-785. [PubMed: 19102678]

(93). Grimme S; Antony J; Ehrlich S; Krieg H A Consistent and Accurate Ab Initio Parametrization of Density Functional Dispersion Correction (DFT-D) for the 94 Elements H-Pu. J. Chem. Phys 2010, 132, 154104. [PubMed: 20423165]

(94). Ghiladi RA; Hatwell KR; Karlin KD; Huang H; Moënne-Loccoz P; Krebs C; Huynh BH; Marzilli LA; Cotter RJ; Kaderli S; Zuberbühler AD Dioxygen Reactivity of Mononuclear Heme and Copper Components Yielding A High-Spin Heme-Peroxo-Cu Complex. J. Am. Chem. Soc 2001, 123, 6183-6184. [PubMed: 11414855]

(95). Curley JJ; Bergman RG; Tilley TD Preparation and Physical Properties of Early-Late Heterobimetallic Compounds Featuring Ir-M Bonds ( $\mathrm{M}=\mathrm{Ti}, \mathrm{Zr}$, Hf). Dalton Trans. 2012, 41, 192-200. [PubMed: 22020701] 


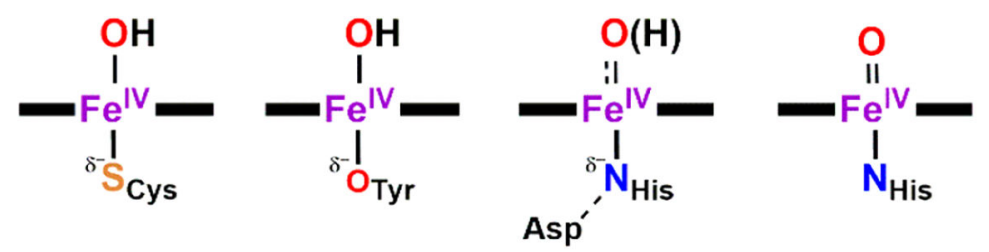

\section{Cytochrome Catalase Peroxidase Cytochrome $c$ P450 \\ Oxidase}

Figure 1.

Heme $\mathrm{Fe}^{\mathrm{IV}}=\mathrm{O}$ enzyme intermediates with various axial ligands. The "push" from strongly electron-donating axial bases with anionic character found in cytochrome P450 and catalase results in the greater "pull" on an H-atom so that their Cmpd-II species are formally protonated, giving an iron(IV)-hydroxide. ${ }^{13}$ Due to hydrogen-bonding interactions with a nearby proximal residue, the axial histidine ligand in most peroxidases has partial anionic character, which may result in the formation of an $\mathrm{Fe}^{\mathrm{IV}}-\mathrm{OH}(\mathrm{APX})$ or $\mathrm{Fe}^{\mathrm{IV}}=\mathrm{O}(\mathrm{HRP})$ species. 


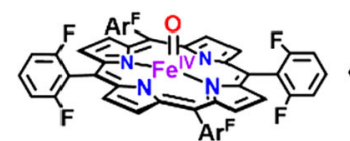

Parent Ferryl Complex
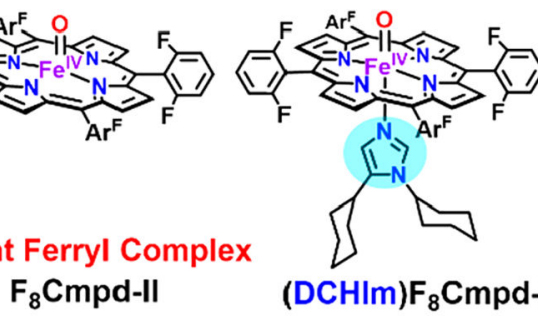

$(\mathrm{DCHIm}) \mathrm{F}_{8} \mathrm{Cmpd}-\mathrm{II}$
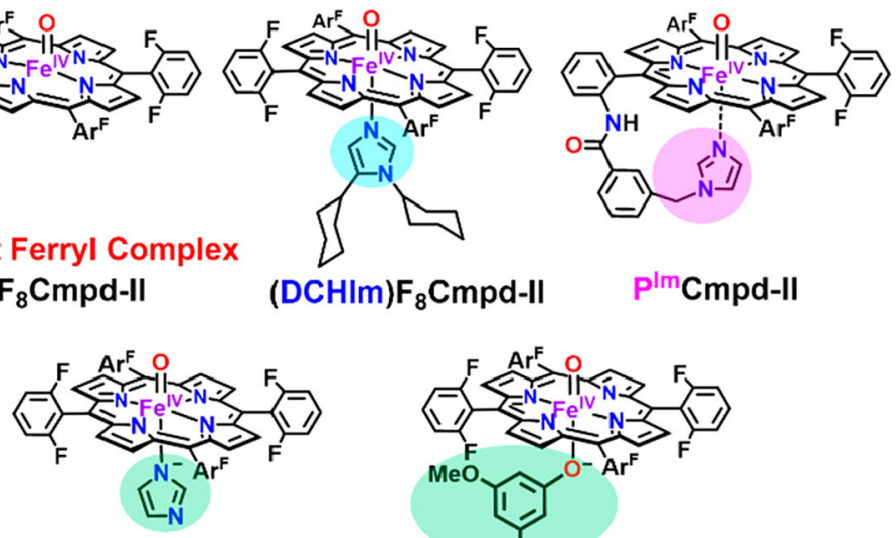

$\left(\mathrm{Im}^{-}\right) \mathrm{F}_{8} \mathrm{Cmpd}-\mathrm{II}$

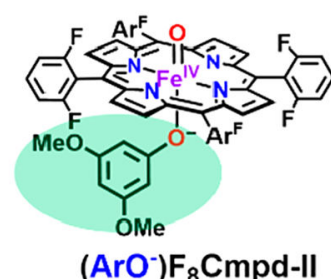

Figure 2.

Synthetic Cmpd-II complexes generated and studied as part of this report, including (1) the parent ferryl species, (2) derivatives formed by adding various exogenous strongly electrondonating axial ligands and (3) the tethered derivative $\mathrm{P}^{\mathrm{Im}} \mathrm{Cmpd}-\mathrm{II}$. 

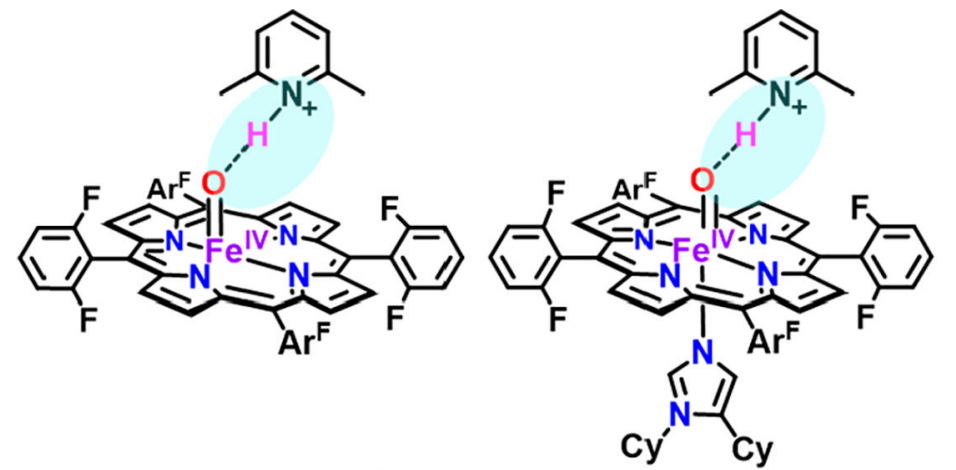

\section{$\mathrm{F}_{8} \mathrm{Cmpd}-\mathrm{II}\left(\mathrm{LutH}^{+}\right) \quad$ (DCHIm) $\mathrm{F}_{8} \mathrm{Cmpd}-\mathrm{II}\left(\mathrm{LutH}^{+}\right)$ Lewis Acid Adducts}

Figure 3.

Generation of high-valent ferryl Lewis acid adducts by addition of 2,6-lutidinium triflate $\left(\mathrm{LutH}^{+}\right)$to $\mathrm{F}_{8} \mathrm{Cmpd}-\mathrm{II}$ and (DCHIm) $\mathrm{F}_{8} \mathrm{Cmpd}-\mathrm{II}$. 

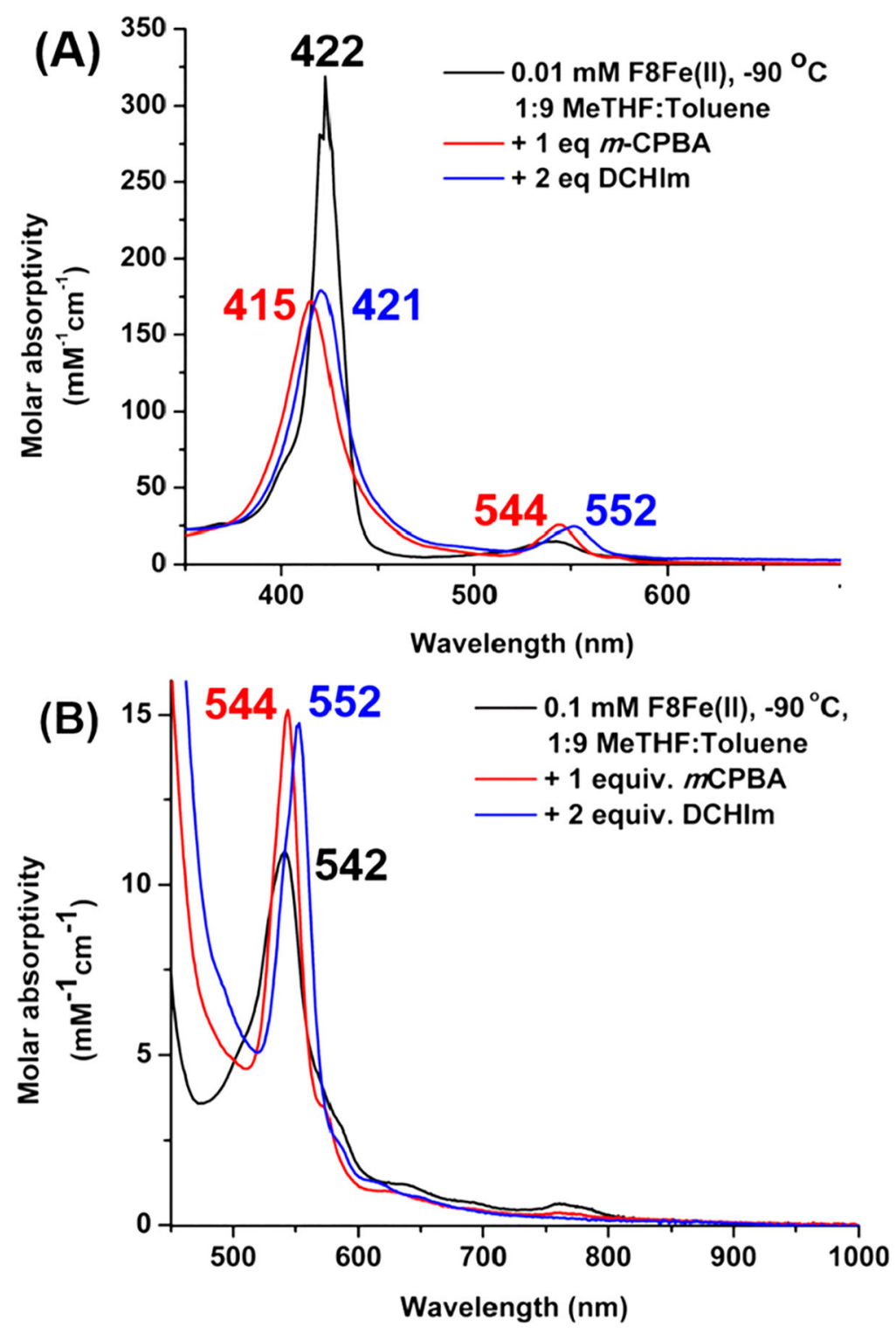

Figure 4.

UV-vis monitoring of the formation of (DCHIm) $\mathrm{F}_{8} \mathrm{Cmpd}-\mathrm{II}$ at $0.01 \mathrm{mM}$ : the Soret band (A) and the Q-band (B) at $-90{ }^{\circ} \mathrm{C}$ in 1:9 MeTHF:toluene. 


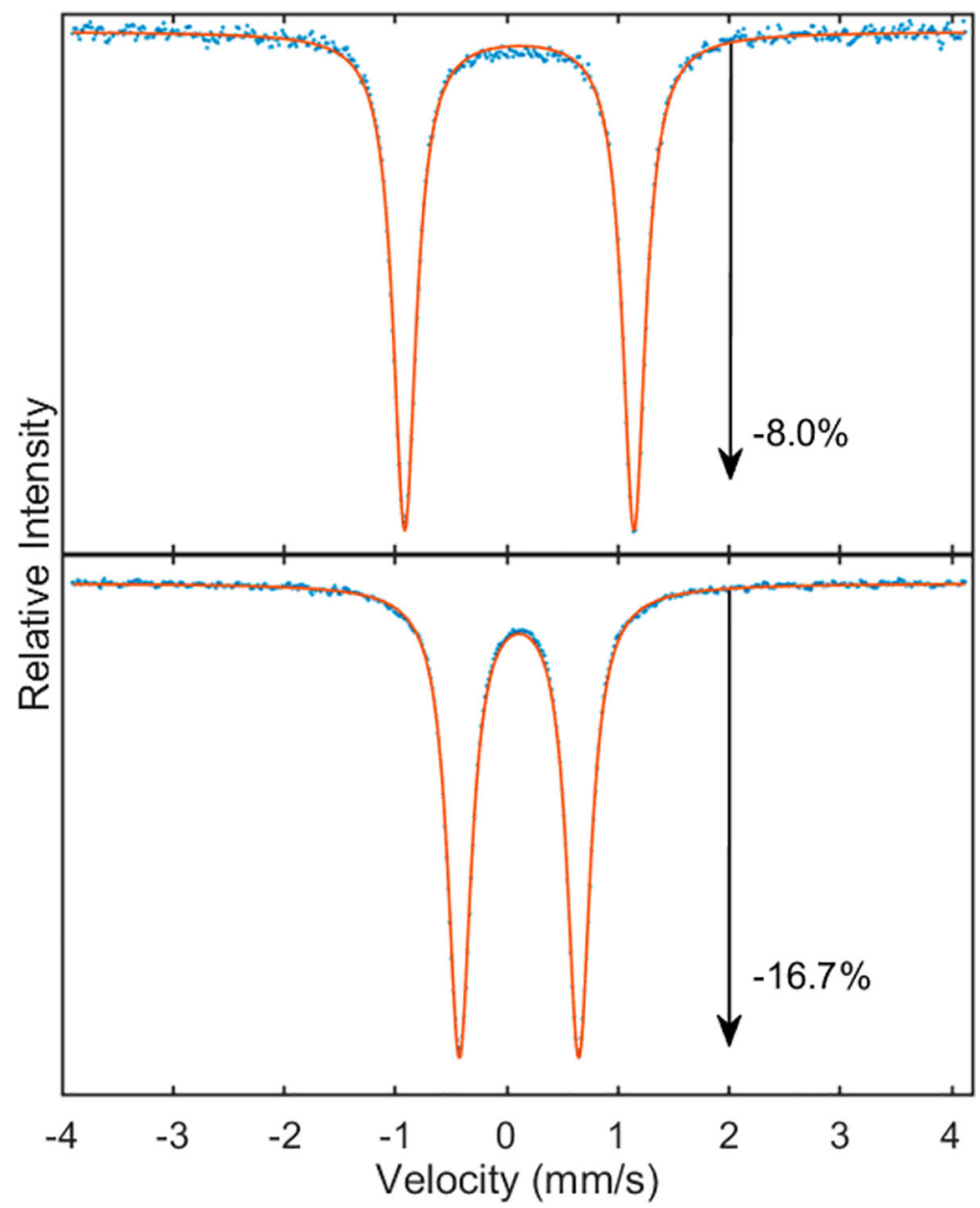

Figure 5.

$80 \mathrm{~K}$, zero applied magnetic field ${ }^{57} \mathrm{Fe}$ Mössbauer spectra (blue) with corresponding fits (orange) at $2 \mathrm{mM}$ in 1:9 MeTHF:toluene: (top) $\mathrm{F}_{8} \mathrm{Cmpd}-\mathrm{II}$ and (bottom) (DCHIm)- $\mathrm{F}_{8} \mathrm{Cmpd}-$ II. The fits for these Mössbauer spectra indicated a single quadrupole doublet, implying high purity of the samples. Mössbauer parameters are given in Table 1. 


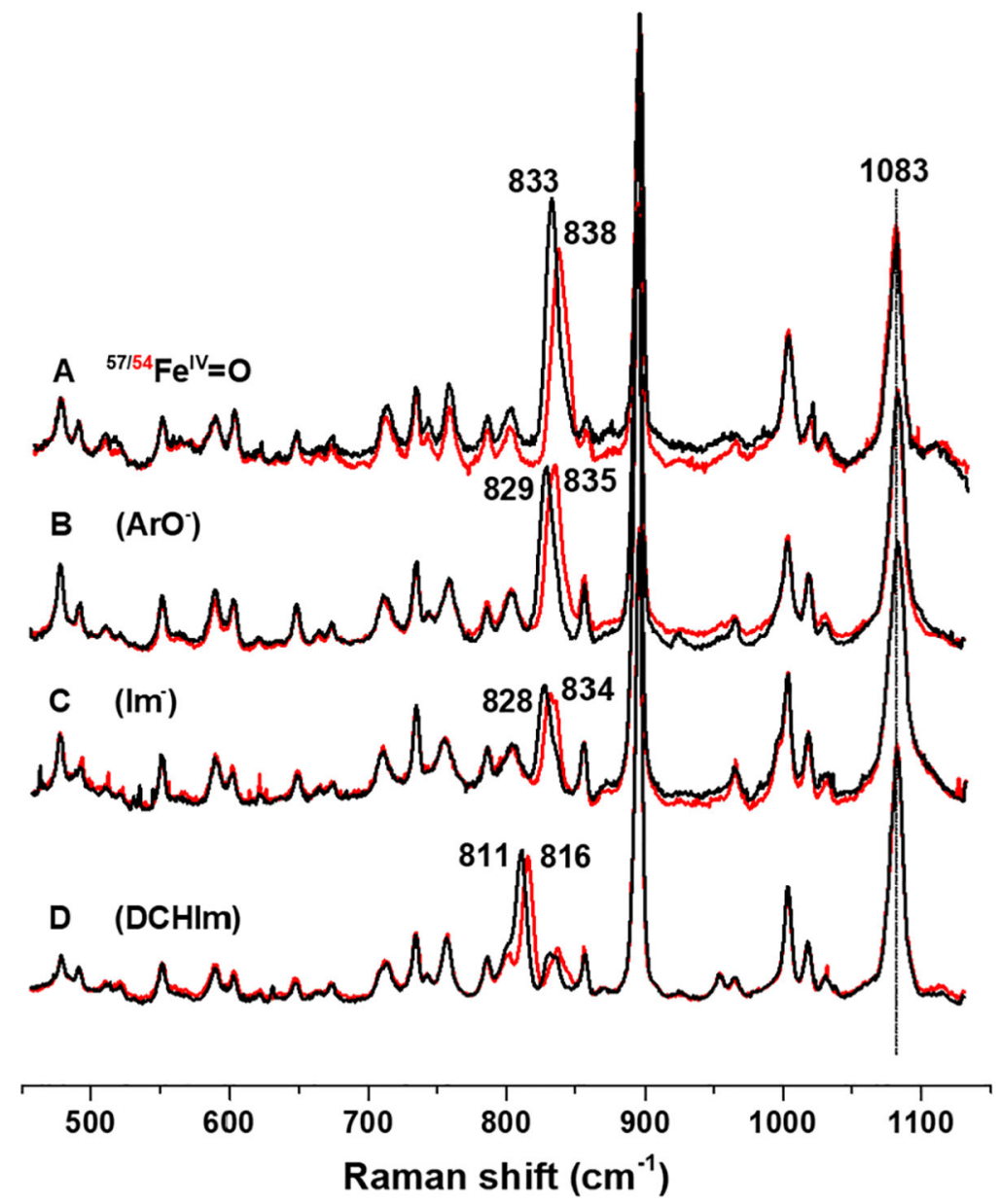

Figure 6.

Resonance Raman spectra in the mid-frequency region for the $\mathrm{F}_{8}{ }^{54 / 57} \mathrm{~F}^{\mathrm{IV}} \mathrm{Fe}=\mathrm{O}$ complexes $\left({ }^{57} \mathrm{Fe}\right.$ spectra in black and ${ }^{54} \mathrm{Fe}$ spectra in red) without and with phenolate, imidazolate, and DCHIm axial bases. (All spectra are normalized with respect to the $1083 \mathrm{~cm}^{-1}$ band.) The $v(\mathrm{Fe}=\mathrm{O})$ for each derivative is labeled and was observed to be in the expected $800 \mathrm{~cm}^{-1}$ region. See the SI for additional details (e.g., rR spectra showing the oxidation and spin state features). 


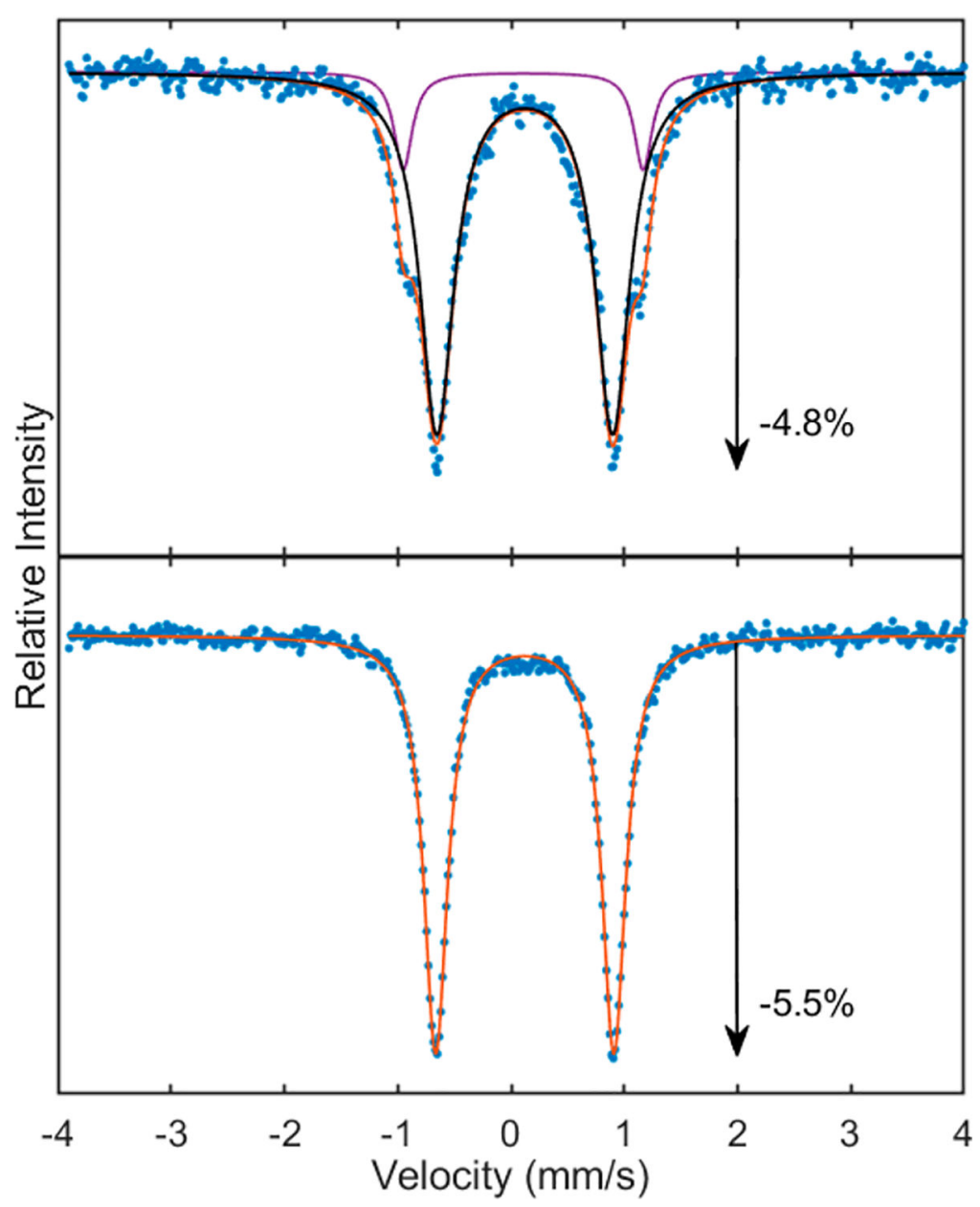

Figure 7.

$80 \mathrm{~K}$, zero applied magnetic field ${ }^{57} \mathrm{Fe}$ Mössbauer spectra (blue) with corresponding fits (orange) at $2 \mathrm{mM}$ in 1:9 MeTHF:toluene: (top) $\left(\mathrm{Im}^{-}\right) \mathrm{F}_{8} \mathrm{Cmpd}-\mathrm{II}$ major (black) and minor (purple) species (unreacted $\left.\mathrm{F}_{8} \mathrm{Cmpd}-\mathrm{II}\right)$ and (bottom) $\left(\mathrm{ArO}^{-}\right)-\mathrm{F}_{8} \mathrm{Cmpd}-\mathrm{II}$ (one quadrupole doublet, indicating high purity). Changes in the absorption are due to differences in sample cell path length. Major species parameters given in Table 1, and the parameters for the minor species are given in Table S2. 


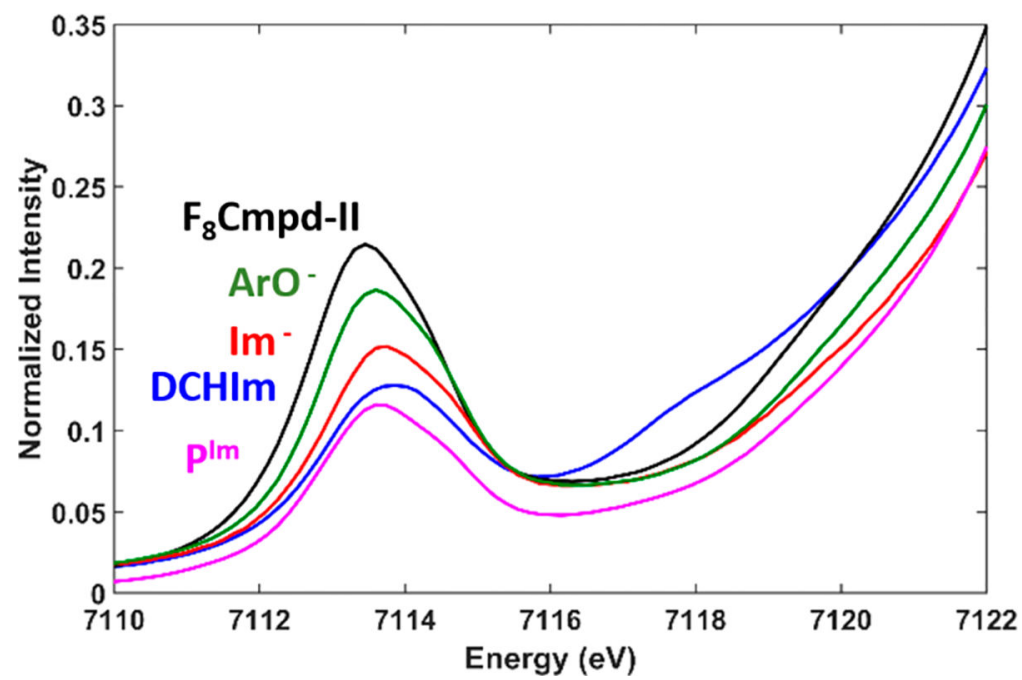

Figure 8.

XANES spectra of the tethered imidazole complex (magenta), the five-coordinate $\mathrm{F}_{8} \mathrm{Cmpd}$ II complex (black) and axially ligated derivatives: (DCHIm) $\mathrm{F}_{8} \mathrm{Cmpd}-\mathrm{II}$ (blue), (Imidazolate) $\mathrm{F}_{8} \mathrm{Cmpd}-\mathrm{II}$ (red), and (3,5-dimethoxy-phenolate)- $\mathrm{F}_{8} \mathrm{Cmpd}-\mathrm{II}$ (green). Decreased pre-edge intensity was indicative of axial ligand strength, which correlated well with the electronic influence of the various axial ligands on the $v(\mathrm{Fe}=\mathrm{O})$ obtained from $\mathrm{rR}$. 


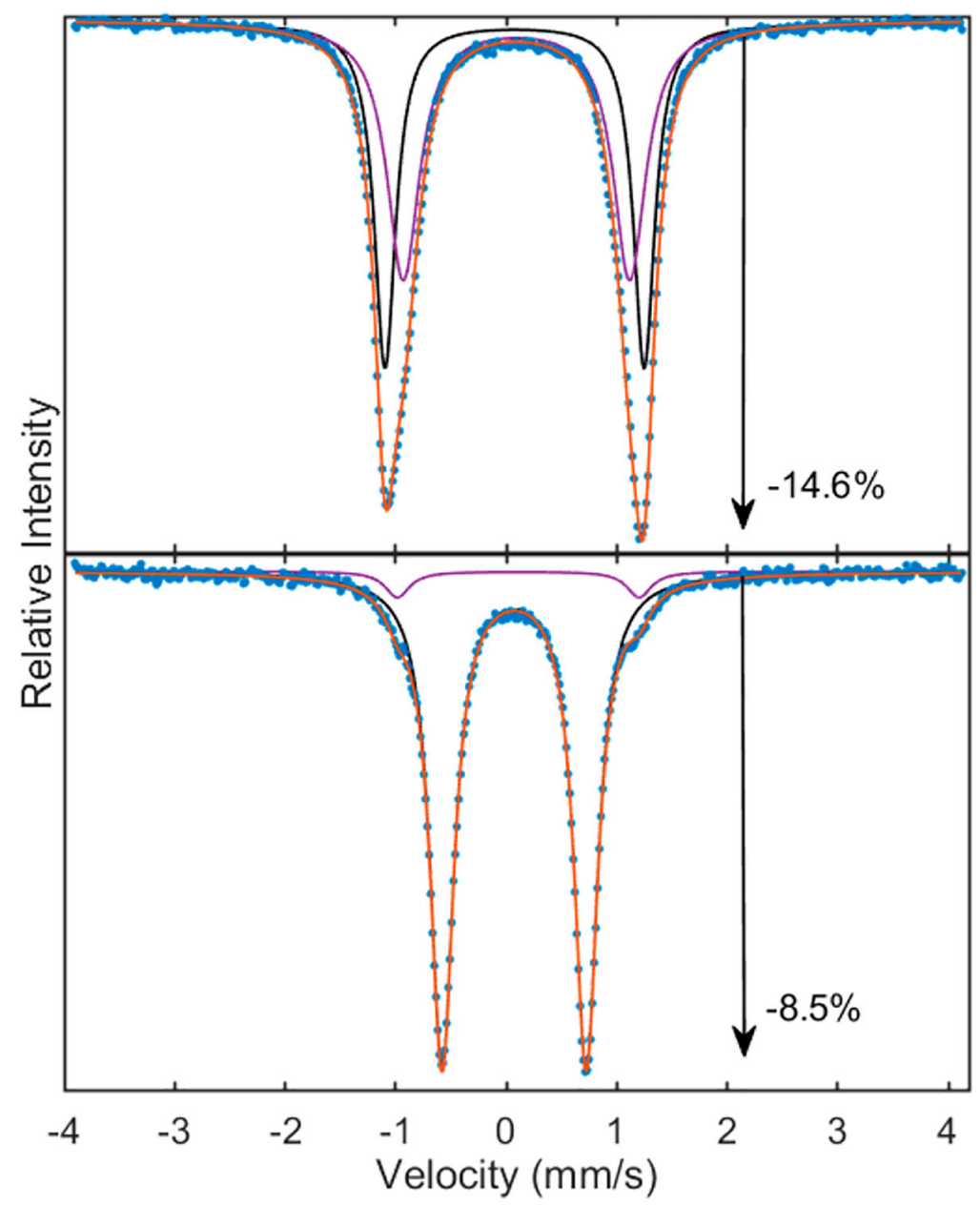

Figure 9.

$80 \mathrm{~K}$ zero applied magnetic field ${ }^{57} \mathrm{Fe}$ Mössbauer spectra (blue) with corresponding fits (orange) at $2 \mathrm{mM}$ in 1:9 MeTHF:toluene: (top) $\mathrm{F}_{8} \mathrm{Cmpd}-\mathrm{II}\left(\mathrm{LutH}^{+}\right)$and (bottom) (DCHIm)$\mathrm{F}_{8} \mathrm{Cmpd}-\mathrm{II}\left(\mathrm{LutH}^{+}\right)$. Major species in black and minor species in purple. Changes in absorption are due to differences in sample cell path length. Parameters ascribed to the Lewis acid species are given in Table 2, and parameters for the other species seen are given in Table S2. Both species were fitted to two quadrupole doublets, of which one was ascribed to the Lewis acid ferryl complex and the other to $\mathrm{F}_{8} \mathrm{Cmpd}-\mathrm{II}$. $\mathrm{F}_{8} \mathrm{Cmpd}-\mathrm{II}\left(\mathrm{LutH}^{+}\right)$was close to a 50/50 mixture with $\mathrm{F}_{8} \mathrm{Cmpd}-\mathrm{II}$; however, (DCHIm) $\mathrm{F}_{8} \mathrm{Cmpd}-\mathrm{II}\left(\mathrm{LutH}^{+}\right)$was of high purity with only $10 \%$ being $\mathrm{F}_{8} \mathrm{Cmpd}$-II. 


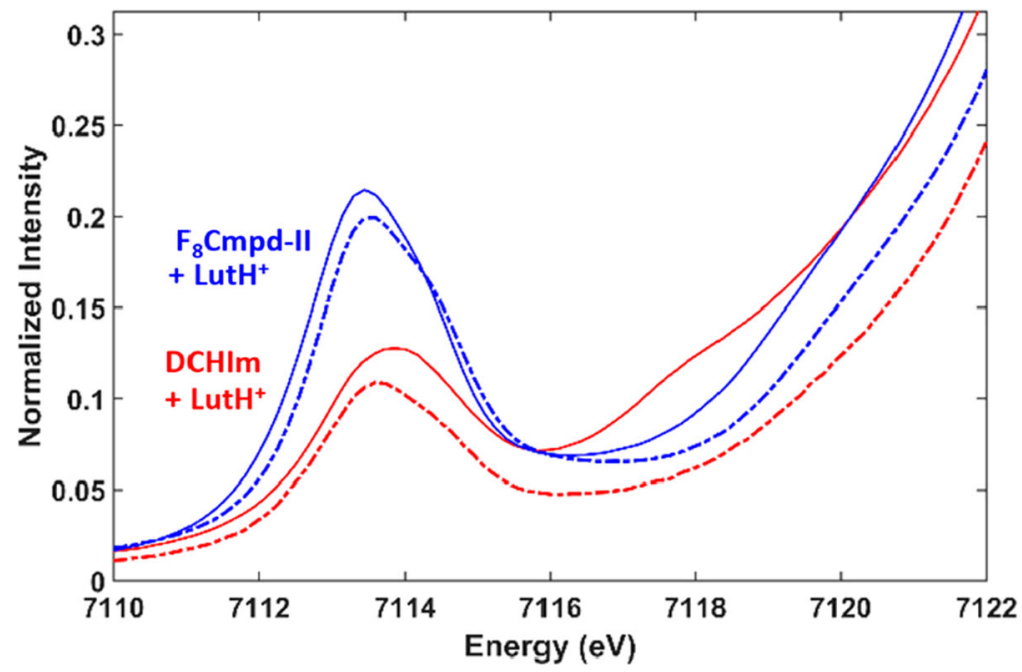

Figure 10.

$\mathrm{X}$-ray absorption edge spectra of $\mathrm{F}_{8} \mathrm{Cmpd}-\mathrm{II}$ (blue) and (DCHIm) $\mathrm{F}_{8} \mathrm{Cmpd}-\mathrm{II}$ (red) and as dashed lines $\mathrm{F}_{8}$ Cmpd-II(LutH ${ }^{+}$) (blue) and (DCHIm)F $\mathrm{F}_{8} \mathrm{Cmpd}_{-\mathrm{II}}\left(\mathrm{LutH}^{+}\right.$) (red). Addition of $\mathrm{LutH}^{+}$decreases pre-edge intensity, which is indicative of slight elongation of the iron(IV)oxo bond length. 

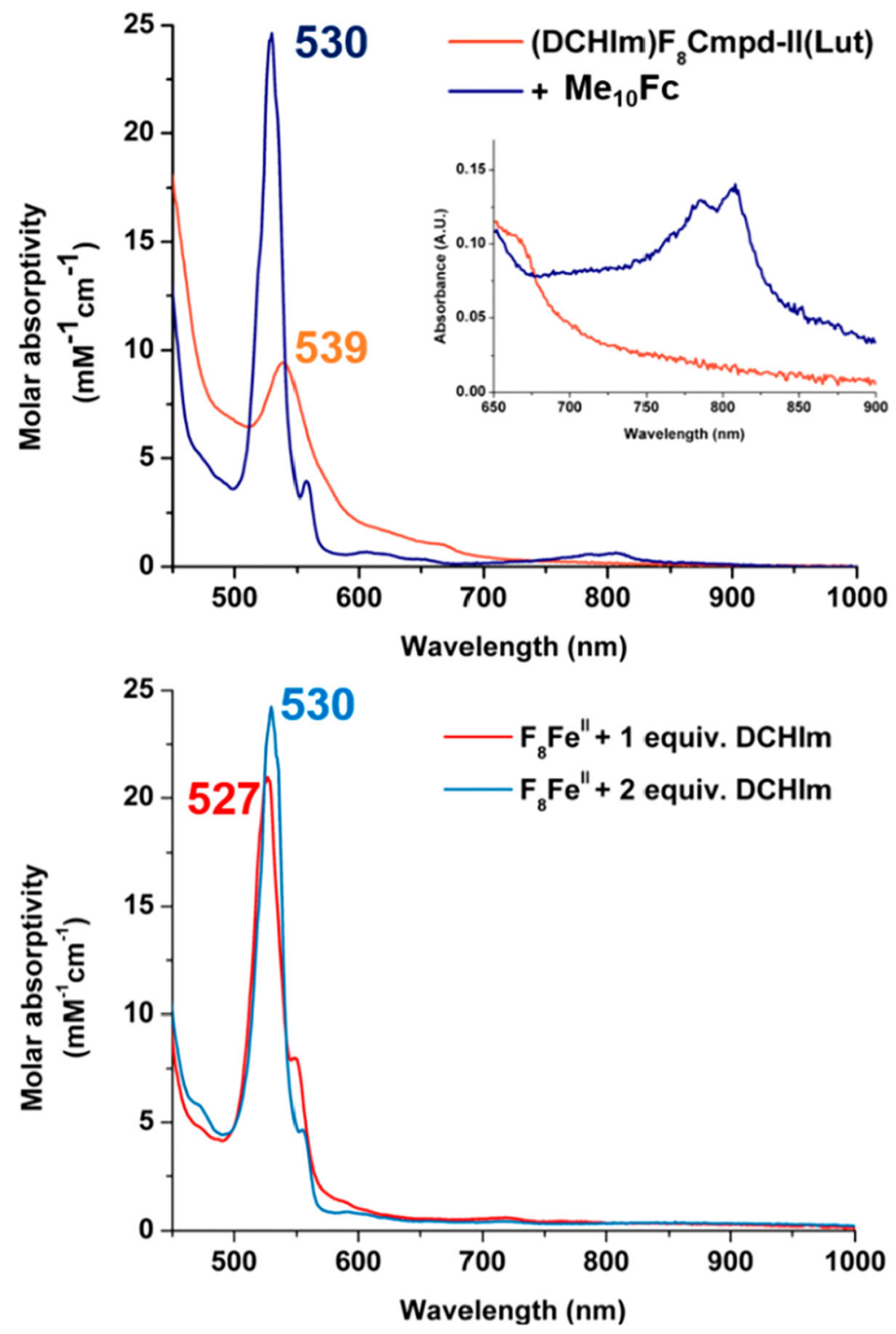

Figure 11.

$\mathrm{UV}$-vis spectroscopy following the addition of 10 equiv of $\mathrm{Me}_{10} \mathrm{Fc}$ to $0.1 \mathrm{mM}$

(DCHIm) $\mathrm{F}_{8} \mathrm{Cmpd}-\mathrm{II}\left(\mathrm{LutH}^{+}\right)$in 1:9 MeTHF:toluene at $-90{ }^{\circ} \mathrm{C}$, wherein there was an immediate change from the LA ferryl adduct in orange to the resulting reaction mixture in navy (top). The products in the reaction mixture were independently generated by adding 1 equiv of DCHIm to $0.1 \mathrm{mM} \mathrm{F}_{8} \mathrm{Fe}^{\mathrm{II}}$ in 1:9 MeTHF:toluene at $-90{ }^{\circ} \mathrm{C}$ (red) and by adding a second equiv of DCHIm to allow the favorable formation of the major product (DCHIm) ${ }_{2} \mathrm{~F}_{8} \mathrm{Fe}^{\mathrm{II}}$ (blue) (bottom), a low-spin six-coordinate $\mathrm{d}^{6}$ complex. The top reaction mixture in navy and the bottom (DCHIm) ${ }_{2} \mathrm{~F}_{8} \mathrm{Fe}^{\mathrm{II}}$ complex in light blue had comparable UV -vis features, Soret at $420 \mathrm{~nm}$ and Q-band at $530 \mathrm{~nm}$ (Figures S19 and Figure S32). Quantification of the low-energy decamethylferrocenium peaks observed in the 700-800 nm region indicated two electrons were transferred at the end of the reaction (Figures S19 and S30 and Table S5). 


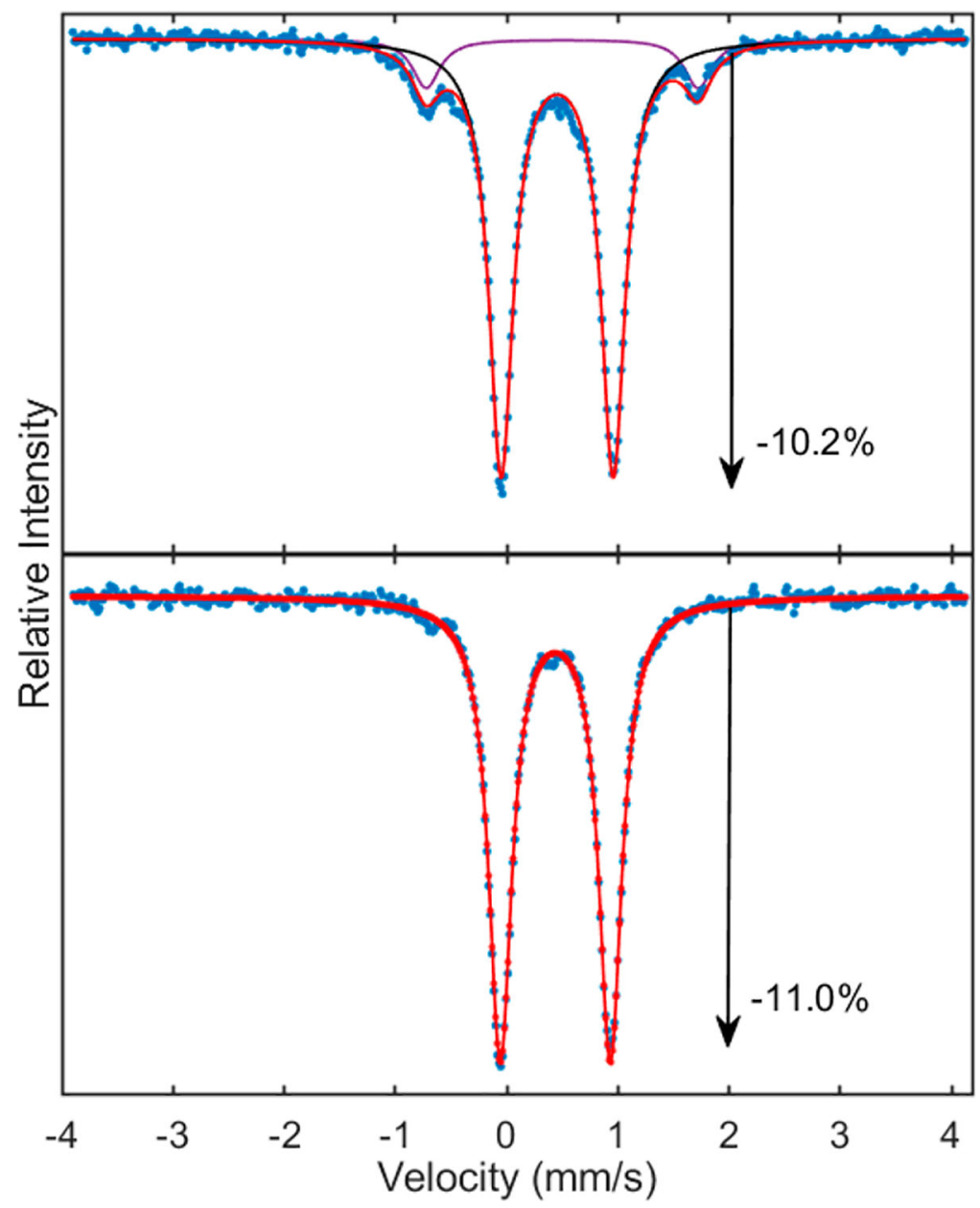

Figure 12.

$80 \mathrm{~K}$, zero applied magnetic field ${ }^{57} \mathrm{Fe}$ Mössbauer spectra (blue) with total fits (red): addition of 10 equiv of $\mathrm{Me}_{10} \mathrm{Fc}$ to $2 \mathrm{mM}(\mathrm{DCHIm}) \mathrm{F}_{8} \mathrm{Cmpd}-\mathrm{II}\left(\mathrm{LutH}^{+}\right)$in 1:9

MeTHF:toluene at $-90^{\circ} \mathrm{C}$ (top). (DCHIm) ${ }_{2} \mathrm{~F}_{8} \mathrm{Fe}^{\mathrm{II}}$ was prepared by adding 2 equiv of DCHIm to $2 \mathrm{mM} \mathrm{F}_{8} \mathrm{Fe}^{\mathrm{II}}$ in 1:9 MeTHF:toluene at $-90{ }^{\circ} \mathrm{C}$ (bottom). The values in the resulting reaction mixture were comparable to those for (DCHIm) ${ }_{2} \mathrm{~F}_{8} \mathrm{Fe}^{\mathrm{II}}$ and thus $(\mathrm{DCHIm}) \mathrm{F}_{8} \mathrm{Cmpd}-\mathrm{II}\left(\mathrm{LutH}^{+}\right)$was reduced by two electrons, forming the corresponding lowspin ferrous species and water. Mössbauer parameters are given in Table S2. 

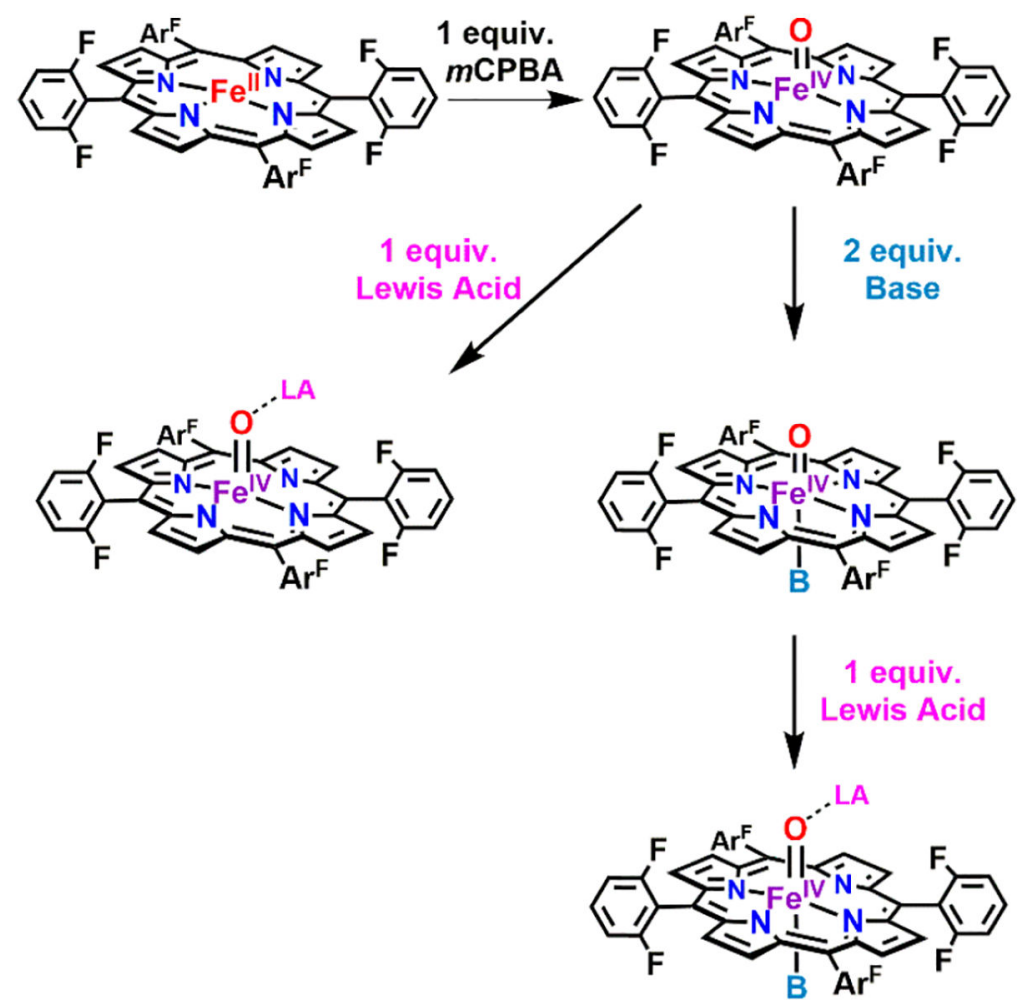

Scheme 1.

Addition of 1 Equiv of $m C P B A$ to $\mathrm{F}_{8} \mathrm{Fe}^{\mathrm{II}}$ Species in 1:9 MeTHF:Toluene at $-90{ }^{\circ} \mathrm{C}$ Yielded $\mathrm{F}_{8} \mathrm{Cmpd}$-II; Further Treatment with an Exogenous Base or Lewis Acid Resulted in the Formation of an Axial Base Ferryl Derivative and/or a Lewis Acid Iron(IV)-Oxo Species 

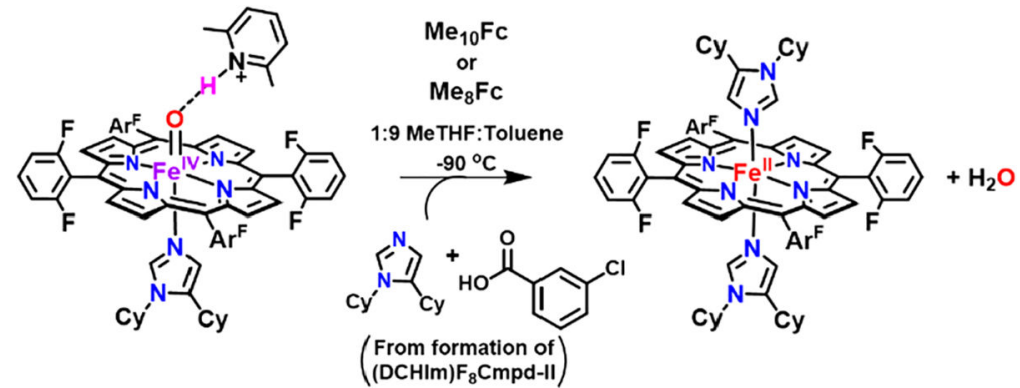

Scheme 2.

Addition of $\mathrm{Me}_{10} \mathrm{Fc}$ or $\mathrm{Me}_{8} \mathrm{Fc}$ to $(\mathrm{DCHIm}) \mathrm{F}_{8} \mathrm{Cmpd}-\mathrm{II}\left(\mathrm{LutH}^{+}\right)$Results in a Two-Electron Reduction To Give (DCHIm) ${ }_{2} \mathrm{~F}_{8} \mathrm{Fe}^{\mathrm{II}}$ as the Final Product, As Supported by UV-Vis and Mössbauer Spectroscopic Measurements 

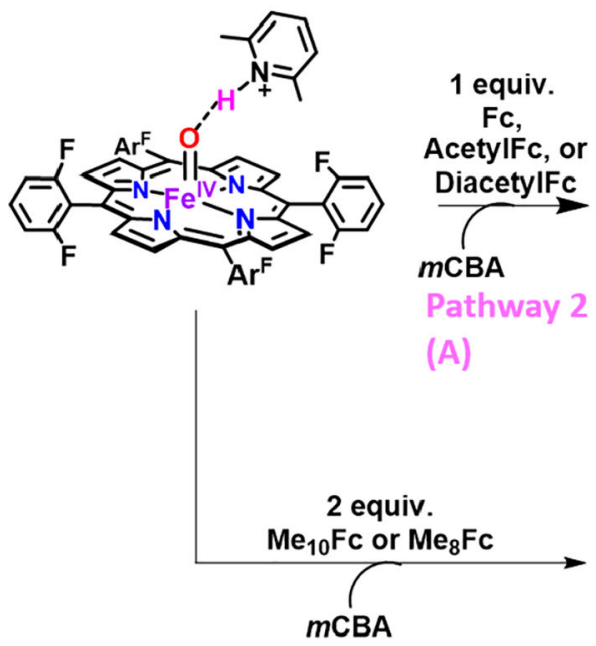

Pathway 3

Fc, AcetylFc, or DiacetylFc

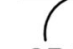
$m$ CBA Pathway 2
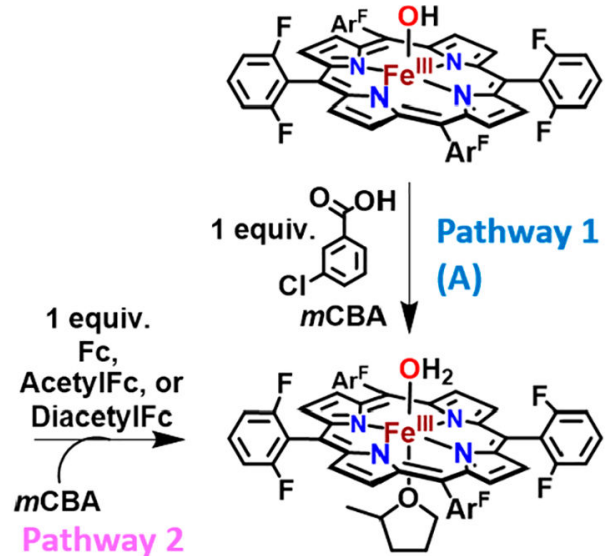
1 equiv. $\mathrm{Me}_{10} \mathrm{FC}$ or $\mathrm{Me}_{8} \mathrm{Fc}$

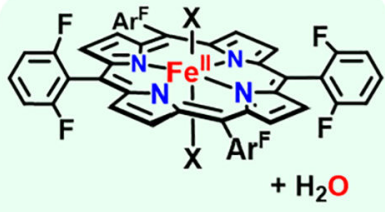

$X=$ MeTHF, or

3-chlorobenzoic acid

All paths lead to $\mathrm{Fe}^{\text {II }}$

Overall $2 e^{-}$reduction

Scheme 3. F 8 Cmpd-II $\left(\mathrm{LutH}^{+}\right)$Can Be Reduced by Various Ferrocene Derivatives ${ }^{a}$

${ }^{a}$ When stronger reductants $\left(\mathrm{Me}_{10} \mathrm{Fc}\right.$ or $\left.\mathrm{Me}_{8} \mathrm{Fc}\right)$ are used, the iron(IV) is reduced by two electrons to $(\mathrm{X}){ }_{2} \mathrm{~F}_{8} \mathrm{Fe}^{\mathrm{II}} \mathrm{Fe}$ (Pathway 3). However, when weaker reductants ( $\mathrm{Fc}$, AcetylFc, or DiacetylFc) are used, one-electron reduction occurs, giving (MeTHF)F Fe ${ }^{\mathrm{III}}\left(\mathrm{OH}_{2}\right)$ (Pathway $2 \mathrm{~A}$ ), as determined by comparison with the independently generated (MeTHF) $\mathrm{F}_{8} \mathrm{Fe}^{\mathrm{III}}$ $\left(\mathrm{OH}_{2}\right)$ prepared by addition of 3-chlorobenzoic acid to $\mathrm{F}_{8} \mathrm{Fe}^{\mathrm{III}}(\mathrm{OH})$ (Pathway 1A). Further, the assignment of (MeTHF)- $\mathrm{F}_{8} \mathrm{Fe} \mathrm{Fe}^{\mathrm{III}}\left(\mathrm{OH}_{2}\right)$ is supported due to its ability to be reduced by $\mathrm{Me}_{10} \mathrm{Fc}$ or $\mathrm{Me}_{8} \mathrm{Fc}$ to give $(\mathrm{X})_{2} \mathrm{~F}_{8} \mathrm{Fe}$ II, which similarly occurs when those reductants are added to the Fc, AcetylFc, or DiacetylFc reaction mixture (B). All reactions were carried out in 1:9 MeTHF:toluene at $-90^{\circ} \mathrm{C}$. See Supporting Information for further details. 

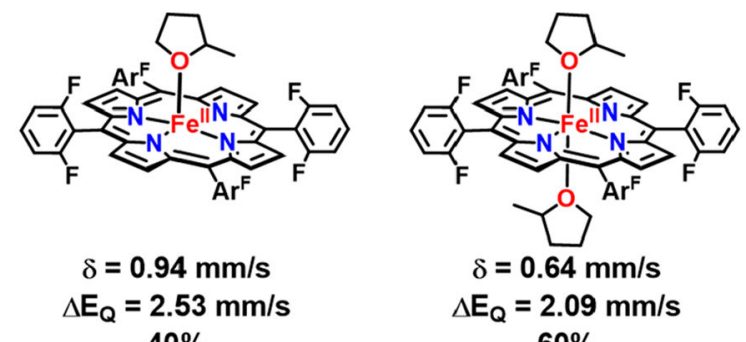

$\delta=0.64 \mathrm{~mm} / \mathrm{s}$

$\Delta \mathrm{E}_{\mathrm{Q}}=2.09 \mathrm{~mm} / \mathrm{s}$

$40 \%$

$60 \%$
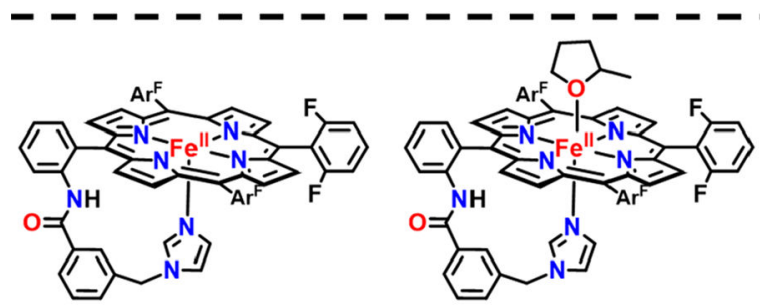

$\delta=0.96 \mathrm{~mm} / \mathrm{s}$

$\Delta E_{Q}=2.48 \mathrm{~mm} / \mathrm{s}$

$20 \%$

$\delta=0.44 \mathrm{~mm} / \mathrm{s}$

$\Delta E_{Q}=0.92 \mathrm{~mm} / \mathrm{s}$

$44 \%$

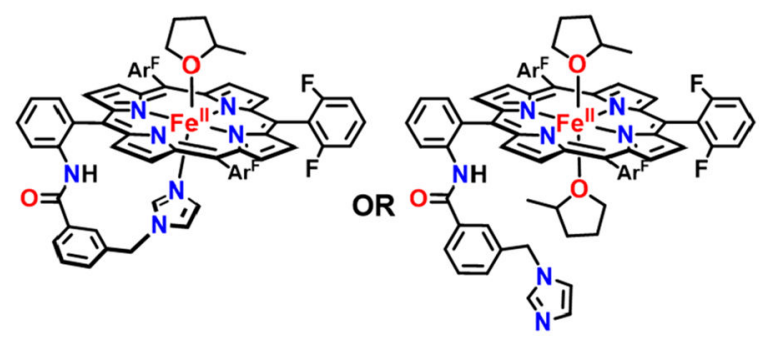

$\delta=0.49 \mathrm{~mm} / \mathrm{s}$

$\Delta \mathrm{E}_{\mathrm{Q}}=1.68 \mathrm{~mm} / \mathrm{s}$

$36 \%$

Chart 1. Proposed Ferrous Species Based on Mössbauer Parameters and Similar Assignments Found in the Literature ${ }^{a}$

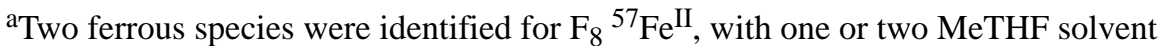
molecules bound. Three ferrous species were detected for $\mathrm{Pim}^{57} \mathrm{Fe}^{\mathrm{II}}$, with approximately $80 \%$ of the sample favoring a six-coordinate geometry. The six-coordinate complexes may be ascribed to (1) a tethered base and one solvent molecule bound (with the tethered base possibly taking on two conformations; i.e., coming out of the plane in one conformer) or (2) two solvent molecules bound to the iron center. 

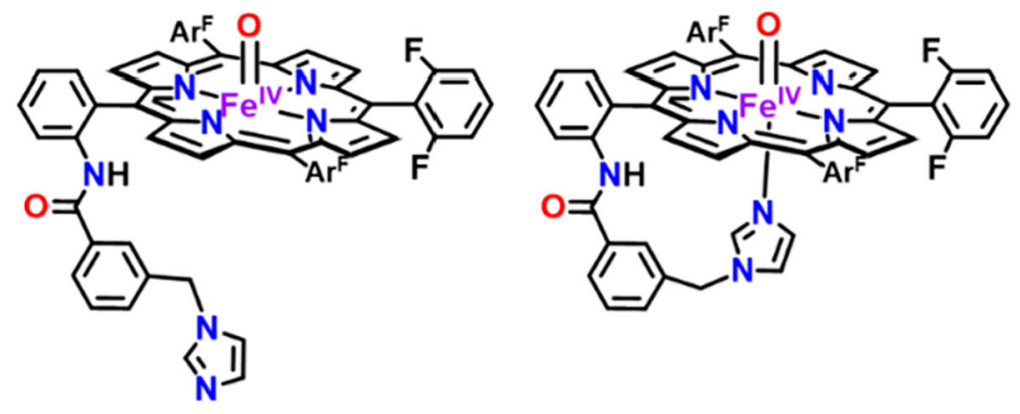

$$
\begin{gathered}
\delta=0.16 \mathrm{~mm} / \mathrm{s} \\
\Delta \mathrm{E}_{\mathrm{Q}}=2.06 \mathrm{~mm} / \mathrm{s} \\
24 \%
\end{gathered}
$$

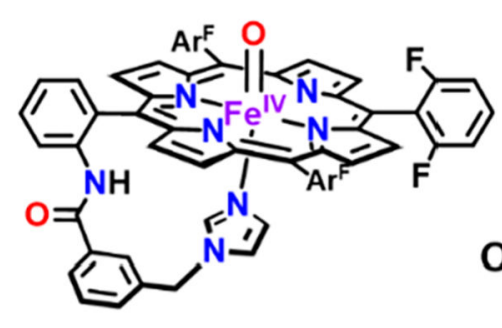

$$
\begin{gathered}
\delta=0.11 \mathrm{~mm} / \mathrm{s} \\
\Delta \mathrm{E}_{\mathrm{Q}}=1.06 \mathrm{~mm} / \mathrm{s} \\
18 \%
\end{gathered}
$$

$$
\begin{gathered}
\delta=0.11 \mathrm{~mm} / \mathrm{s} \\
\Delta \mathrm{E}_{\mathrm{Q}}=1.22 \mathrm{~mm} / \mathrm{s} \\
58 \%
\end{gathered}
$$

Chart 2. Proposed PIm Ferryl Derivatives Based on Mössbauer Parameters (Table S2 and $^{\text {Figure S13 }}$ ) and Previous Reports of $\mathbf{P}^{\mathrm{Im}}$-Based Species ${ }^{63,72,73 \text { a }}$

${ }^{a}$ Approximately $76 \%$ of the sample favored being six-coordinate, wherein we assign $58 \%$ of the sample to the tethered imidazole axial base coordinated to iron. The second sixcoordinate species may be a different conformer that the tethered base could adopt when bound to the iron ion (bottom left; e.g., the tether could be coming out of the plane) or a MeTHF solvent molecule bound to the iron ion (bottom right). 

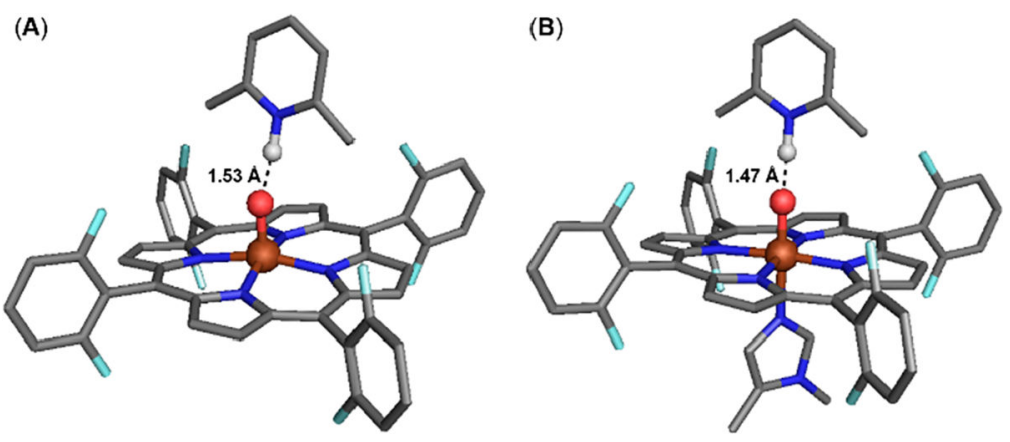

Chart 3. DFT Structures of F8Cmpd-II(LutH $\left.{ }^{+}\right)(\mathrm{A})$ and (DCHIm) $\mathrm{F}_{8} \mathrm{Cmpd}-\mathrm{II}(\mathrm{LutH}+)(\mathrm{B})^{a}$ ${ }^{a}$ Hydrogen atoms (except for the proton of $\mathrm{LutH}^{+}$) and the cyclohexyl groups of DCHIm were omitted for clarity. 


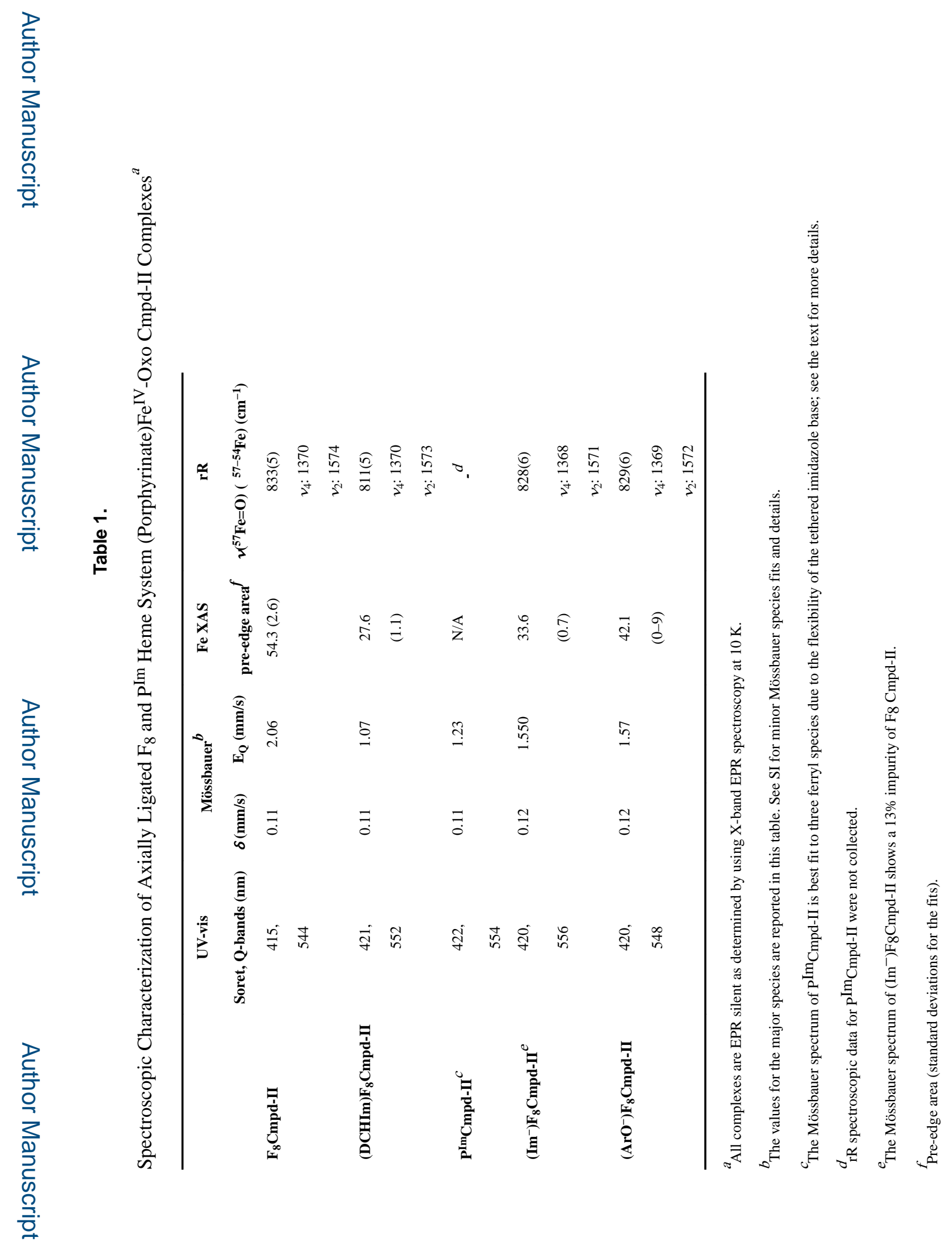




\section{롤 \\ ํㅗㄹ}

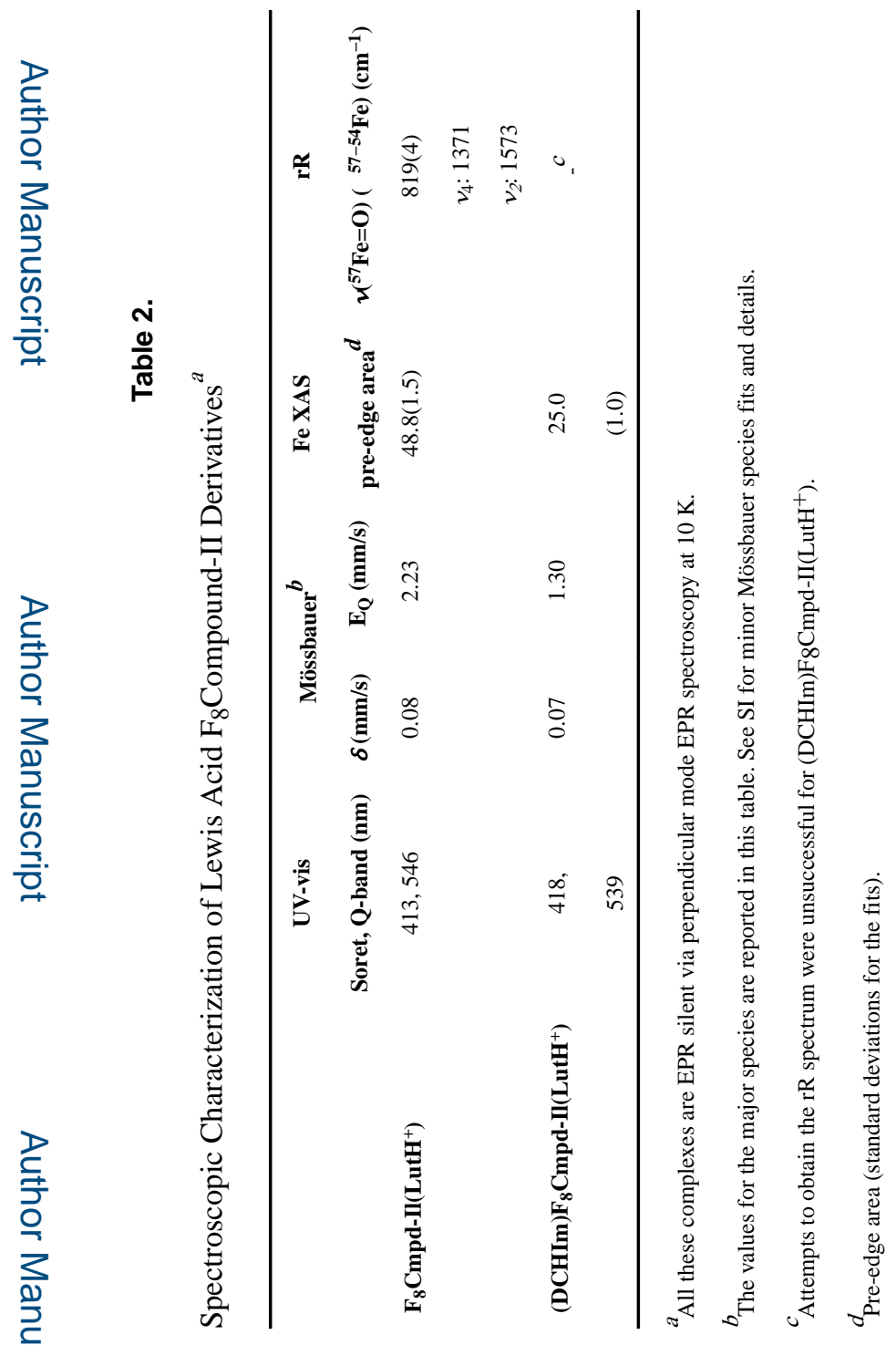




\section{롤 \\ 文}

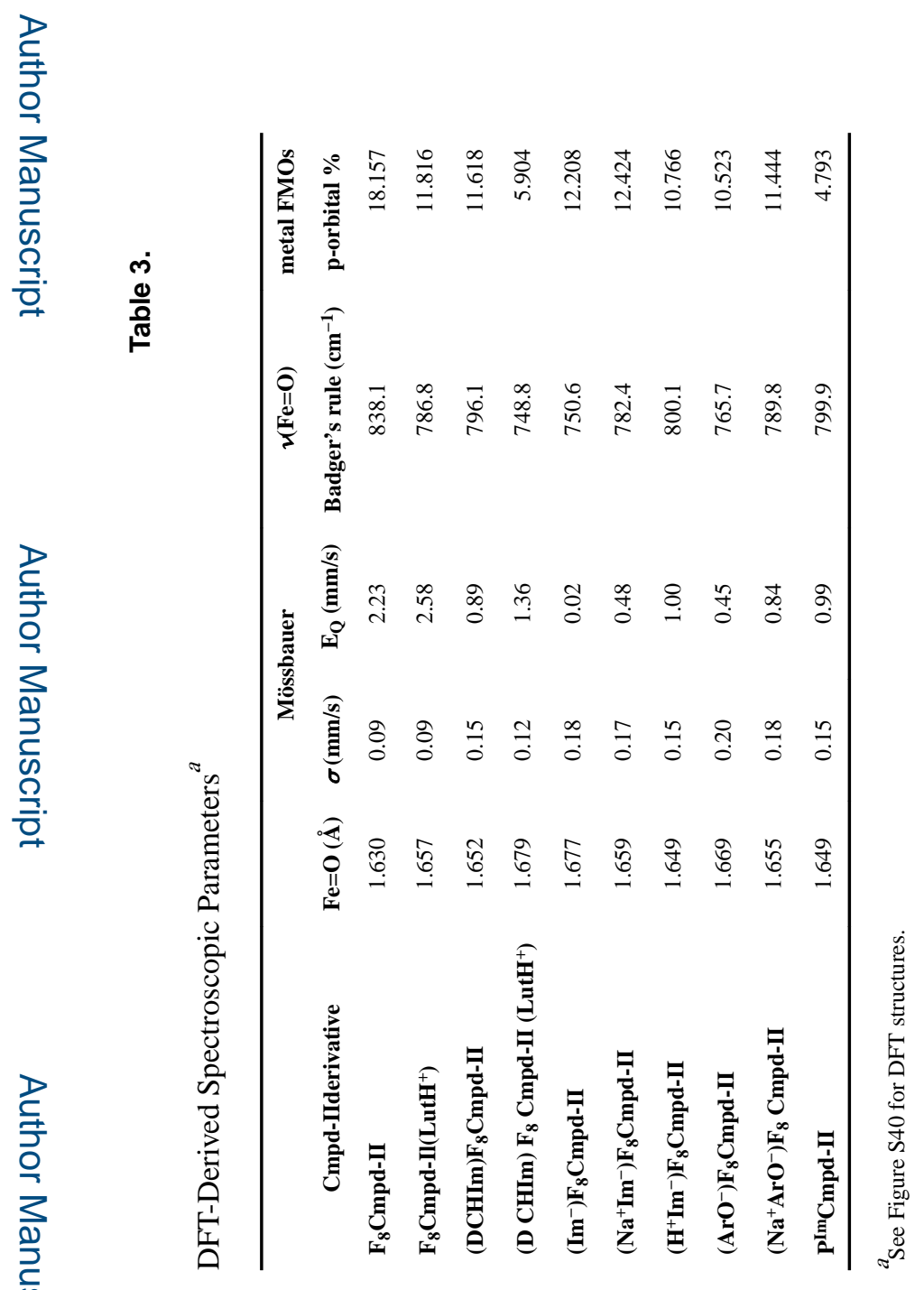

J Am Chem Soc. Author manuscript; available in PMC 2020 April 10. 


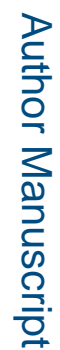

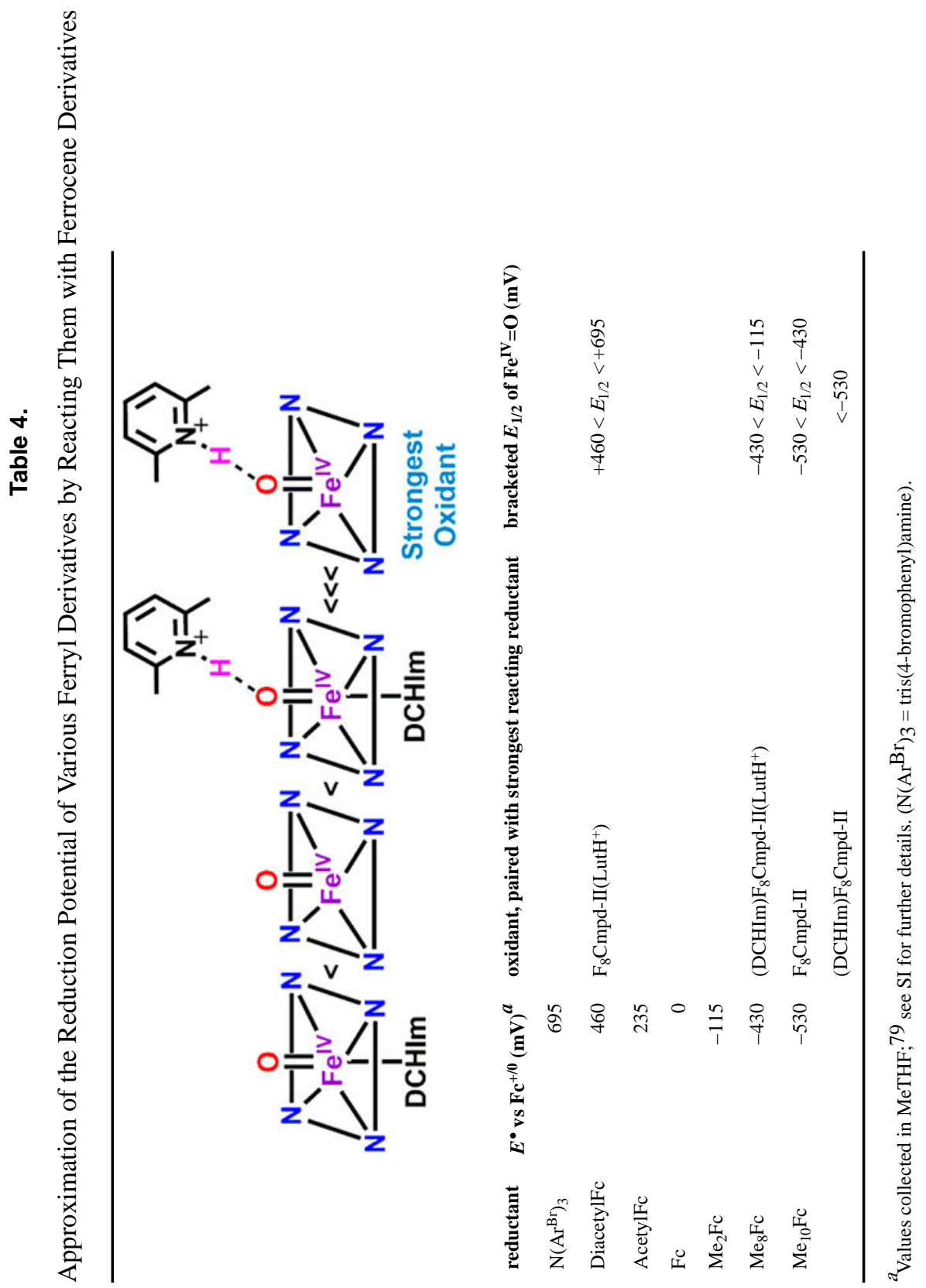

